JAMA | Original Investigation

\title{
Assessment of Global Kidney Health Care Status
}

Aminu K. Bello, PhD; Adeera Levin, FRCPC; Marcello Tonelli, MD; Ikechi G. Okpechi, PhD; John Feehally, FRCP; David Harris, FRACP; Kailash Jindal, FRCPC; Babatunde L. Salako, FRCP; Ahmed Rateb, MD;

Mohamed A. Osman, MD; Bilal Qarni, BSci; Syed Saad, BSci; Meaghan Lunney, MSci; Natasha Wiebe, MMath; Feng Ye, MSc; David W. Johnson, PhD

IMPORTANCE Kidney disease is a substantial worldwide clinical and public health problem, but information about available care is limited.

OBJECTIVE To collect information on the current state of readiness, capacity, and competence for the delivery of kidney care across countries and regions of the world.

DESIGN, SETTING, AND PARTICIPANTS Questionnaire survey administered from May to September 2016 by the International Society of Nephrology (ISN) to 130 ISN-affiliated countries with sampling of key stakeholders (national nephrology society leadership, policy makers, and patient organization representatives) identified by the country and regional nephrology leadership through the ISN.

MAIN OUTCOMES AND MEASURES Core areas of country capacity and response for kidney care.

RESULTS Responses were received from 125 of 130 countries (96\%), including 289 of 337 individuals ( $85.8 \%$, with a median of 2 respondents [interquartile range, 1-3]), representing an estimated $93 \%$ ( 6.8 billion) of the world's population of 7.3 billion. There was wide variation in country readiness, capacity, and response in terms of service delivery, financing, workforce, information systems, and leadership and governance. Overall, 119 (95\%), 95 (76\%), and 94 (75\%) countries had facilities for hemodialysis, peritoneal dialysis, and kidney transplantation, respectively. In contrast, 33 (94\%), 16 (45\%), and 12 (34\%) countries in Africa had facilities for hemodialysis, peritoneal dialysis, and kidney transplantation, respectively. For chronic kidney disease (CKD) monitoring in primary care, serum creatinine with estimated glomerular filtration rate and proteinuria measurements were reported as always available in only $21(18 \%)$ and $9(8 \%)$ countries, respectively. Hemodialysis, peritoneal dialysis, and transplantation services were funded publicly and free at the point of care delivery in 50 (42\%), 48 (51\%), and 46 (49\%) countries, respectively. The number of nephrologists was variable and was low (<10 per million population) in Africa, the Middle East, South Asia, and Oceania and South East Asia (OSEA) regions. Health information system (renal registry) availability was limited, particularly for acute kidney injury (8 countries [7\%]) and nondialysis CKD ( 9 countries [8\%]). International acute kidney injury and CKD guidelines were reportedly accessible in 52 (45\%) and 62 (52\%) countries, respectively. There was relatively low capacity for clinical studies in developing nations.

CONCLUSIONS AND RELEVANCE This survey demonstrated significant interregional and intraregional variability in the current capacity for kidney care across the world, including important gaps in services and workforce. Assuming the responses accurately reflect the status of kidney care in the respondent countries, the findings may be useful to inform efforts to improve the quality of kidney care worldwide.

JAMA. 2017;317(18):1864-1881. doi:10.1001/jama.2017.4046 Published online April 21, 2017.
Editorial page 1838

Supplemental content
Author Affiliations: Author affiliations are listed at the end of this article.

Corresponding Author: Aminu K. Bello, PhD, Division of Nephrology and Immunology, Department of Medicine, University of Alberta, 8440112 th St NW, 11-107 Clinical Sciences Bldg, Edmonton, AB T6B 2B7, Canada (aminu1@ualberta.ca). 
K dney disease is a substantial worldwide clinical and public health problem. ${ }^{1-3}$ Acute kidney injury (AKI) and chronic kidney disease (CKD) are linked to high health care costs, poor quality of life, and serious adverse health outcomes (including cardiovascular disease, kidney failure requiring kidney replacement therapy, infection, depression, and mortality). ${ }^{3-7}$ However, despite the burden and population health effect of kidney diseases, AKI and CKD are often not included in the major chronic disease control strategies. As an example, the World Health Organization's (WHO's) Global Status Report on Noncommunicable Diseases $2014^{8}$ makes almost no mention of kidney disease. This presents an obstacle for engaging with various governments in addressing AKI and CKD.

The Closing the Gaps initiative is led by the International Society of Nephrology (ISN) and aims to define the current state of kidney care (for AKI and CKD) worldwide, including policy recommendations for improvement. As part of this initiative, a global survey, the Global Kidney Health Atlas (GKHA) Project, was conducted to collect information on the current state of readiness, capacity, and competence for the delivery of kidney health care in each country and region.

\section{Methods}

\section{Design and Participants}

The GKHA Project was a multinational survey conducted by the ISN to assess current capacity for kidney care across the world. The survey was administered electronically to individuals in 130 countries with ISN affiliate societies through the ISN's 10 regional boards (Africa, Central and Eastern Europe, Latin America, Middle East, North America, North and East Asia, Oceania and South East Asia [OSEA], newly independent states and Russia, South Asia, and Western Europe). The project was approved by the University of Alberta Research Ethics Committee (protocol number PRO00063121). All individual participants provided written informed consent.

Purposive sampling was undertaken to include at least 3 key stakeholders per country (national nephrology society leadership, health policy makers, and patient organization/ foundation/advocacy representatives), each of whom was identified as being knowledgeable about their country's kidney care status and nominated by the country and regional nephrology leadership through the ISN. In some cases, country stakeholders had a dual role (eg, both nephrology leader and policy maker) or particular stakeholders (eg, consumer organization representative) were unable to be identified, such that some countries were represented by fewer than 3 key stakeholders. The key representatives were sent a letter of invitation to participate that included a link to the survey's online portal (an electronic questionnaire via SurveyMonkey [https://www.surveymonkey.com/]). Respondents were asked specifically about important within-country heterogeneity on kidney care funding and delivery and to identify other potential key respondents, increasing the likelihood

\section{Key Points}

Question What is the status of kidney health care across the world?

Findings In a survey of 125 (96\%) of 130 International Society of Nephrology-affiliated countries (representing an estimated 93\% of the world's population) with a response rate of $85.8 \%$ ( 289 of 337 individuals surveyed), the findings identified major variation in reported service delivery, funding mechanisms for kidney replacement therapy, and available technologies, such as facilities for kidney disease detection and management (eg, serum creatinine and proteinuria assessments).

Meaning These findings on the status of global kidney care may inform efforts by governmental and nongovernmental groups to improve the quality of kidney care worldwide.

that relevant information would be widely captured. The survey was conducted from May to September 2016. During this period, follow-up was conducted by email and telephone to ISN regional leaders and country leadership to facilitate completion and timely responses. During the survey period, each survey respondent who had not yet returned their survey received a personalized email reminder every 2 to 3 weeks up to a maximum of 3 attempts.

\section{Development and Validation of Survey Instrument}

The design of the GKHA questionnaire was meant to collect information about nations' capacities and responses about noncommunicable disease prevention and control. The survey development process considered a number of documents, including WHO's Universal Health Coverage: Supporting Country Needs, the ISN's AKI “O by 25” project, WHO Noncommunicable Disease Surveys (2000, 2005, 2010, and 2013), the World Heart Federation's “ 25 by 25 ” goal, the International Diabetes Federation's Global Diabetes Atlas, and WHO's Global Atlas on Cardiovascular Disease Prevention and Control, as well as multiple United Nations policy documents on strategies, and policies for noncommunicable diseases. ${ }^{9-14}$ The initial survey questions were further developed through a series of reviews with relevant experts, the ISN Executive Committee, and regional leaderships.

The questionnaire was reviewed by the GKHA steering committee (scientific experts) and ISN regional leaders for content validity and comprehensiveness. The questionnaire was piloted across the 10 ISN regional board memberships to identify any logistical and feasibility issues (eg, need for translation). The format and content of the questionnaire (eAppendix 1 in the Supplement) were finalized based on feedback and identified issues, including translating the original English-language survey instrument into French and Spanish by certified translators. The French and Spanish surveys were checked by relevant regional boards and were back-translated into English.

The questionnaire was designed in 2 sections that addressed the core areas of country and regional capacity for kidney care delivery. The first section comprised 6 modules assessing country and regional profile for readiness, 


\begin{tabular}{|c|c|c|c|c|c|c|c|c|}
\hline & $\begin{array}{l}\text { Total No. of } \\
\text { Countries } \\
\text { Recognized } \\
\text { by UN }\end{array}$ & $\begin{array}{l}\text { Total Population } \\
\text { in All } \\
\text { UN-Recognized } \\
\text { Countries, } \\
\text { in Millions }\end{array}$ & $\begin{array}{l}\text { Total No. of } \\
\text { Countries } \\
\text { Receiving } \\
\text { Survey }\end{array}$ & $\begin{array}{l}\text { Total Population } \\
\text { in Countries } \\
\text { Receiving } \\
\text { Survey, } \\
\text { in Millions }\end{array}$ & $\begin{array}{l}\text { No. (\%) of } \\
\text { Countries } \\
\text { Completing } \\
\text { Survey }^{\mathrm{a}}\end{array}$ & $\begin{array}{l}\text { Total Population } \\
\text { in Countries } \\
\text { Completing } \\
\text { Survey, } \\
\text { in Millions }\end{array}$ & $\begin{array}{l}\% \text { of Population } \\
\text { in Countries } \\
\text { Receiving } \\
\text { Survey }^{b}\end{array}$ & $\begin{array}{l}\% \text { of Population } \\
\text { in all } \\
\text { UN-Recognized } \\
\text { Countries }^{\mathrm{c}}\end{array}$ \\
\hline Overall & 200 & 7248 & 130 & 6778 & $125(96)$ & 6754 & 99.6 & 93 \\
\hline \multicolumn{9}{|l|}{ ISN regions } \\
\hline Africa & 54 & 1156 & 37 & 969 & $35(95)$ & 964 & 99 & 83 \\
\hline Middle East & 14 & 225 & 13 & 223 & $13(100)$ & 223 & 100 & 99 \\
\hline Latin America & 25 & 608 & 18 & 571 & $17(94)$ & 560 & 98 & 92 \\
\hline North and East Asia & 7 & 1602 & 6 & 1577 & $6(100)$ & 1577 & 100 & 98 \\
\hline South Asia & 8 & 1707 & 5 & 1673 & $5(100)$ & 1673 & 100 & 98 \\
\hline OSEA & 25 & 671 & 13 & 661 & $13(100)$ & 661 & 100 & 99 \\
\hline East and Central Europe & 20 & 209 & 19 & 207 & $17(89)$ & 199 & 96 & 95 \\
\hline NIS and Russia & 11 & 281 & 6 & 223 & $6(100)$ & 223 & 100 & 79 \\
\hline Western Europe & 22 & 429 & 11 & 318 & $11(100)$ & 318 & 100 & 74 \\
\hline North America & 14 & 362 & 2 & 356 & $2(100)$ & 356 & 100 & 398 \\
\hline \multicolumn{9}{|l|}{ World Bank income groups } \\
\hline Low & 31 & 631 & 18 & 405 & $18(100)$ & 405 & 100 & 64 \\
\hline Lower middle & 52 & 2862 & 35 & 2789 & $34(97)$ & 2786 & 99.9 & 97 \\
\hline Upper middle & 53 & 2370 & 35 & 2313 & $32(91)$ & 2293 & 99 & 97 \\
\hline High & 63 & 1386 & 41 & 1271 & $40(98)$ & 1270 & 99.9 & 92 \\
\hline Not classified & 1 & 0.02 & 1 & 0.02 & $1(100)$ & 0.02 & 100 & 100 \\
\hline \multicolumn{9}{|c|}{$\begin{array}{lc}\text { Abbreviations: ISN, International Society of Nephrology; NIS, newly } & \text { b The proportion was calculated as total population for countries that } \\
\text { independent states; OSEA, Oceania and South East Asia; UN, United Nations. } & \text { completed the survey/total population for countries that received the survey. }\end{array}$} \\
\hline \multicolumn{4}{|c|}{$\begin{array}{l}\text { a The percentage was calculated as total No. of countries that completed the } \\
\text { survey/total No. of countries that received the survey. }\end{array}$} & \multicolumn{5}{|c|}{$\begin{array}{l}\text { ' } \text { The proportion was calculated as total population for countries that } \\
\text { completed the survey/total population in all UN-recognized countries. }\end{array}$} \\
\hline
\end{tabular}

\begin{tabular}{|c|c|c|c|c|c|c|}
\hline & \multirow{2}{*}{$\begin{array}{l}\text { Total No. of } \\
\text { Respondents }\end{array}$} & \multirow{2}{*}{$\begin{array}{l}\text { No. of Respondents } \\
\text { Per Country, Median } \\
\text { (Interquartile Range) }^{c}\end{array}$} & \multicolumn{4}{|c|}{ Respondent Affiliation, No. (\%) } \\
\hline & & & Nephrologists & Other Physicians & Administrators/Policy Makers & Other $^{\mathrm{b}}$ \\
\hline Overall & $289^{\mathrm{d}}$ & $2(1-3)$ & $247(85)$ & $10(3)$ & $16(6)$ & $16(6)$ \\
\hline \multicolumn{7}{|l|}{ ISN regions } \\
\hline Africa & 58 & $1(1-2)$ & $42(73)$ & $4(7)$ & $6(10)$ & $6(10)$ \\
\hline Middle East & 32 & $3(2-3)$ & $29(91)$ & $1(3)$ & $1(3)$ & $1(3)$ \\
\hline Latin America & 50 & $2(1-3)$ & $50(100)$ & 0 & 0 & 0 \\
\hline North and East Asia & 31 & $6(2-8)$ & $29(94)$ & 0 & $1(3)$ & $1(3)$ \\
\hline South Asia & 12 & $2(2-3)$ & $10(84)$ & $1(8)$ & $1(8)$ & 0 \\
\hline OSEA & 39 & $2(1-4)$ & $31(79)$ & $2(5)$ & $3(8)$ & $3(8)$ \\
\hline East and Central Europe & 27 & $1(1-2)$ & $26(96)$ & $1(4)$ & 0 & 0 \\
\hline NIS and Russia & 12 & $1.5(1-2)$ & $7(59)$ & 0 & $4(33)$ & $1(8)$ \\
\hline Western Europe & 21 & $2(1-3)$ & $17(81)$ & $1(5)$ & 0 & $3(14)$ \\
\hline North America & 7 & $3.5(3-4)$ & $6(86)$ & 0 & 0 & $1(14)$ \\
\hline \multicolumn{7}{|l|}{ World Bank income groups } \\
\hline Low & 30 & $2(1-2)$ & $22(73)$ & $4(13)$ & $2(7)$ & $2(7)$ \\
\hline Lower middle & 68 & $2(1-3)$ & $50(73)$ & $4(6)$ & $10(15)$ & $4(6)$ \\
\hline Upper middle & 83 & $2(1-3)$ & $76(92)$ & $1(1)$ & $4(5)$ & $2(2)$ \\
\hline High & 107 & $2(1-3.5)$ & $98(92)$ & $1(1)$ & 0 & $8(7)$ \\
\hline Not classified & 1 & $1(1-1)$ & $1(100)$ & 0 & 0 & 0 \\
\hline \multicolumn{3}{|c|}{$\begin{array}{l}\text { Abbreviations: ISN, International Society of Nephrology; NIS, newly } \\
\text { independent states; OSEA, Oceania and South East Asia. } \\
\text { a Total number of respondents to the survey, overall and by ISN regions and } \\
\text { World Bank income groups. }\end{array}$} & \multicolumn{4}{|c|}{$\begin{array}{l}{ }^{\mathrm{C}} \text { Median and interquartile range of respondents per country. } \\
{ }^{\mathrm{d}} \text { Overall number of individual respondents among } 337 \text { contacted (individual } \\
\text { response rate of } 85.8 \% \text { ). }\end{array}$} \\
\hline
\end{tabular}



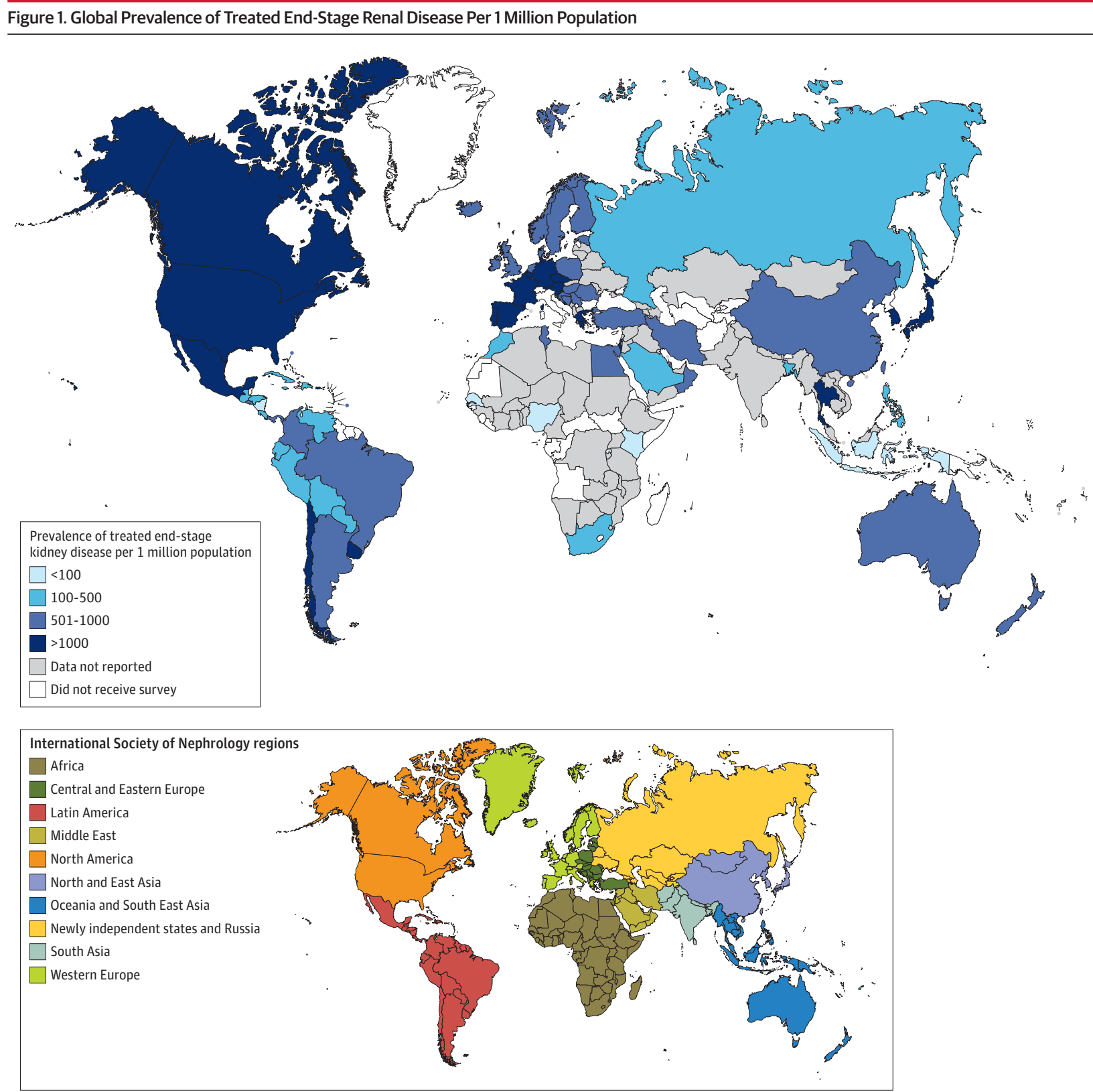

The map depicts the prevalence of treated kidney failure per 1 million population based on individual country data. Data not available indicates that data were either not known or not provided on the questionnaire for countries that received the survey.

capacity, and response to CKD and AKI premised on the 6 health system building blocks (access to essential medicines and technologies, health systems financing, health service delivery, health workforce, health information systems, and leadership and governance). ${ }^{15}$ The second section contained questions that assessed response of the nephrology community (including care guidelines, position papers, service frameworks, and advocacy initiatives) and capacity for research and development.

Data Handling, Analysis, and Reporting

To facilitate data collation, responses to the French and Spanish surveys were first converted to English by certified translators. Data from all individual questionnaires were subsequently automatically extracted and checked for inconsistencies, missing data, duplications, and formatting errors. The data were then merged into a single file to create the global database. This was housed in a secured centralized computer system with automated backups.

Liaison with ISN regional leaders was undertaken to ensure that collated data were consistent with their understanding and were of high quality. Each of 10 regional boards reviewed their output to clarify any ambiguity or inconsistencies. Any major inconsistencies that remained following the reviews were systematically addressed by follow-up of individuals who responded to the survey. 


\begin{tabular}{|c|c|c|c|c|c|c|c|}
\hline & \multirow[b]{2}{*}{$\begin{array}{l}\text { No. of } \\
\text { Responding } \\
\text { Countries }\end{array}$} & \multicolumn{6}{|c|}{ No. (\%) of Responding Countries } \\
\hline & & $\begin{array}{l}\text { Publicly Funded } \\
\text { by Government Free } \\
\text { at the Point of Delivery }\end{array}$ & $\begin{array}{l}\text { Publicly Funded } \\
\text { by Government } \\
\text { But With Some Fees } \\
\text { at the Point of Delivery }\end{array}$ & $\begin{array}{l}\text { Mix of Public } \\
\text { and Private } \\
\text { Funding Systems }\end{array}$ & $\begin{array}{l}\text { Solely Private } \\
\text { and Out of Pocket }\end{array}$ & $\begin{array}{l}\text { Solely Private } \\
\text { Through } \\
\text { Health Insurance } \\
\text { Providers }\end{array}$ & $\begin{array}{l}\text { Multiple } \\
\text { Funding } \\
\text { Systems }^{\mathrm{a}}\end{array}$ \\
\hline \multicolumn{8}{|c|}{ (2) } \\
\hline Overall & 118 & $50(42)$ & $14(12)$ & $41(35)$ & $2(2)$ & 0 & $11(9)$ \\
\hline \multicolumn{8}{|l|}{ ISN regions } \\
\hline Africa & 33 & $10(30)$ & $7(21)$ & $12(37)$ & $1(3)$ & 0 & $3(9)$ \\
\hline Middle East & 13 & $9(69)$ & $1(8)$ & $1(8)$ & 0 & 0 & $2(15)$ \\
\hline Latin America & 15 & $3(20)$ & 0 & $11(73)$ & 0 & 0 & $1(7)$ \\
\hline North and East Asia & 6 & 0 & $3(50)$ & $2(33)$ & 0 & 0 & $1(17)$ \\
\hline South Asia & 5 & 0 & $1(20)$ & $3(60)$ & 0 & 0 & $1(20)$ \\
\hline OSEA & 13 & $1(8)$ & $2(15)$ & $7(54)$ & $1(8)$ & 0 & $2(15)$ \\
\hline East and Central Europe & 16 & $14(87)$ & 0 & $2(13)$ & 0 & 0 & 0 \\
\hline NIS and Russia & 6 & $4(66)$ & 0 & $1(17)$ & 0 & 0 & $1(17)$ \\
\hline Western Europe & 9 & $7(78)$ & 0 & $2(22)$ & 0 & 0 & 0 \\
\hline North America & 2 & $2(100)$ & 0 & 0 & 0 & 0 & 0 \\
\hline \multicolumn{8}{|l|}{ World Bank income groups } \\
\hline Low & 17 & $3(18)^{b}$ & $4(24)$ & $6(34)$ & $2(12)$ & 0 & $2(12)$ \\
\hline Lower middle & 32 & $7(21)$ & $6(19)$ & $14(44)$ & 0 & 0 & $5(16)$ \\
\hline Upper middle & 31 & $18(59)$ & 0 & $11(35)$ & 0 & 0 & $2(6)$ \\
\hline High & 38 & $22(58)$ & $4(11)$ & $10(26)$ & 0 & 0 & $2(5)$ \\
\hline \multicolumn{8}{|l|}{ Peritoneal Dialysis } \\
\hline Overall & 95 & $48(51)$ & $11(12)$ & $28(29)$ & $1(1)$ & 0 & $7(7)$ \\
\hline \multicolumn{8}{|l|}{ ISN regions } \\
\hline Africa & 17 & $6(35)$ & $4(24)$ & $6(35)$ & 0 & 0 & $1(6)$ \\
\hline Middle East & 11 & $7(64)$ & $2(18)$ & 0 & $1(9)$ & 0 & $1(9)$ \\
\hline Latin America & 15 & $4(27)$ & 0 & $11(73)$ & 0 & 0 & 0 \\
\hline North and East Asia & 6 & 0 & $4(66)$ & $1(17)$ & 0 & 0 & $1(17)$ \\
\hline South Asia & 5 & $1(20)$ & $1(20)$ & $2(40)$ & 0 & 0 & $1(20)$ \\
\hline OSEA & 9 & $1(11)$ & 0 & $6(67)$ & 0 & 0 & $2(22)$ \\
\hline East and Central Europe & 15 & $14(93)$ & 0 & $1(7)$ & 0 & 0 & 0 \\
\hline NIS and Russia & 6 & $5(83)$ & 0 & 0 & 0 & 0 & $1(17)$ \\
\hline Western Europe & 9 & $8(89)$ & 0 & $1(11)$ & 0 & 0 & 0 \\
\hline North America & 2 & $2(100)$ & 0 & 0 & 0 & 0 & 0 \\
\hline \multicolumn{8}{|l|}{ World Bank income groups } \\
\hline Low & 6 & 0 & $2(33)$ & $3(50)$ & 0 & 0 & $1(17)$ \\
\hline Lower middle & 22 & $6(27)$ & $3(14)$ & $10(45)$ & $1(5)$ & 0 & $2(9)$ \\
\hline Upper middle & 29 & $17(58)$ & $2(7)$ & $8(28)$ & 0 & 0 & $2(7)$ \\
\hline High & 38 & $25(66)$ & $4(11)$ & $7(18)$ & 0 & 0 & $2(5)$ \\
\hline \multicolumn{8}{|l|}{ Kidney Transplantation } \\
\hline Overall & 93 & $46(49)$ & $10(11)$ & $28(30)$ & $1(1)$ & 0 & $8(9)$ \\
\hline \multicolumn{8}{|l|}{ ISN regions } \\
\hline Africa & 12 & $4(33)$ & $1(8)$ & $4(33)$ & $1(8)$ & 0 & $2(18)$ \\
\hline Middle East & 13 & $6(46)$ & $4(31)$ & 0 & 0 & 0 & $3(23)$ \\
\hline Latin America & 15 & $2(13)$ & 0 & $12(80)$ & 0 & 0 & $1(7)$ \\
\hline North and East Asia & 6 & 0 & $5(83)$ & 0 & 0 & 0 & $1(17)$ \\
\hline South Asia & 5 & 0 & 0 & $5(100)$ & 0 & 0 & 0 \\
\hline OSEA & 9 & $3(33)$ & 0 & $5(56)$ & 0 & 0 & $1(11)$ \\
\hline East and Central Europe & 16 & $16(100)$ & 0 & 0 & 0 & 0 & 0 \\
\hline NIS and Russia & 6 & $5(83)$ & 0 & $1(17)$ & 0 & 0 & 0 \\
\hline Western Europe & 9 & $8(89)$ & 0 & $1(11)$ & 0 & 0 & 0 \\
\hline North America & 2 & $2(100)$ & 0 & 0 & 0 & 0 & 0 \\
\hline
\end{tabular}




\begin{tabular}{|c|c|c|c|c|c|c|c|}
\hline & \multirow[b]{2}{*}{$\begin{array}{l}\text { No. of } \\
\text { Responding } \\
\text { Countries }\end{array}$} & \multicolumn{6}{|c|}{ No. (\%) of Responding Countries } \\
\hline & & $\begin{array}{l}\text { Publicly Funded } \\
\text { by Government Free } \\
\text { at the Point of Delivery }\end{array}$ & $\begin{array}{l}\text { Publicly Funded } \\
\text { by Government } \\
\text { But With Some Fees } \\
\text { at the Point of Delivery }\end{array}$ & $\begin{array}{l}\text { Mix of Public } \\
\text { and Private } \\
\text { Funding Systems }\end{array}$ & $\begin{array}{l}\text { Solely Private } \\
\text { and Out of Pocket }\end{array}$ & $\begin{array}{l}\text { Solely Private } \\
\text { Through } \\
\text { Health Insurance } \\
\text { Providers }\end{array}$ & $\begin{array}{l}\text { Multiple } \\
\text { Funding } \\
\text { Systems }{ }^{\mathrm{a}}\end{array}$ \\
\hline \multicolumn{8}{|c|}{ World Bank income groups } \\
\hline Low & 2 & $1(50)$ & 0 & $1(50)$ & 0 & 0 & 0 \\
\hline Lower middle & 24 & $4(17)$ & $3(13)$ & $13(53)$ & $1(4)$ & 0 & $3(13)$ \\
\hline Upper middle & 29 & $15(52)$ & $2(7)$ & $9(31)$ & 0 & 0 & $3(10)$ \\
\hline High & 38 & $26(69)$ & $5(13)$ & $5(13)$ & 0 & 0 & $2(5)$ \\
\hline
\end{tabular}

Further validation was carried out at country and regional levels by triangulation of the findings with published literature and other sources of information (government reports and other sources provided by the survey respondents). For example, among the responses for New Zealand, 2 indicated that there was an official registry for dialysis and transplantation, whereas 1 indicated that there was not an official registry. The existence of a New Zealand dialysis registry was subsequently confirmed by cross-checking with the OSEA Regional Board and the Australian and New Zealand Dialysis and Transplant Registry (http://www.anzdata.org.au/). Similarly, 2 Kenyan respondents indicated that there was a nephrology training program in Kenya, whereas 1 respondent said there was not a nephrology training program but also indicated only moderate certainty of the answer. Telephone discussion with the African Regional Board confirmed that a nephrology training program did exist in Kenya.

The framework developed by WHO (Assessing National Capacity for the Prevention and Control of Noncommunicable Diseases) was leveraged in the approach to the statistical analysis of the collated data. ${ }^{16}$ The analysis was conducted using Stata version 13 software (Stata Corp). The unit of analysis was responding country, and results were stratified by ISN region $(n=10)$ and World Bank country classification ( $\mathrm{n}=4$ ) as low-, lower middle-, upper middle-, and highincome nations. Responses were summarized based on the key questionnaire domains using a descriptive statistical approach and reported as counts and percentages or medians and interquartile ranges, as appropriate. Nonquantitative data (text response items of the questionnaire) were thematically analyzed using a standard approach. ${ }^{17}$ The results were examined with an emphasis on identification of key gaps and challenges across the various domains based on the preexisting protocol and reported according to the Guidelines for Accurate and Transparent Health Estimates Reporting (GATHER) statement. ${ }^{18}$

\section{Results}

Response Rate

Responses were received from 125 (96\%) of 130 countries, including 289 (85.8\%) of 337 individuals (median of 2 respondents per country [interquartile range, 1-3]) representing an estimated 93\% (6.8 billion) of the world's population of 7.3 billion (Table 1). Responses were received from $100 \%(18 / 18), 97 \%$ (34/35), 91\% (32/35), and 98\% (40/41) of low-income, lower middle-income, upper middle-income, and high-income countries, respectively (Table 1). The respondent countries were representative of the countries in each region by population size (Table 1$)$. The survey respondents consisted of nephrologists (247 [85\%]), other physicians (10 [3\%]), administrators/policy makers (16 [6\%]), and others (16 [6\%]) affiliated with kidney disease patient advocacy (Table 2).

Country Readiness, Capacity, and Response to CKD and AKI Access to Essential Medicines and Technologies

There were variations across ISN regions $(n=10)$ and World Bank income groups $(n=4)$ in the prevalence of treated end-stage renal disease represented by kidney replacement therapy (kidney replacement therapy: hemodialysis, peritoneal dialysis, and kidney transplantation), with the highest prevalence in developed regions in comparison with developing nations (Figure 1). The reported availability and access to essential medicines for CKD care and technologies also showed significant variations across regions and countries (eAppendix 2 in the Supplement). Among all countries ( $\mathrm{n}=125$ responding), 119 (95\%), 95 (76\%), and 94 (75\%) had facilities for hemodialysis, long-term peritoneal dialysis, and kidney transplantation, respectively; 100\% of highincome countries had such facilities. In contrast, 33 (94\%), 16 (45\%), and 12 (34\%) countries in Africa had facilities for hemodialysis, long-term peritoneal dialysis, and kidney transplantation, respectively (eAppendix 2).

\section{Health Systems Financing}

The number of countries ( $\mathrm{n}=118$ responding) that reported complete public funding (completely free care at the point of delivery covered by the government) for chronic hemodialysis, long-term peritoneal dialysis, and kidney transplantation were $50(42 \%), 48(51 \%)$, and $46(49 \%)$, respectively (Table 3). Overall, 45 (39\%) and 34 (49\%) countries reported complete public funding for hemodialysis and peritoneal dialysis, respectively, in the acute setting (Table 4). The public funding structures for all forms of 


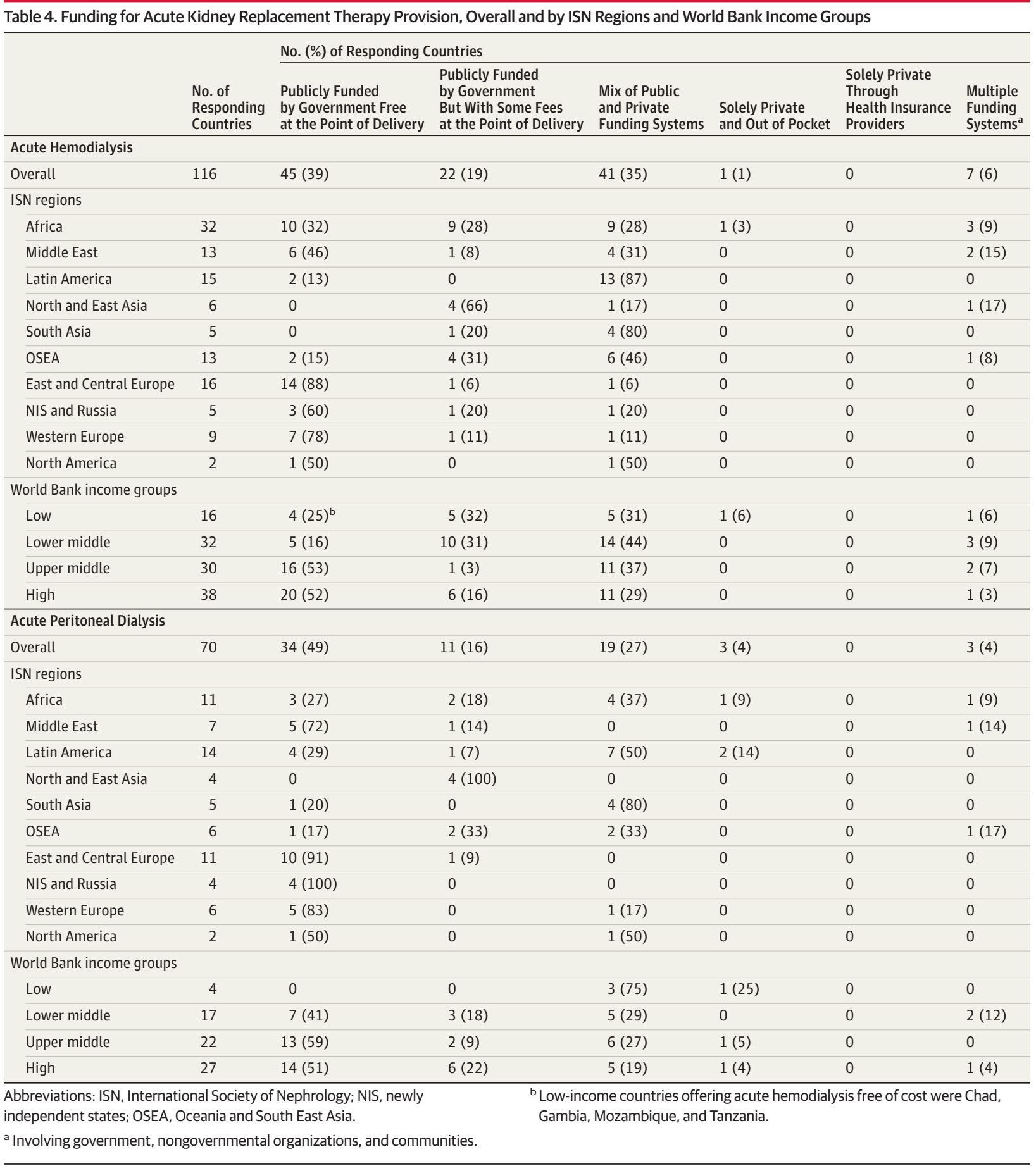

kidney replacement therapy (hemodialysis, peritoneal dialysis, and kidney transplantation) were less common in the low- and lower middle-income countries (Table 3 and Table 4). There was significant variation across regions in access to medications for kidney care. For instance, no country from the low-income and lower middle-income categories reported complete public funding for medications for nondialysis CKD care (including angiotensin-converting enzyme inhibitors, angiotensin receptor blockers, other antihypertensive agents, statins, and glucose-lowering agents) (Table 5 and eAppendix 2 in the Supplement). In contrast, 12 (32\%) and 10 (32\%) high- and upper middleincome nations reported complete public funding for medications in nondialysis CKD care (Table 5).

\section{Health Service Delivery}

Globally, infrastructure available for kidney care was reported to be good/above average in 48 (39\%) and excellent in 11 (9\%) countries for AKI. For CKD, 46 (38\%) countries were rated good/above average and $9(7 \%)$ were rated excellent 
Table 5. Access to Medications and Reimbursement Plans, Overall and by ISN Regions and World Bank Income Groups

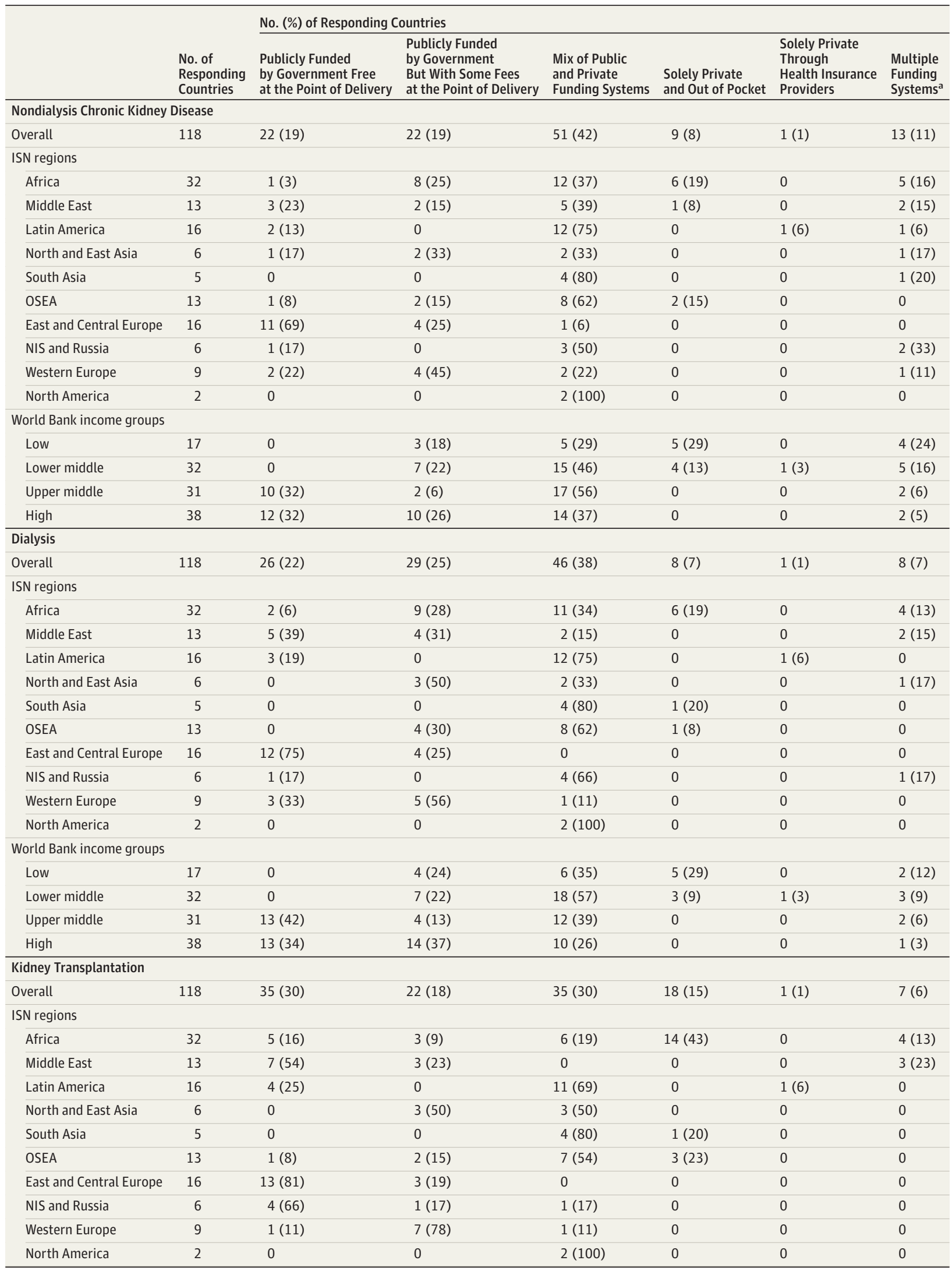




\begin{tabular}{|c|c|c|c|c|c|c|c|}
\hline & \multirow[b]{2}{*}{$\begin{array}{l}\text { No. of } \\
\text { Responding } \\
\text { Countries }\end{array}$} & \multicolumn{6}{|c|}{ No. (\%) of Responding Countries } \\
\hline & & $\begin{array}{l}\text { Publicly Funded } \\
\text { by Government Free } \\
\text { at the Point of Delivery }\end{array}$ & $\begin{array}{l}\text { Publicly Funded } \\
\text { by Government } \\
\text { But With Some Fees } \\
\text { at the Point of Delivery }\end{array}$ & $\begin{array}{l}\text { Mix of Public } \\
\text { and Private } \\
\text { Funding Systems }\end{array}$ & $\begin{array}{l}\text { Solely Private } \\
\text { and Out of Pocket }\end{array}$ & $\begin{array}{l}\text { Solely Private } \\
\text { Through } \\
\text { Health Insurance } \\
\text { Providers }\end{array}$ & $\begin{array}{l}\text { Multiple } \\
\text { Funding } \\
\text { Systems }^{\mathrm{a}}\end{array}$ \\
\hline \multicolumn{8}{|c|}{ World Bank income groups } \\
\hline Low & 17 & 0 & $1(6)$ & $3(18)$ & $10(58)$ & 0 & $3(18)$ \\
\hline Lower middle & 32 & $6(19)$ & $4(13)$ & $12(37)$ & $7(22)$ & $1(3)$ & $2(6)$ \\
\hline Upper middle & 31 & $15(49)$ & $3(10)$ & $11(35)$ & $1(3)$ & 0 & $1(3)$ \\
\hline High & 38 & $14(37)$ & $14(37)$ & $9(23)$ & 0 & 0 & $1(3)$ \\
\hline
\end{tabular}

Abbreviations: ISN, International Society of Nephrology; NIS, newly independent states; OSEA, Oceania and South East Asia.

a Involving government, nongovernmental organizations, and communities.

(eTable 1 in the Supplement). Reports of extremely poor or poor/below average infrastructure for AKI and CKD care were highest in Africa and South Asia and lowest in Western Europe and North America (eTable 1). Pertaining to services used for monitoring $\mathrm{CKD}$, measurement of serum creatinine reported with estimated glomerular filtration rate (eGFR) was described as always or usually available at the primary and secondary care levels in only $21(18 \%)$ or $23(19 \%)$ and $43(40 \%)$ or 25 (23\%) countries, respectively (Table 6, Table 7, and eAppendix 3 in the Supplement). Pathological services for renal biopsy were always available at the secondary care level for 27 (23\%) countries but were otherwise rarely or never available in 28 (24\%) and 16 (14\%) countries, respectively (Table 7 and eAppendix 3).

\section{Health Workforce}

Respondents from countries were asked to provide estimates of the number of trained nephrologists, as defined by the relevant regulatory authorities, and provide an opinion regarding shortage (yes/no) of the workforce required for kidney care delivery. There was a low reported nephrology workforce density ( $\leq 10$ per 1 million population) for several countries in the Africa, North and East Asia, and South Asia regions as well as in parts of Latin America (Figure 2). There were also wide disparities in the number of nephrologists across countries and regions. For instance, 9 of the 10 countries with the lowest numbers of nephrologists were in subSaharan Africa (eFigure 1A in the Supplement), whereas the countries with the highest number of nephrologists were from several regions, with Lithuania, Taiwan, and Japan reporting the highest numbers of nephrologists per 1 million population (eFigure 1B in the Supplement). Overall, there were frequent reported shortages of the various categories of other health care workers. Most countries had reported shortages of vascular access coordinators, transplant coordinators, social workers, renal pathologists, nurse practitioners, nephrologists, dieticians, dialysis technicians, dialysis nurses, and counselors and psychologists (Figure 2C). In contrast, fewer countries reported shortages of pharmacists, laboratory technicians, and primary care physicians (Figure 2C). By region, shortages of other health care clinicians were more common in Africa, the Middle East, Latin America, South Asia, North and East Asia, OSEA, and
East and Central Europe (eTable 2 in the Supplement). For example, 28 (85\%) countries in Africa had reported shortages of nephrologists compared with only 2 (20\%) countries in Western Europe with reported shortages of this category of workforce (eTable 2).

\section{Health Information Systems}

Countries were asked to provide data on the availability of registries (surveillance and monitoring systems) for kidney replacement therapy and nondialysis CKD and AKI. The prevalence of treated end-stage renal disease was comparatively low in some regions compared with others (Figure 1). For instance, Africa, the Middle East, and South Asia had low prevalence of treated end-stage renal disease in comparison with North America and Western Europe (where the prevalence was generally above 1000 per 1 million population) (Figure 1). Overall, only $9(7.7 \%)$ and $8(6.8 \%)$ countries reported having registries for nondialysis CKD and AKI, respectively (eFigure 2 and eAppendix 3 in the Supplement). There was wide variation in the presence of kidney replacement therapy registries across regions, with most countries reporting having dialysis registries and fewer reporting having kidney transplant registries, particularly in Africa, the Middle East, and South Asia (eFigure 2 and eAppendix 3). Dialysis and kidney transplant registries were most commonly available in Western Europe, North and East Asia, North America, and East and Central European countries (eFigure 2 and eAppendix 3).

\section{Leadership and Governance}

Specific national strategies for improving the care of patients with CKD were reported as present in only 19 countries (17\%) (eTable 3 in the Supplement). There were variations in the availability of 1 or more of the various strategies (national position paper, identification tools, incentives, etc) for improving identification of AKI across regions; 59 countries (51\%) had none of these strategies (eTable 4 in the Supplement).

\section{Response of the Nephrology Community}

(Guidelines and Advocacy for Kidney Care)

The majority of countries reported access predominantly to international guidelines compared with national guidelines. 
Table 6. Availability of Services for Chronic Kidney Disease Monitoring and Management at Primary Care Level

\begin{tabular}{|c|c|c|c|c|c|}
\hline & \multirow{2}{*}{$\begin{array}{l}\text { No. of } \\
\text { Responding Countries }\end{array}$} & \multicolumn{4}{|c|}{ Availability, No. (\%) of Responding Countries } \\
\hline & & Always & Usually & Rarely & Never \\
\hline \multicolumn{6}{|l|}{ Blood Pressure } \\
\hline Overall & 119 & $75(63)$ & $40(34)$ & $4(3)$ & 0 \\
\hline \multicolumn{6}{|l|}{ ISN regions } \\
\hline Africa & 33 & $15(45)$ & $16(49)$ & $2(6)$ & 0 \\
\hline Middle East & 13 & $9(70)$ & $2(15)$ & $2(15)$ & 0 \\
\hline Latin America & 16 & $12(75)$ & $4(25)$ & 0 & 0 \\
\hline $\begin{array}{l}\text { North and East } \\
\text { Asia }\end{array}$ & 6 & $1(17)$ & $5(83)$ & 0 & 0 \\
\hline South Asia & 5 & $3(60)$ & $2(40)$ & 0 & 0 \\
\hline OSEA & 13 & $8(62)$ & $5(38)$ & 0 & 0 \\
\hline $\begin{array}{l}\text { East and Central } \\
\text { Europe }\end{array}$ & 16 & $14(87)$ & $2(13)$ & 0 & 0 \\
\hline NIS and Russia & 6 & $4(67)$ & $2(33)$ & 0 & 0 \\
\hline Western Europe & 9 & $7(78)$ & $2(22)$ & 0 & 0 \\
\hline North America & 2 & $2(100)$ & 0 & 0 & 0 \\
\hline \multicolumn{6}{|c|}{ World Bank income groups } \\
\hline Low & 17 & $8(47)$ & $8(47)$ & $1(6)$ & 0 \\
\hline Lower middle & 33 & $16(49)$ & $15(45)$ & $2(6)$ & 0 \\
\hline Upper middle & 31 & $23(74)$ & $8(26)$ & 0 & 0 \\
\hline High & 38 & $28(73)$ & $9(24)$ & $1(3)$ & 0 \\
\hline \multicolumn{6}{|l|}{ Blood Glucose } \\
\hline Overall & 119 & $48(40)$ & $50(42)$ & $19(16)$ & $2(2)$ \\
\hline \multicolumn{6}{|l|}{ ISN regions } \\
\hline Africa & 33 & $9(27)$ & $10(30)$ & $12(37)$ & $2(6)$ \\
\hline Middle East & 13 & $6(46)$ & $6(46)$ & $1(8)$ & 0 \\
\hline Latin America & 16 & $7(44)$ & $7(44)$ & $2(12)$ & 0 \\
\hline $\begin{array}{l}\text { North and East } \\
\text { Asia }\end{array}$ & 6 & 0 & $6(100)$ & 0 & 0 \\
\hline South Asia & 5 & $1(20)$ & $2(40)$ & $2(40)$ & 0 \\
\hline OSEA & 13 & $4(31)$ & $8(61)$ & $1(8)$ & 0 \\
\hline $\begin{array}{l}\text { East and Central } \\
\text { Europe }\end{array}$ & 16 & $10(63)$ & $5(31)$ & $1(6)$ & 0 \\
\hline NIS and Russia & 6 & $2(33)$ & $4(67)$ & 0 & 0 \\
\hline Western Europe & 9 & $8(89)$ & $1(11)$ & 0 & 0 \\
\hline North America & 2 & $1(50)$ & $1(50)$ & 0 & 0 \\
\hline \multicolumn{6}{|c|}{ World Bank income groups } \\
\hline Low & 17 & $4(24)$ & $3(18)$ & $8(46)$ & $2(12)$ \\
\hline Lower middle & 33 & $9(27)$ & $16(49)$ & $8(24)$ & 0 \\
\hline Upper middle & 31 & $12(39)$ & $17(55)$ & $2(6)$ & 0 \\
\hline High & 38 & $23(60)$ & $14(37)$ & $1(3)$ & 0 \\
\hline \multicolumn{6}{|l|}{ Serum Creatinine } \\
\hline \multicolumn{6}{|c|}{ Serum creatinine with eGFR reporting } \\
\hline Overall & 119 & $21(18)$ & $23(19)$ & $48(40)$ & $27(23)$ \\
\hline \multicolumn{6}{|l|}{ ISN regions } \\
\hline Africa & 33 & $1(3)$ & $4(12)$ & $15(46)$ & $13(39)$ \\
\hline Middle East & 13 & $1(8)$ & $3(23)$ & $7(54)$ & $2(15)$ \\
\hline Latin America & 16 & $2(13)$ & $4(25)$ & $7(43)$ & $3(19)$ \\
\hline $\begin{array}{l}\text { North and East } \\
\text { Asia }\end{array}$ & 6 & 0 & $2(33)$ & $3(50)$ & $1(17)$ \\
\hline South Asia & 5 & $1(20)$ & 0 & $3(60)$ & $1(20)$ \\
\hline OSEA & 13 & $2(15)$ & $3(23)$ & $6(47)$ & $2(15)$ \\
\hline $\begin{array}{l}\text { East and Central } \\
\text { Europe }\end{array}$ & 16 & $8(49)$ & $3(19)$ & $3(19)$ & $2(13)$ \\
\hline NIS and Russia & 6 & 0 & $1(17)$ & $2(33)$ & $3(50)$ \\
\hline Western Europe & 9 & $5(56)$ & $2(22)$ & $2(22)$ & 0 \\
\hline North America & 2 & $1(50)$ & $1(50)$ & 0 & 0 \\
\hline
\end{tabular}


Table 6. Availability of Services for Chronic Kidney Disease Monitoring and Management at Primary Care Level (continued)

\begin{tabular}{|c|c|c|c|c|c|}
\hline & \multirow{2}{*}{$\begin{array}{l}\text { No. of } \\
\text { Responding Countries }\end{array}$} & \multicolumn{4}{|c|}{ Availability, No. (\%) of Responding Countries } \\
\hline & & Always & Usually & Rarely & Never \\
\hline \multicolumn{6}{|l|}{ World Bank income groups } \\
\hline Low & 17 & 0 & 0 & $7(41)$ & $10(59)$ \\
\hline Lower middle & 33 & $3(9)$ & $2(6)$ & $18(55)$ & $10(30)$ \\
\hline Upper middle & 31 & $4(13)$ & $9(29)$ & $12(39)$ & $6(19)$ \\
\hline High & 38 & $14(36)$ & $12(32)$ & $11(29)$ & $1(3)$ \\
\hline \multicolumn{6}{|c|}{ Serum creatinine without eGFR reporting } \\
\hline Overall & 119 & $31(26)$ & $46(39)$ & $32(27)$ & $10(8)$ \\
\hline \multicolumn{6}{|l|}{ ISN regions } \\
\hline Africa & 33 & $5(15)$ & $10(30)$ & $12(37)$ & $6(18)$ \\
\hline Middle East & 13 & $5(38)$ & $5(38)$ & $3(24)$ & 0 \\
\hline Latin America & 16 & $4(25)$ & $9(56)$ & $3(19)$ & 0 \\
\hline North and East Asia & 6 & 0 & $5(83)$ & $1(17)$ & 0 \\
\hline South Asia & 5 & $1(20)$ & $1(20)$ & $2(40)$ & $1(20)$ \\
\hline OSEA & 13 & $3(23)$ & $3(23)$ & $5(39)$ & $2(15)$ \\
\hline East and Central Europe & 16 & $7(44)$ & $4(25)$ & $4(25)$ & $1(6)$ \\
\hline NIS and Russia & 6 & $1(17)$ & $5(83)$ & 0 & 0 \\
\hline Western Europe & 9 & $5(56)$ & $2(22)$ & $2(22)$ & 0 \\
\hline North America & 2 & 0 & $2(100)$ & 0 & 0 \\
\hline \multicolumn{6}{|l|}{ World Bank income groups } \\
\hline Low & 17 & $1(6)$ & $4(24)$ & $5(29)$ & $7(41)$ \\
\hline Lower middle & 33 & $5(15)$ & $13(40)$ & $13(39)$ & $2(6)$ \\
\hline Upper middle & 31 & $9(29)$ & $18(58)$ & $4(13)$ & 0 \\
\hline High & 38 & $16(42)$ & $11(29)$ & $10(26)$ & $1(3)$ \\
\hline \multicolumn{6}{|l|}{ Radiology Services } \\
\hline Overall & 119 & $17(14)$ & $38(32)$ & $48(41)$ & $16(13)$ \\
\hline \multicolumn{6}{|l|}{ ISN regions } \\
\hline Africa & 33 & $5(15)$ & $5(15)$ & $14(43)$ & $9(27)$ \\
\hline Middle East & 13 & $1(8)$ & $3(23)$ & $6(46)$ & $3(23)$ \\
\hline Latin America & 16 & $3(19)$ & $3(19)$ & $9(56)$ & $1(6)$ \\
\hline North and East Asia & 6 & $1(17)$ & $1(17)$ & $4(66)$ & 0 \\
\hline South Asia & 5 & $1(20)$ & $1(20)$ & $3(60)$ & 0 \\
\hline OSEA & 13 & 0 & $6(46)$ & $6(46)$ & $1(8)$ \\
\hline East and Central Europe & 16 & $3(19)$ & $9(56)$ & $3(19)$ & $1(6)$ \\
\hline NIS and Russia & 6 & $1(17)$ & $3(50)$ & $2(33)$ & 0 \\
\hline Western Europe & 9 & $2(22)$ & $5(56)$ & $1(11)$ & $1(11)$ \\
\hline North America & 2 & 0 & $2(100)$ & 0 & 0 \\
\hline \multicolumn{6}{|l|}{ World Bank income groups } \\
\hline Low & 17 & $1(6)$ & $1(6)$ & $8(47)$ & $7(41)$ \\
\hline Lower middle & 33 & $4(12)$ & $8(24)$ & $18(55)$ & $3(9)$ \\
\hline Upper middle & 31 & $6(19)$ & $10(32)$ & $11(36)$ & $4(13)$ \\
\hline High & 38 & $6(16)$ & $19(50)$ & $11(29)$ & $2(5)$ \\
\hline \multicolumn{6}{|l|}{ Urinalysis (Qualitative Assays) } \\
\hline Overall & 119 & $26(22)$ & $54(45)$ & $32(27)$ & $7(6)$ \\
\hline \multicolumn{6}{|l|}{ ISN regions } \\
\hline Africa & 33 & $5(15)$ & $11(33)$ & $13(40)$ & $4(12)$ \\
\hline Middle East & 13 & $2(15)$ & $10(77)$ & $1(8)$ & 0 \\
\hline Latin America & 16 & $3(19)$ & $6(38)$ & $6(37)$ & $1(6)$ \\
\hline North and East Asia & 6 & 0 & $4(67)$ & $2(33)$ & 0 \\
\hline South Asia & 5 & $2(40)$ & $2(40)$ & $1(20)$ & 0 \\
\hline OSEA & 13 & $2(16)$ & $5(38)$ & $5(38)$ & $1(8)$ \\
\hline East and Central Europe & 16 & $7(44)$ & $7(44)$ & $1(6)$ & $1(6)$ \\
\hline NIS and Russia & 6 & $1(17)$ & $2(33)$ & $3(50)$ & 0 \\
\hline Western Europe & 9 & $4(44)$ & $5(56)$ & 0 & 0 \\
\hline North America & 2 & 0 & $2(100)$ & 0 & 0 \\
\hline
\end{tabular}


Table 6. Availability of Services for Chronic Kidney Disease Monitoring and Management at Primary Care Level (continued)

\begin{tabular}{|c|c|c|c|c|c|}
\hline & \multirow{2}{*}{$\begin{array}{l}\text { No. of } \\
\text { Responding Countries }\end{array}$} & \multicolumn{4}{|c|}{ Availability, No. (\%) of Responding Countries } \\
\hline & & Always & Usually & Rarely & Never \\
\hline \multicolumn{6}{|l|}{ World Bank income groups } \\
\hline Low & 17 & $3(18)$ & $4(24)$ & $7(41)$ & $3(18)$ \\
\hline Lower middle & 33 & $5(16)$ & $13(39)$ & $13(39)$ & $2(6)$ \\
\hline Upper middle & 31 & $4(13)$ & $18(58)$ & $7(23)$ & $2(6)$ \\
\hline High & 38 & $14(37)$ & $19(50)$ & $5(13)$ & 0 \\
\hline \multicolumn{6}{|l|}{ UACR or UPCR Measurement } \\
\hline Overall & 119 & $9(8)$ & $29(24)$ & $52(44)$ & $29(24)$ \\
\hline \multicolumn{6}{|l|}{ ISN regions } \\
\hline Africa & 33 & 0 & $4(12)$ & $11(33)$ & $18(55)$ \\
\hline Middle East & 13 & 0 & $6(46)$ & $6(46)$ & $1(8)$ \\
\hline Latin America & 16 & $3(19)$ & $5(31)$ & $5(31)$ & $3(19)$ \\
\hline North and East Asia & 6 & 0 & 0 & $6(100)$ & 0 \\
\hline South Asia & 5 & 0 & $1(20)$ & $4(80)$ & 0 \\
\hline OSEA & 13 & $1(8)$ & $3(23)$ & $7(54)$ & $2(15)$ \\
\hline East and Central Europe & 16 & $2(13)$ & $2(13)$ & $9(55)$ & $3(19)$ \\
\hline NIS and Russia & 6 & 0 & $1(17)$ & $3(50)$ & $2(33)$ \\
\hline Western Europe & 9 & $3(33)$ & $5(56)$ & $1(11)$ & 0 \\
\hline North America & 2 & 0 & $2(100)$ & 0 & 0 \\
\hline \multicolumn{6}{|l|}{ World Bank income groups } \\
\hline Low & 17 & 0 & 0 & $3(18)$ & $14(82)$ \\
\hline Lower middle & 33 & $1(3)$ & $4(12)$ & $18(55)$ & $10(30)$ \\
\hline Upper middle & 31 & $3(10)$ & $8(26)$ & $16(51)$ & $4(13)$ \\
\hline High & 38 & $5(13)$ & $17(45)$ & $15(39)$ & $1(3)$ \\
\hline
\end{tabular}

Abbreviations: eGFR, estimated glomerular filtration rate; ISN, International Society of Nephrology; NIS, newly independent states; OSEA, Oceania and South East Asia; UACR, urine albumin:creatinine ratio; UPCR, urine protein:creatinine ratio.
Access to international CKD and AKI management guidelines was reported in 60 (52\%) and 52 (45\%) countries, respectively (eTable 5 in the Supplement). Thirty-one countries (27\%) reported availability of national guidelines for CKD (eTable 5). In contrast, only 8 countries (7\%) reported access to national guidelines for AKI. Presence of CKD and AKI advocacy groups were limited in most regions and were more common for CKD than for AKI (eFigure 3 and eAppendix 3 in the Supplement).

\section{Capacity for Research and Development}

Respondents rated their involvement with different phases of clinical trials and observational research studies (available infrastructure, trained workforce, ethical frameworks, etc). Low capacity for participation in different aspects of clinical trials was frequently reported, especially in developing countries and regions (eAppendix 3 in the Supplement). For example, only 33 (28\%) and 46 (40\%) countries overall could participate in phase 1 and phase 2 clinical trials, respectively (eTable 6 and eAppendix 3 in the Supplement). Western Europe and North America reported the highest capacity to participate in all phases of clinical trials (eTable 6 and eAppendix 3). For instance, all countries in these 2 regions reported capacity to participate in phase 3 and 4 trials in contrast to only 5 (17\%) and 4 (13\%) in Africa, respectively (eTable 6). Although most countries described some capacity to conduct or participate in observational cohort studies, Africa and Middle East countries reported no capacity to participate in transplantation cohort studies (eTable 6). Institutional ethics approval was the most com- mon study approval type in most countries overall and across most regions (eTable 6).

\section{Discussion}

To our knowledge, this is the first systematic assessment of the global capacity for kidney care in terms of the key building blocks of a functional health system and readiness of countries and regions to enhance such care. There were significant gaps reported in services, facilities, and workforce in some countries and regions. Most countries in Africa described no facilities for peritoneal dialysis or kidney transplantation. Few countries reported complete public funding for kidney replacement therapy services and medications for CKD care (including dialysis and transplantation); there was a large private contribution toward payment for kidney replacement therapy services and medications reported particularly in countries across the Africa, South Asia, and OSEA regions. Even though the infrastructure available for AKI and CKD care was mostly rated as average or above average, survey responses suggested that measurement of serum creatinine with eGFR was common at the primary care level in only a few countries. Availability of pathological services for kidney biopsy was described as very low. Overall, there was a reported shortage of nephrology workforce and other workforce categories in many settings. There was limited availability of health information systems (renal registries), particularly for nondialysis CKD and AKI. National or regional strategies for improving CKD 


\begin{tabular}{|c|c|c|c|c|c|}
\hline & \multirow{2}{*}{$\begin{array}{l}\text { No. of } \\
\text { Responding Countries }\end{array}$} & \multicolumn{4}{|c|}{ Availability, No. (\%) of Responding Countries } \\
\hline & & Always & Usually & Rarely & Never \\
\hline \multicolumn{6}{|l|}{ Blood Pressure } \\
\hline Overall & 119 & $106(89)$ & $13(11)$ & 0 & 0 \\
\hline \multicolumn{6}{|l|}{ ISN regions } \\
\hline Africa & 33 & $27(82)$ & $6(18)$ & 0 & 0 \\
\hline Middle East & 13 & $13(100)$ & 0 & 0 & 0 \\
\hline Latin America & 16 & $15(94)$ & $1(6)$ & 0 & 0 \\
\hline North and East Asia & 6 & $3(50)$ & $3(50)$ & 0 & 0 \\
\hline South Asia & 5 & $5(100)$ & 0 & 0 & 0 \\
\hline OSEA & 13 & $12(92)$ & $1(8)$ & 0 & 0 \\
\hline East and Central Europe & 16 & $16(100)$ & 0 & 0 & 0 \\
\hline NIS and Russia & 6 & $5(83)$ & $1(17)$ & 0 & 0 \\
\hline Western Europe & 9 & $8(89)$ & $1(11)$ & 0 & 0 \\
\hline North America & 2 & $2(100)$ & 0 & 0 & 0 \\
\hline \multicolumn{6}{|l|}{ World Bank income groups } \\
\hline Low & 17 & $14(82)$ & $3(18)$ & 0 & 0 \\
\hline Lower middle & 33 & $28(85)$ & $5(15)$ & 0 & 0 \\
\hline Upper middle & 31 & $29(94)$ & $2(6)$ & 0 & 0 \\
\hline High & 38 & $35(92)$ & $3(8)$ & 0 & 0 \\
\hline \multicolumn{6}{|l|}{ Blood Glucose } \\
\hline Overall & 119 & $83(70)$ & $35(29)$ & $1(1)$ & 0 \\
\hline \multicolumn{6}{|l|}{ ISN regions } \\
\hline Africa & 33 & $18(55)$ & $14(42)$ & $1(3)$ & 0 \\
\hline Middle East & 13 & $12(92)$ & $1(8)$ & 0 & 0 \\
\hline Latin America & 16 & $14(87)$ & $2(13)$ & 0 & 0 \\
\hline North and East Asia & 6 & $1(17)$ & $5(83)$ & 0 & 0 \\
\hline South Asia & 5 & $4(80)$ & $1(20)$ & 0 & 0 \\
\hline OSEA & 13 & $7(54)$ & $6(46)$ & 0 & 0 \\
\hline East and Central Europe & 16 & $15(94)$ & $1(6)$ & 0 & 0 \\
\hline NIS and Russia & 6 & $3(50)$ & $3(50)$ & 0 & 0 \\
\hline Western Europe & 9 & $7(78)$ & $2(22)$ & 0 & 0 \\
\hline North America & 2 & $2(100)$ & 0 & 0 & 0 \\
\hline \multicolumn{6}{|l|}{ World Bank income groups } \\
\hline Low & 17 & $10(59)$ & $7(41)$ & 0 & 0 \\
\hline Lower middle & 33 & $17(52)$ & $15(45)$ & $1(3)$ & 0 \\
\hline Upper middle & 31 & $25(81)$ & $6(19)$ & 0 & 0 \\
\hline High & 38 & $31(82)$ & $7(18)$ & 0 & 0 \\
\hline \multicolumn{6}{|l|}{ Serum Creatinine } \\
\hline \multicolumn{6}{|c|}{ Serum creatinine with eGFR reporting } \\
\hline Overall & 108 & $43(40)$ & $25(23)$ & $25(23)$ & $15(14)$ \\
\hline \multicolumn{6}{|l|}{ ISN regions } \\
\hline Africa & 33 & $7(21)$ & $6(18)$ & $8(24)$ & $12(37)$ \\
\hline Middle East & 13 & $5(38)$ & $5(38)$ & $3(24)$ & 0 \\
\hline Latin America & 5 & $2(40)$ & $1(20)$ & $1(20)$ & $1(20)$ \\
\hline North and East Asia & 6 & $1(17)$ & $4(66)$ & $1(17)$ & 0 \\
\hline South Asia & 5 & 0 & $2(40)$ & $2(40)$ & $1(20)$ \\
\hline OSEA & 13 & $6(46)$ & $3(23)$ & $4(31)$ & 0 \\
\hline East and Central Europe & 16 & $11(68)$ & $2(13)$ & $2(13)$ & $1(6)$ \\
\hline NIS and Russia & 6 & $2(33)$ & $1(17)$ & $3(50)$ & 0 \\
\hline Western Europe & 9 & $7(78)$ & $1(11)$ & $1(11)$ & 0 \\
\hline North America & 2 & $2(100)$ & 0 & 0 & 0 \\
\hline \multicolumn{6}{|l|}{ World Bank income groups } \\
\hline Low & 17 & $2(12)$ & $1(6)$ & $3(18)$ & $11(64)$ \\
\hline Lower middle & 29 & $5(17)$ & $9(31)$ & $13(45)$ & $2(7)$ \\
\hline Upper middle & 27 & $10(37)$ & $10(37)$ & $5(19)$ & $2(7)$ \\
\hline High & 35 & $26(75)$ & $5(14)$ & $4(11)$ & 0 \\
\hline
\end{tabular}


Table 7. Availability of Services for Chronic Kidney Disease Monitoring and Management at Secondary or Tertiary Care Levels (continued)

\begin{tabular}{|c|c|c|c|c|c|}
\hline & \multirow{2}{*}{$\begin{array}{l}\text { No. of } \\
\text { Responding Countries }\end{array}$} & \multicolumn{4}{|c|}{ Availability, No. (\%) of Responding Countries } \\
\hline & & Always & Usually & Rarely & Never \\
\hline \multicolumn{6}{|l|}{$\begin{array}{l}\text { Serum creatinine } \\
\text { without eGFR reporting }\end{array}$} \\
\hline Overall & 117 & $68(58)$ & $40(34)$ & $7(6)$ & $2(2)$ \\
\hline \multicolumn{6}{|l|}{ ISN regions } \\
\hline Africa & 32 & $9(28)$ & $19(60)$ & $3(9)$ & $1(3)$ \\
\hline Middle East & 13 & $13(100)$ & 0 & 0 & 0 \\
\hline Latin America & 16 & $10(62)$ & $6(38)$ & 0 & 0 \\
\hline North and East Asia & 6 & $3(50)$ & $3(50)$ & 0 & 0 \\
\hline South Asia & 5 & $3(60)$ & $2(40)$ & 0 & 0 \\
\hline OSEA & 12 & $6(50)$ & $5(42)$ & $1(8)$ & 0 \\
\hline East and Central Europe & 16 & $12(75)$ & $2(13)$ & $1(6)$ & $1(6)$ \\
\hline NIS and Russia & 6 & $5(83)$ & $1(17)$ & 0 & 0 \\
\hline Western Europe & 9 & $5(56)$ & $2(22)$ & $2(22)$ & 0 \\
\hline North America & 2 & $2(100)$ & 0 & 0 & 0 \\
\hline \multicolumn{6}{|l|}{ World Bank income groups } \\
\hline Low & 17 & $2(12)$ & $12(70)$ & $2(12)$ & $1(6)$ \\
\hline Lower middle & 31 & $16(52)$ & $13(42)$ & $2(6)$ & 0 \\
\hline Upper middle & 31 & $24(77)$ & $7(23)$ & 0 & 0 \\
\hline High & 38 & $26(68)$ & $8(21)$ & $3(8)$ & $1(3)$ \\
\hline \multicolumn{6}{|l|}{ UACR or UPCR Measurement } \\
\hline Overall & 118 & $32(27)$ & $47(40)$ & $28(24)$ & $11(9)$ \\
\hline \multicolumn{6}{|l|}{ ISN regions } \\
\hline Africa & 32 & $2(6)$ & $8(25)$ & $14(44)$ & $8(25)$ \\
\hline Middle East & 13 & $5(38)$ & $8(62)$ & 0 & 0 \\
\hline Latin America & 16 & $4(25)$ & $10(62)$ & $2(13)$ & 0 \\
\hline North and East Asia & 6 & $1(17)$ & $4(66)$ & 0 & $1(17)$ \\
\hline South Asia & 5 & 0 & $3(60)$ & $2(40)$ & 0 \\
\hline OSEA & 13 & $4(31)$ & $4(31)$ & $5(38)$ & 0 \\
\hline East and Central Europe & 16 & $7(44)$ & $4(25)$ & $4(25)$ & $1(6)$ \\
\hline NIS and Russia & 6 & $1(17)$ & $3(49)$ & $1(17)$ & $1(17)$ \\
\hline Western Europe & 9 & $6(67)$ & $3(33)$ & 0 & 0 \\
\hline North America & 2 & $2(100)$ & 0 & 0 & 0 \\
\hline \multicolumn{6}{|l|}{ World Bank income groups } \\
\hline Low & 17 & 0 & $1(6)$ & $10(59)$ & $6(35)$ \\
\hline Lower middle & 33 & $3(9)$ & $15(46)$ & $13(39)$ & $2(6)$ \\
\hline Upper middle & 30 & $9(30)$ & $14(47)$ & $4(13)$ & $3(10)$ \\
\hline High & 38 & $20(52)$ & $17(45)$ & $1(3)$ & 0 \\
\hline \multicolumn{6}{|l|}{ Radiology Services (Ultrasound) } \\
\hline Overall & 119 & $68(57)$ & $45(38)$ & $6(5)$ & 0 \\
\hline \multicolumn{6}{|l|}{ ISN regions } \\
\hline Africa & 33 & $13(39)$ & $16(49)$ & $4(12)$ & 0 \\
\hline Middle East & 13 & $12(92)$ & $1(8)$ & 0 & 0 \\
\hline Latin America & 16 & $8(50)$ & $8(50)$ & 0 & 0 \\
\hline North and East Asia & 6 & $3(50)$ & $3(50)$ & 0 & 0 \\
\hline South Asia & 5 & $3(60)$ & $2(40)$ & 0 & 0 \\
\hline OSEA & 13 & $5(38)$ & $6(47)$ & $2(15)$ & 0 \\
\hline East and Central Europe & 16 & $12(75)$ & $4(25)$ & 0 & 0 \\
\hline NIS and Russia & 6 & $4(67)$ & $2(33)$ & 0 & 0 \\
\hline Western Europe & 9 & $6(67)$ & $3(33)$ & 0 & 0 \\
\hline North America & 2 & $2(100)$ & 0 & 0 & 0 \\
\hline \multicolumn{6}{|l|}{ World Bank income groups } \\
\hline Low & 17 & $5(29)$ & $9(53)$ & $3(18)$ & 0 \\
\hline Lower middle & 33 & $15(45)$ & $16(49)$ & $2(6)$ & 0 \\
\hline Upper middle & 31 & $19(62)$ & $11(35)$ & $1(3)$ & 0 \\
\hline High & 38 & $29(76)$ & $9(24)$ & 0 & 0 \\
\hline
\end{tabular}


Table 7. Availability of Services for Chronic Kidney Disease Monitoring and Management at Secondary or Tertiary Care Levels (continued)

\begin{tabular}{|c|c|c|c|c|c|}
\hline & \multirow{2}{*}{$\begin{array}{l}\text { No. of } \\
\text { Responding Countries }\end{array}$} & \multicolumn{4}{|c|}{ Availability, No. (\%) of Responding Countries } \\
\hline & & Always & Usually & Rarely & Never \\
\hline \multicolumn{6}{|c|}{ Pathology Services (Renal Biopsy) } \\
\hline Overall & 118 & $27(23)$ & $47(39)$ & $28(24)$ & $16(14)$ \\
\hline \multicolumn{6}{|l|}{ ISN regions } \\
\hline Africa & 32 & $1(3)$ & $6(19)$ & $13(40)$ & $12(38)$ \\
\hline Middle East & 13 & $4(31)$ & $8(61)$ & $1(8)$ & 0 \\
\hline Latin America & 16 & $2(13)$ & $11(68)$ & $2(13)$ & $1(6)$ \\
\hline North and East Asia & 6 & $1(17)$ & $3(50)$ & $2(33)$ & 0 \\
\hline South Asia & 5 & 0 & $4(80)$ & $1(20)$ & 0 \\
\hline OSEA & 13 & $3(23)$ & $3(23)$ & $5(39)$ & $2(15)$ \\
\hline East and Central Europe & 16 & $9(56)$ & $4(25)$ & $2(13)$ & $1(6)$ \\
\hline NIS and Russia & 6 & 0 & $4(67)$ & $2(33)$ & 0 \\
\hline Western Europe & 9 & $5(56)$ & $4(44)$ & 0 & 0 \\
\hline North America & 2 & $2(100)$ & 0 & 0 & 0 \\
\hline \multicolumn{6}{|l|}{ World Bank income groups } \\
\hline Low & 17 & 0 & $3(18)$ & $5(29)$ & $9(53)$ \\
\hline Lower middle & 32 & $1(3)$ & $12(37)$ & $15(47)$ & $4(13)$ \\
\hline Upper middle & 31 & $3(10)$ & $18(57)$ & $7(23)$ & $3(10)$ \\
\hline High & 38 & $23(60)$ & $14(37)$ & $1(3)$ & 0 \\
\hline
\end{tabular}

Abbreviations: eGFR, estimated glomerular filtration rate; ISN, International Society of Nephrology; NIS, newly independent states; OSEA, Oceania and South East Asia; UACR, urine albumin:creatinine ratio; UPCR, urine protein:creatinine ratio. and AKI care were present in only a few countries, with wide variations across regions on the reported availability and access to care guidelines. The presence of CKD and AKI advocacy groups was reported as limited in most regions and was more common for AKI than for CKD, with more than two-thirds of countries reporting absence of capacity to participate in clinical research.

The status of kidney health care as suggested by this study indicates that the health systems of many countries face substantial challenges in closing the large gaps that are reported to currently exist in meeting the health needs of people with AKI and CKD around the world. ${ }^{1,19}$ First, the reported limited availability of and public funding for AKI and CKD care (kidney replacement therapy technologies, essential medicines, service delivery and infrastructures, kidney disease detection), particularly in low- and lower middle-income countries, call for strategies at global, regional, and national levels to make these care components accessible and affordable to the burgeoning populace with kidney disease. ${ }^{20-23}$ While community-based kidney disease prevention, identification, and treatment programs represent an important low-cost strategy with the potential for significant public health benefits, ${ }^{24,25}$ the present study found that most countries reported inadequate CKD detection and surveillance systems to achieve this goal. For example, the ability to quantitatively measure serum creatinine with eGFR reporting and proteinuria even at secondary care levels was "always" possible in only 7 (21\%) and 2 (6\%) African countries, respectively. Furthermore, peritoneal dialysis tended to be relatively underutilized in resource-poor countries, even though this mode is generally considered a less expensive and technically less demanding form of kidney replacement therapy ${ }^{26}$ that is particularly suited to low- and lower-middle income countries challenged by limited finances, limited nephrol- ogy workforce, and geographical barriers. ${ }^{21}$ Developing lowcost kidney disease detection programs (integrated with other noncommunicable disease strategies) and low-cost dialysis programs in resource-limited settings requires building partnerships among industry, international health agencies, and governments, ${ }^{22}$ as occurred with the establishment of low-cost chronic disease management programs in Africa. ${ }^{22,27-29}$

A second challenge is the limited availability of reliable surveillance systems reported for both AKI and CKD across countries and regions, which is a major impediment to designing and implementing effective interventions to close the identified gaps in infrastructures and services. ${ }^{30}$ Policy decisions at national and international levels are required to support development of functional information systems across the broad spectrum of kidney diseases and to track and monitor burden, treatment, and related outcomes. ${ }^{29,30}$

A third key challenge is the limited workforce capacity reported in most countries and regions, especially dialysis nurses, laboratory workers, dietitians, transplant coordinators, and nephrologists. Because health care workforce availability is a prerequisite for effective AKI and CKD management programs and policies, ${ }^{29}$ the challenge of health care professional shortages will require a concerted response from major national and international stakeholders. ${ }^{11,27}$

Fourth, the limited capacity reported in most regions and countries to undertake clinical research calls for more investment and a targeted research agenda to improve understanding of kidney disease burden, process of care, outcomes monitoring, and testing of novel interventions, particularly in low- and lower middle-income countries. ${ }^{27}$

The key strengths of the GKHA Project were the development of the study protocol and survey instrument, which followed a well-validated conceptual framework 

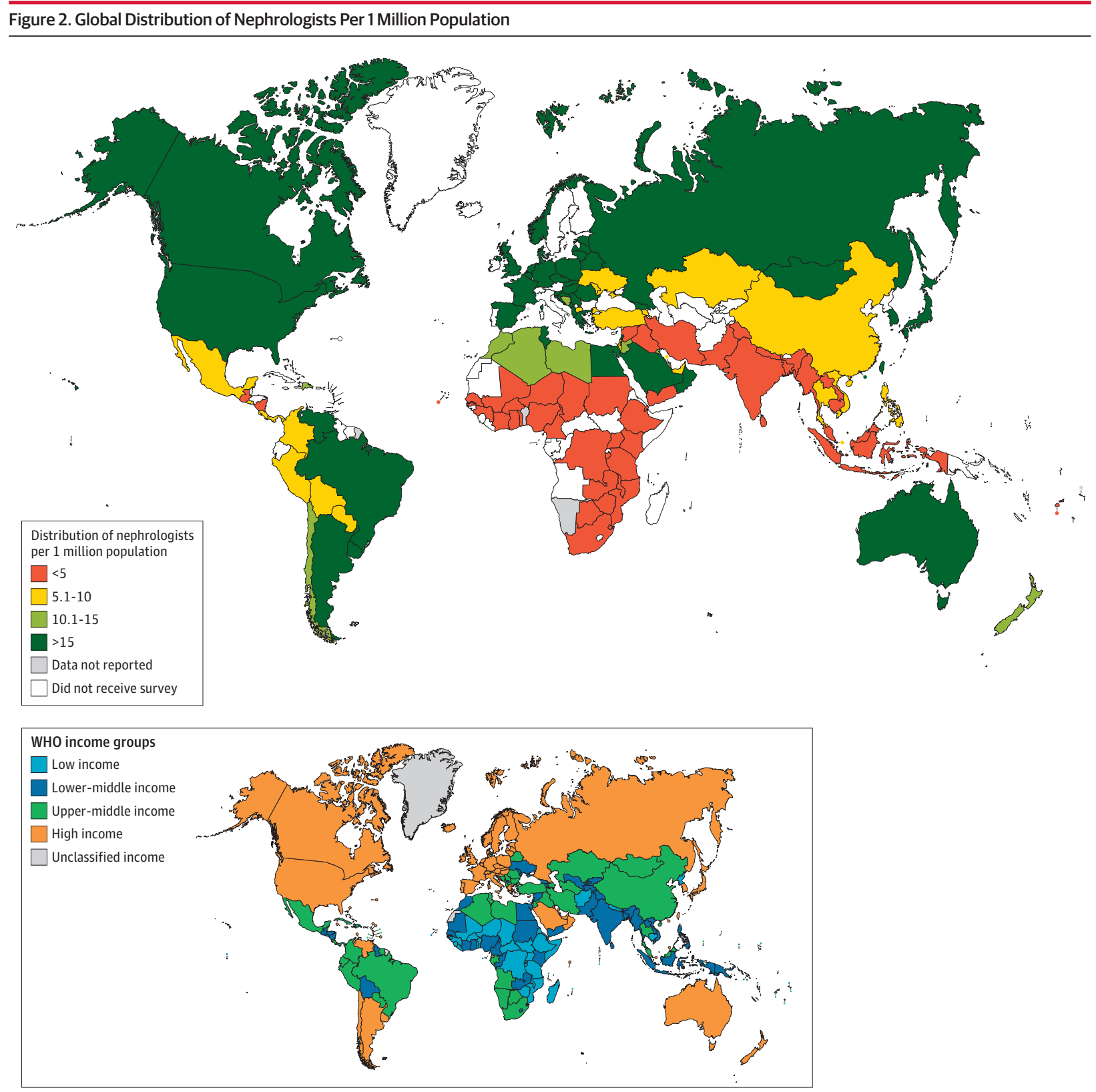

The map depicts global distribution of nephrologists per 1 million population by country and region. Data not available indicates that data were either not known or not provided on the questionnaire for countries that received the survey.

assessing capacity for other chronic diseases based on the widely applied WHO health system building blocks. ${ }^{15}$ The survey had high external validity, involving 125 countries and including very good coverage across regions and income levels. Data were reviewed for accuracy and validity by regional and national stakeholders knowledgeable of the local context across regions and countries. Furthermore, the findings were corroborated and validated via triangulation with secondary data sources based on a review of published and other literature at country levels (provided by survey respondents and other sources). In addition, a future survey using similar methods may provide assessments of improvements or declines in global kidney health care status.

The GKHA Project and this study also have several limitations. The use of a questionnaire survey, although an important source of information, was potentially subjective and highly dependent on the knowledge, expertise, and perceptions of the respondents. Furthermore, there are no internationally agreed on or recommended benchmarks for health care workforce densities, and therefore, precise definition of what constitutes a health worker shortage is likely 
to vary considerably between different countries. The survey questions were limited to only face validity and were reliant on respondents answering fairly and representing the status of services in their country accurately. To address these potential problems, respondents with a range of kidney care knowledge, expertise, and regional representation were carefully selected in liaison with the ISN regional boards. There was potential for social desirability bias to have influenced some responses, which was mitigated by corroborating findings with regional leaders as well as secondary data sources. The study also did not take into account some important dimensions of health systems, such as quality, efficiency, accessibility, geographic distribu- tion, and within-country heterogeneity (particularly between urban and rural regions).

\section{Conclusions}

This survey demonstrated significant interregional and intraregional variability in the current capacity for kidney care across the world, including important gaps in services and workforce. Assuming the responses accurately reflect the status of kidney care in the respondent countries, these findings may be useful to inform efforts to improve the quality of kidney care worldwide.

\section{ARTICLE INFORMATION}

Accepted for Publication: April 4, 2017.

Published Online: April 21, 2017.

doi:10.1001/jama.2017.4046

Author Affiliations: Department of Medicine, University of Alberta, Edmonton, Canada (Bello, Jindal, Rateb, Osman, Qarni, Saad, Wiebe, Ye); Division of Nephrology, University of British Columbia, Vancouver, Canada (Levin); Department of Medicine, University of Calgary, Calgary, Alberta, Canada (Tonelli, Lunney); Department of Community Health Sciences, University of Calgary, Calgary, Alberta, Canada (Tonelli, Lunney); Division of Nephrology and Hypertension, University of Cape Town, Cape Town, South Africa (Okpechi); University Hospitals of Leicester, University of Leicester, Leicester, England (Feehally); Centre for Transplantation and Renal Research, University of Sydney at Westmead Hospital, Sydney, Australia (Harris); Department of Medicine, College of Medicine, University of Ibadan, Ibadan, Nigeria (Salako); Centre for Kidney Disease Research, University of Queensland at Princess Alexandra Hospital, Brisbane, Australia (Johnson); Translational Research Institute, Brisbane, Australia (Johnson); Metro South and Ipswich Nephrology and Transplant Services, Princess Alexandra Hospital, Brisbane, Australia (Johnson).

Author Contributions: Drs Bello and Johnson had full access to all of the data in the study and take responsibility for the integrity of the data and the accuracy of the data analysis.

Study concept and design: Bello, Levin, Tonelli, Feehally, Harris, Jindal, Wiebe, Johnson. Acquisition, analysis, or interpretation of data: Bello Levin, Tonelli, Okpechi, Salako, Rateb, Osman, Qarni, Saad, Lunney, Wiebe, Ye, Johnson. Drafting of the manuscript: Bello, Okpechi, Qarni, Saad, Ye, Johnson.

Critical revision of the manuscript for important intellectual content: Bello, Levin, Tonelli, Feehally, Harris, Jindal, Salako, Rateb, Osman, Lunney, Wiebe, Johnson.

Statistical analysis: Bello, Qarni, Saad, Ye. Obtained funding: Levin, Johnson.

Administrative, technical, or material support: Bello, Levin, Okpechi, Jindal, Salako, Rateb, Osman, Lunney.

Study supervision: Bello, Levin, Wiebe, Johnson.

Conflict of Interest Disclosures: All authors have completed and submitted the ICMJE Form for Disclosure of Potential Conflicts of Interest. Dr Harris reports receipt of lecture fees from
Roche Myanmar and Otsuka. Dr Johnson reports receipt of grants/fellowships, personal fees, and/or travel sponsorship from Baxter Healthcare, Fresenius Medical Care, Amgen, AstraZeneca, and the National Health and Medical Research Council of Australia. No other disclosures were reported

Funding/Support: This work was supported by the International Society of Nephrology (grant RES0033080 to University of Alberta).

Role of the Funder/Sponsor: The ISN provided administrative support in the design and conduct of the study and data collection. The data management, analysis, and interpretation as well as the preparation, review, and approval of the manuscript and decision to submit the manuscript for publication were the responsibility of the authors, and the ISN had no role in any of these activities.

Meeting Presentation: This article was presented at the ISN Global Kidney Policy Forum; April 21, 2017; Mexico City, Mexico.

Additional Contributions: We thank Sandrine Damster, MA, research project manager at the ISN, and the Alberta Kidney Disease Network staff (Ghenette Houston, BA, Sue Szigety, RN, BSci, and Sophanny Tiv, BSci) for support with the organization and conduct of the survey and project management. We thank the ISN staff (Louise Fox, BSc, and Luca Segantini, VDM) for their support. We thank the GKHA steering committee, executive committee of the ISN, ISN regional leadership, and the leaders of the ISN affiliate societies at regional and country levels for their support toward the success of this initiative, particularly with identification of survey respondents and data acquisition. None of the persons acknowledged received compensation for their role in the study.

\section{REFERENCES}

1. Bello AK, Levin A, Manns BJ, et al; Kidney Health for Life Initiative. Effective CKD care in European countries: challenges and opportunities for health policy. Am J Kidney Dis. 2015;65(1):15-25.

2. Radhakrishnan J, Remuzzi G, Saran R, et al; CDC-CKD Surveillance Team; European CKD Burden Consortium; CKD.QLD Group. Taming the chronic kidney disease epidemic: a global view of surveillance efforts. Kidney Int. 2014;86(2):246-250
3. Couser WG, Remuzzi G, Mendis S, Tonelli M. The contribution of chronic kidney disease to the global burden of major noncommunicable diseases. Kidney Int. 2011;80(12):1258-1270.

4. Palmer S, Vecchio M, Craig JC, et al. Prevalence of depression in chronic kidney disease: systematic review and meta-analysis of observational studies. Kidney Int. 2013;84(1):179-191.

5. Go AS, Chertow GM, Fan D, McCulloch CE, Hsu CY. Chronic kidney disease and the risks of death, cardiovascular events, and hospitalization. N Engl J Med. 2004;351(13):1296-1305.

6. Wang HE, Gamboa C, Warnock DG, Muntner P. Chronic kidney disease and risk of death from infection. Am J Nephrol. 2011;34(4):330-336.

7. Levey AS, de Jong PE, Coresh J, et al. The definition, classification, and prognosis of chronic kidney disease: a KDIGO Controversies Conference report. Kidney Int. 2011;80(1):17-28.

8. World Health Organization. Global Status Report on Noncommunicable Diseases 2014. Geneva, Switzerland: WHO Press; 2014.

9. Huffman MD, Perel P, Beller GA, et al. World Heart Federation Emerging Leaders Program: an innovative capacity building program to facilitate the $25 \times 25$ goal. Glob Heart. 2015;10 (4):229-233.

10. Moran AE, Roth GA, Narula J, Mensah GA. 1990-2010 Global Cardiovascular Disease Atlas. Glob Heart. 2014;9(1):3-16.

11. Perico N, Remuzzi G. Acute kidney injury in poor countries should no longer be a death sentence: the ISN "O by 25" Project. Ann Nutr Metab. 2015;66 (suppl 3):42-44.

12. Sacco RL, Roth GA, Reddy KS, et al. The heart of 25 by 25 : achieving the goal of reducing global and regional premature deaths from cardiovascular diseases and stroke: a modeling study from the American Heart Association and World Heart Federation. Circulation. 2016;133(23):e674-e690.

13. World Health Organization. Universal Health Coverage: Supporting Country Needs. http://www who.int/contracting/UHC_Country_Support.pdf. Accessed April 14, 2017.

14. Guariguata L, Whiting D, Weil C, Unwin N. The International Diabetes Federation Diabetes Atlas methodology for estimating global and national prevalence of diabetes in adults. Diabetes Res Clin Pract. 2011;94(3):322-332. 
15. World Health Organization. Monitoring the Building Blocks of Health Systems: A Handbook of Indicators and Their Measurement Strategies. Geneva, Switzerland: WHO Press; 2010

16. Leowski J, Krishnan A. Capacity to control noncommunicable diseases in the countries of South-East Asia. Health Policy. 2009;92(1):43-48.

17. Chapman AL, Hadfield M, Chapman CJ. Qualitative research in healthcare: an introduction to grounded theory using thematic analysis. J R Coll Physicians Edinb. 2015;45(3):201-205.

18. Stevens GA, Alkema L, Black RE, et al; GATHER Working Group. Guidelines for Accurate and Transparent Health Estimates Reporting: the GATHER statement. Lancet. 2016; 388(10062):e19-e23.

19. Jha V, Garcia-Garcia G, Iseki K, et al. Chronic kidney disease: global dimension and perspectives. Lancet. 2013;382(9888):260-272.

20. White SL, Chadban SJ, Jan S, Chapman JR, Cass A. How can we achieve global equity in provision of renal replacement therapy? Bull World Health Organ. 2008;86(3):229-237.
21. Teerawattananon $Y$, Luz A, Pilasant $S$, et al. How to meet the demand for good quality renal dialysis as part of universal health coverage in resource-limited settings? Health Res Policy Syst. 2016;14:21.

22. Jha V, Arici M, Collins AJ, et al. Understanding kidney care needs and implementation strategies in low- and middle-income countries: conclusions from a "Kidney Disease: Improving Global Outcomes" (KDIGO) Controversies Conference. Kidney Int. 2016:90(6):1164-1174.

23. Levey AS, Becker C, Inker LA. Glomerular filtration rate and albuminuria for detection and staging of acute and chronic kidney disease in adults: a systematic review. JAMA 2015;313(8):837-846.

24. Johnson DW, Atai E, Chan M, et al; KHA-CARI. KHA-CARI guideline: early chronic kidney disease: detection, prevention and management. Nephrology (Carlton). 2013;18(5):340-350.

25. Wouters OJ, O'Donoghue DJ, Ritchie J, Kanavos PG, Narva AS. Early chronic kidney disease: diagnosis, management and models of care. Nat Rev Nephrol. 2015;11(8):491-502.

26. Karopadi AN, Mason G, Rettore E, Ronco C. Cost of peritoneal dialysis and haemodialysis across the world. Nephrol Dial Transplant. 2013;28(10): 2553-2569.

27. Pearce N, Ebrahim S, McKee M, et al. Global prevention and control of NCDs: limitations of the standard approach. J Public Health Policy. 2015;36 (4):408-425.

28. Katz IJ, Gerntholtz T, Naicker S. Africa and nephrology: the forgotten continent. Nephron Clin Pract. 2011;117(4):c320-c327.

29. Nuño R, Coleman K, Bengoa R, Sauto R. Integrated care for chronic conditions: the contribution of the ICCC Framework. Health Policy. 2012:105(1):55-64.

30. World Health Organization. Health Metrics Network: Framework and Standards for Country Health Information Systems. 2nd ed. Geneva, Switzerland: WHO Press; 2008. 


\section{Supplementary Online Content}

Bello AK, Levin A, Tonelli M, et al. Assessment of global kidney health care status. JAMA. doi:10.1001/jama.2017.4046

eFigure 1. Global Availability of Nephrology Workforce

eFigure 2. Availability of Renal Registries by Region

eFigure 3. Presence of Advocacy Group for Kidney Care

eTable 1. Assessment of Healthcare Infrastructure Available for Providing Kidney Care

eTable 2. In Your Opinion, Is There a Shortage of Any of the Following Providers in Your Country?

(By Region)

eTable 3. Does Your Country Have a National Strategy for Improving the Care of CKD Patients?

eTable 4. Does Your Country Have a National Strategy for Improving the Identification of AKI?

eTable 5. Access to Clinical Practice Guidelines for Kidney Care

eTable 6. Capacity and Availability of Regulatory Framework for Clinical Research

eAppendix 1. Study Questionnaire

eAppendix 2. Access to RRT, Medication Funding and Workforce Capacity

eAppendix 3. Services for CKD Care, Information Systems, Advocacy Structures, and Capacity for Clinical Trials

This supplementary material has been provided by the authors to give readers additional information about their work. 
eFigure 1. Global availability of nephrology workforce

eFigure 1A. Countries with the lowest number of nephrologists

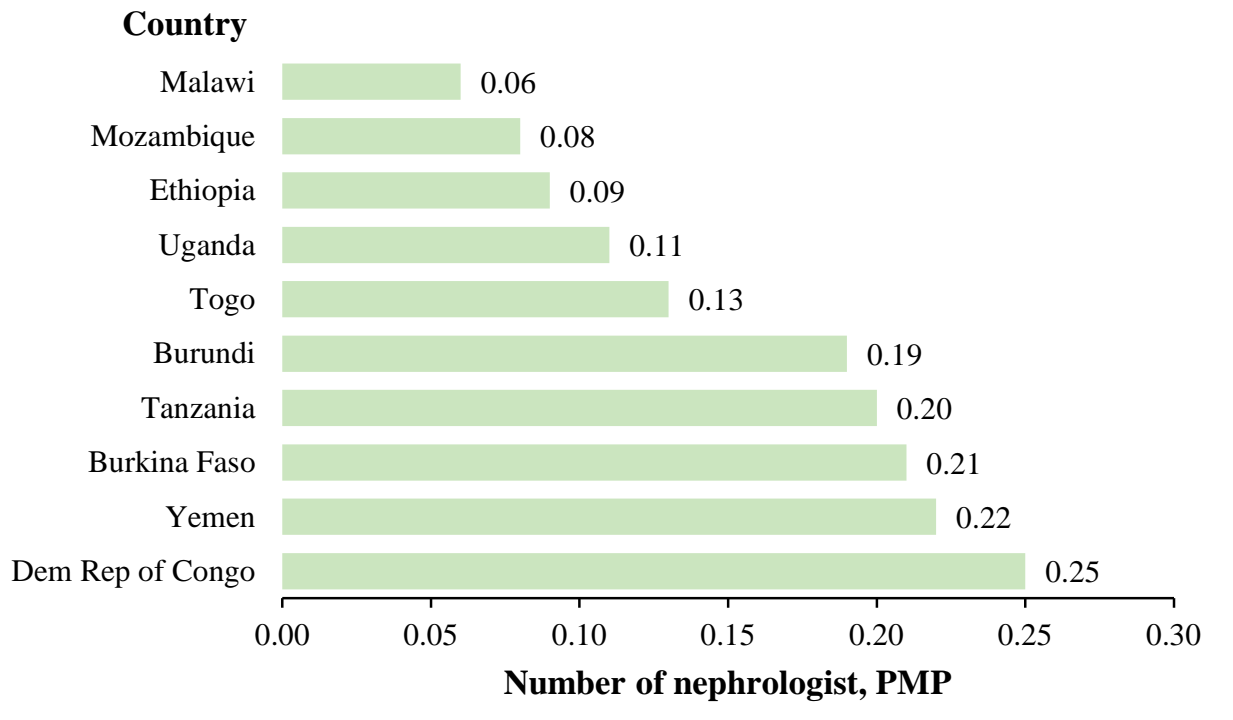

eFigure 1B. Countries with the highest number of nephrologists

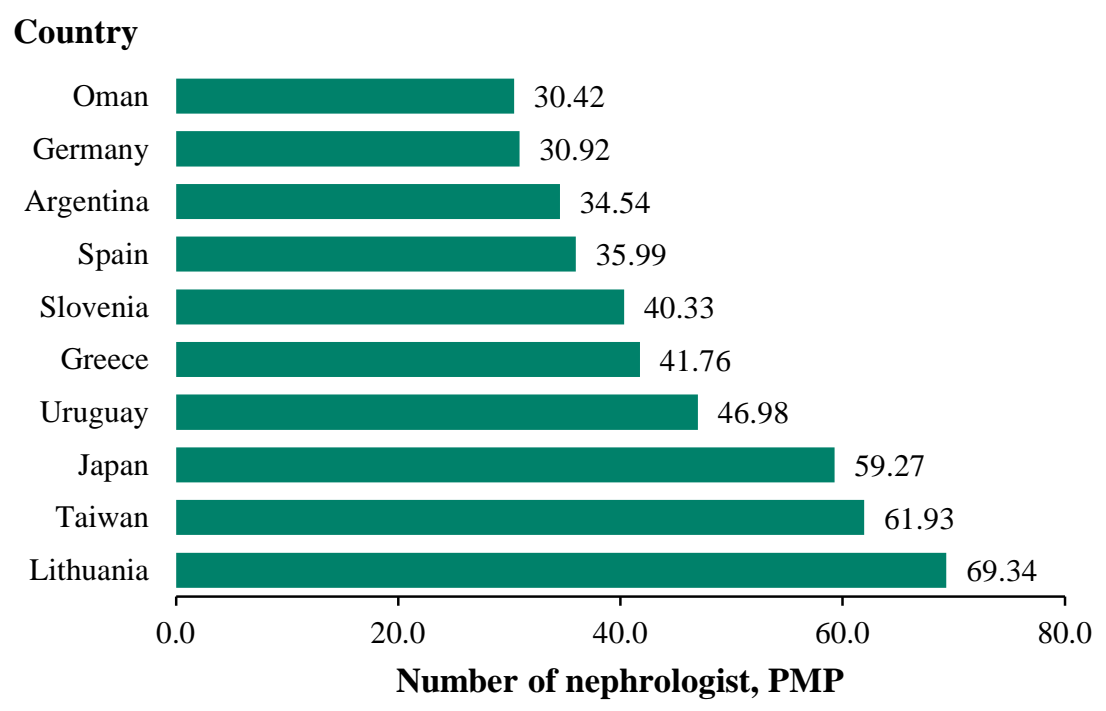


eFigure 1C. In your opinion, is there a shortage of any of the following care providers in your country? Overall "yes" response, \%

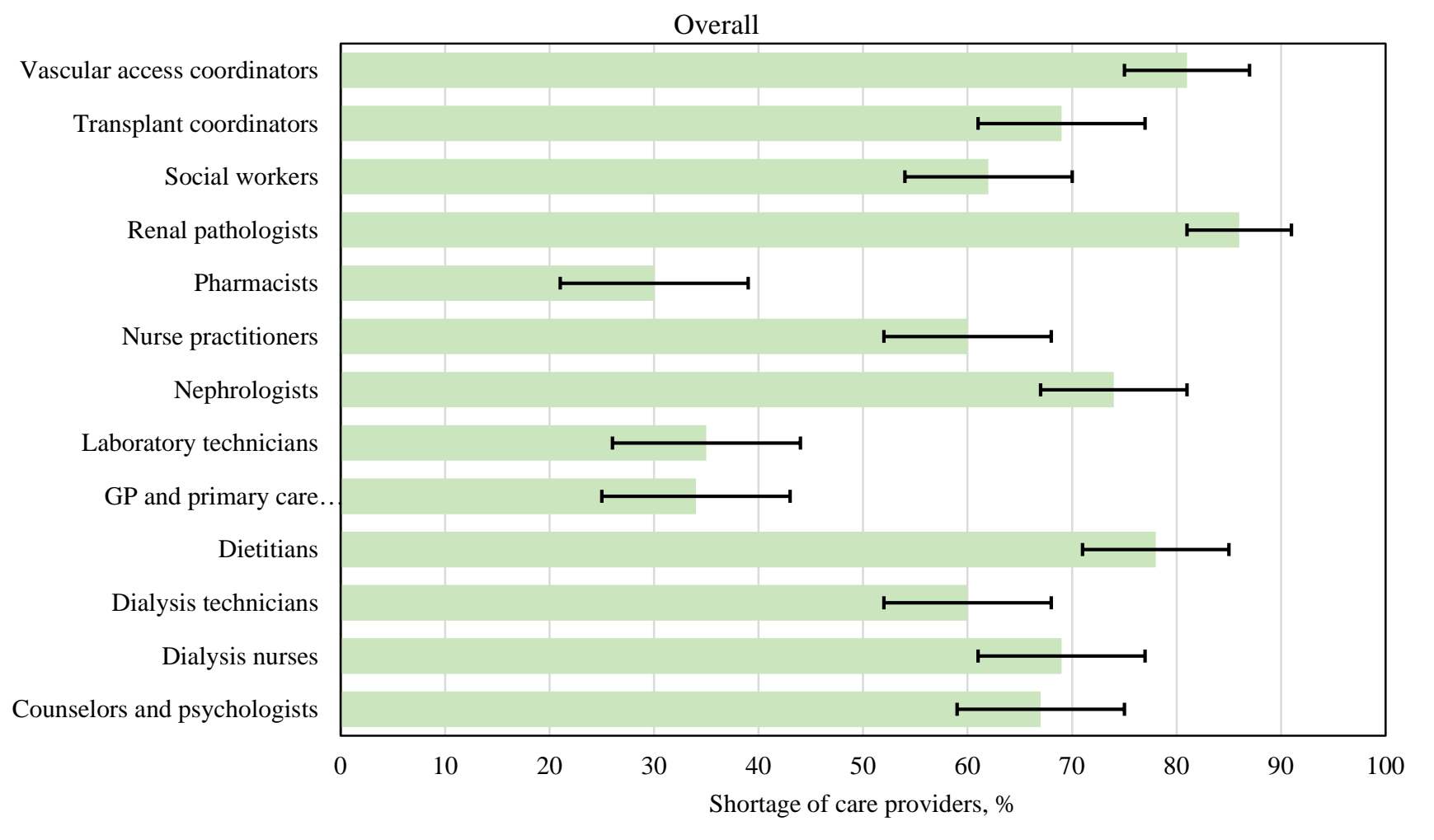

Total number of responding countries $=121$.

Abbreviations: GP - General practitioners; PMP - per 1 million population. 
eFigure 2. Availability of renal registries by region, $n / N(\%)$

CKD

Western Europe South Asia OSEA

North and East Asia

North America

NIS and Russia

Middle East

Latin America

Eastern and Central..

Africa

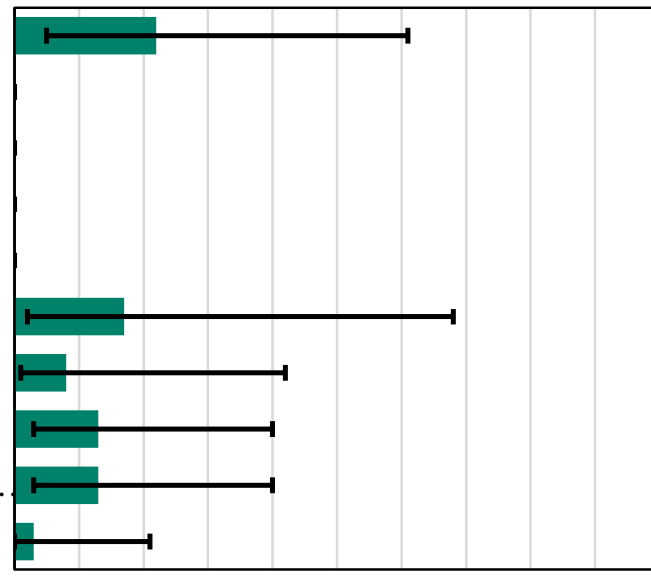

$2 / 9(22)$

$0 / 5(0)$

$0 / 13(0)$

$0 / 6(0)$

$0 / 2(0)$

$1 / 6(17)$

$1 / 13(8)$

$2 / 16(13)$

$2 / 16(13)$

$1 / 31(3)$

$\begin{array}{lllllllllll}0 & 10 & 20 & 30 & 40 & 50 & 60 & 70 & 80 & 90 & 100\end{array}$

Availability of renal registries, \%

Dialysis

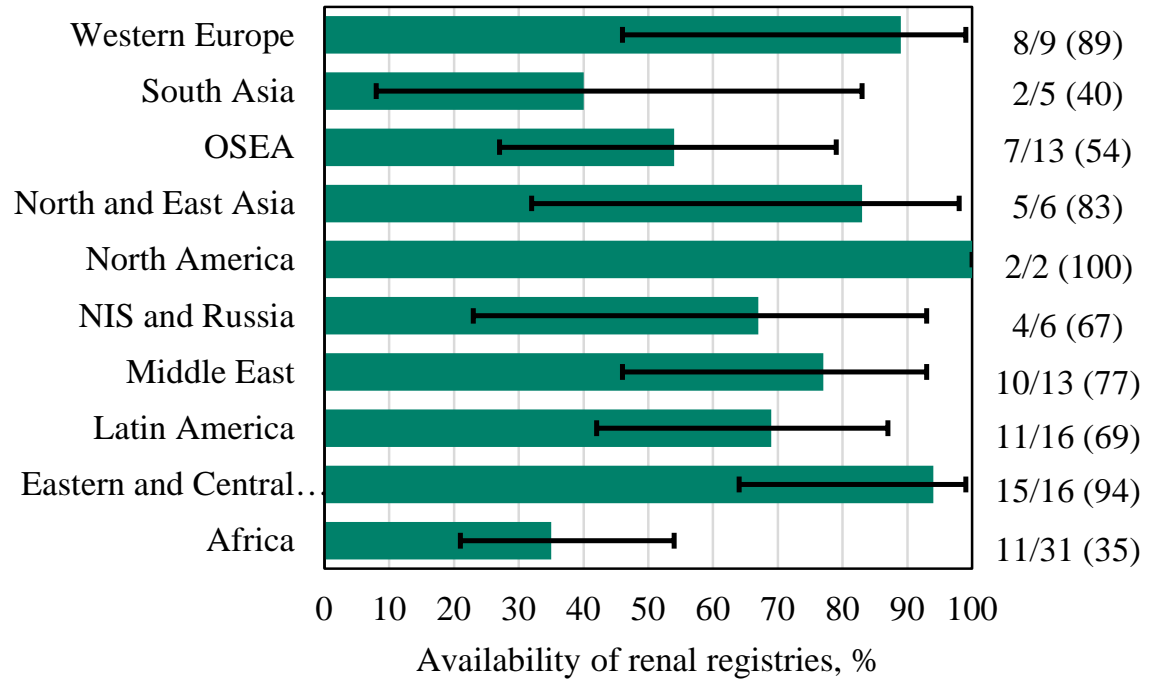




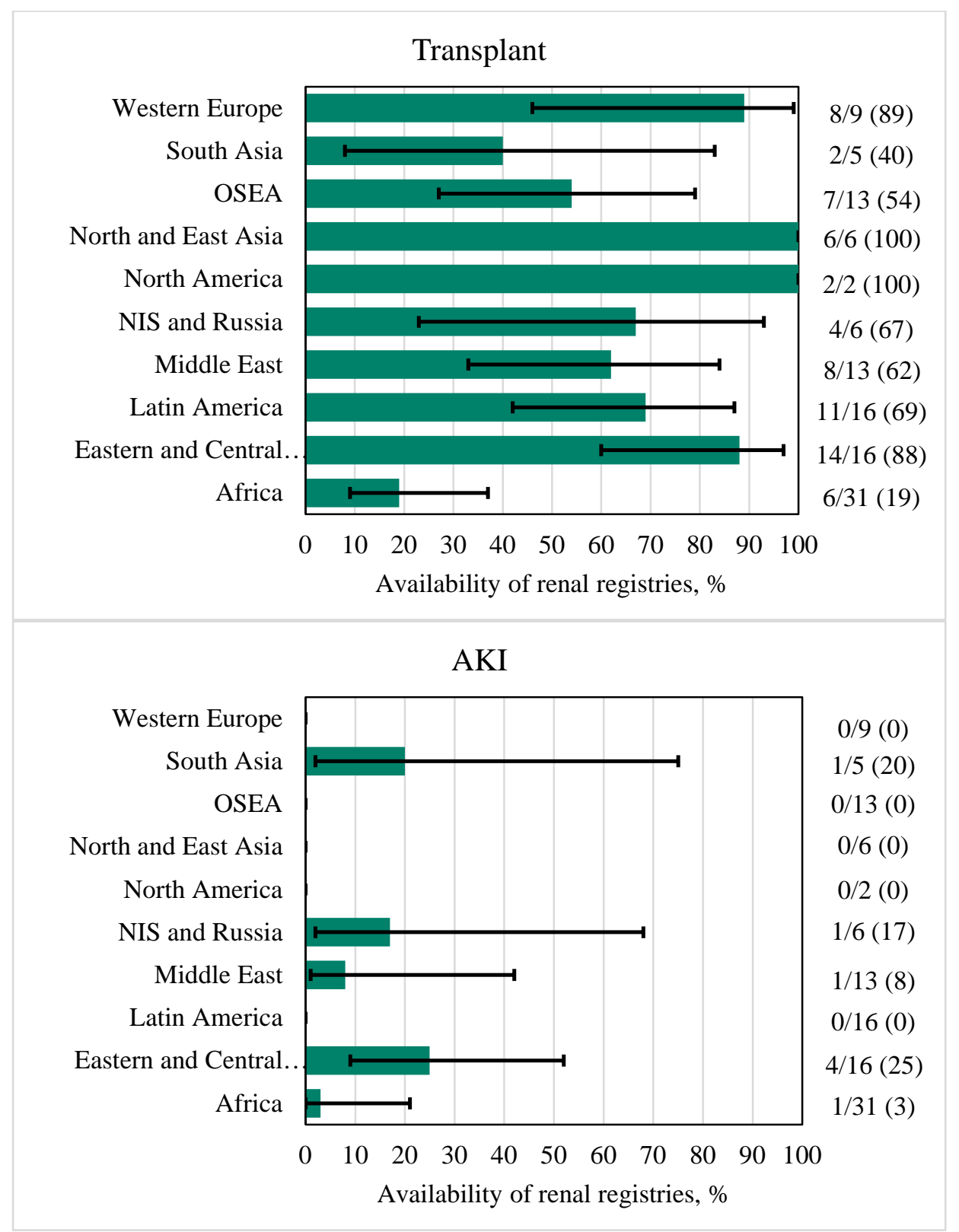

$\mathrm{n} / \mathrm{N}(\%): \mathrm{n}=$ Number of countries; $\mathrm{N}=$ Total countries in region

Abbreviations: NIS - Newly Independent States; OSEA - Oceania and South East Asia 
eFigure 3. Presence of advocacy group for kidney care, $\mathbf{n} / \mathbf{N}(\%)$

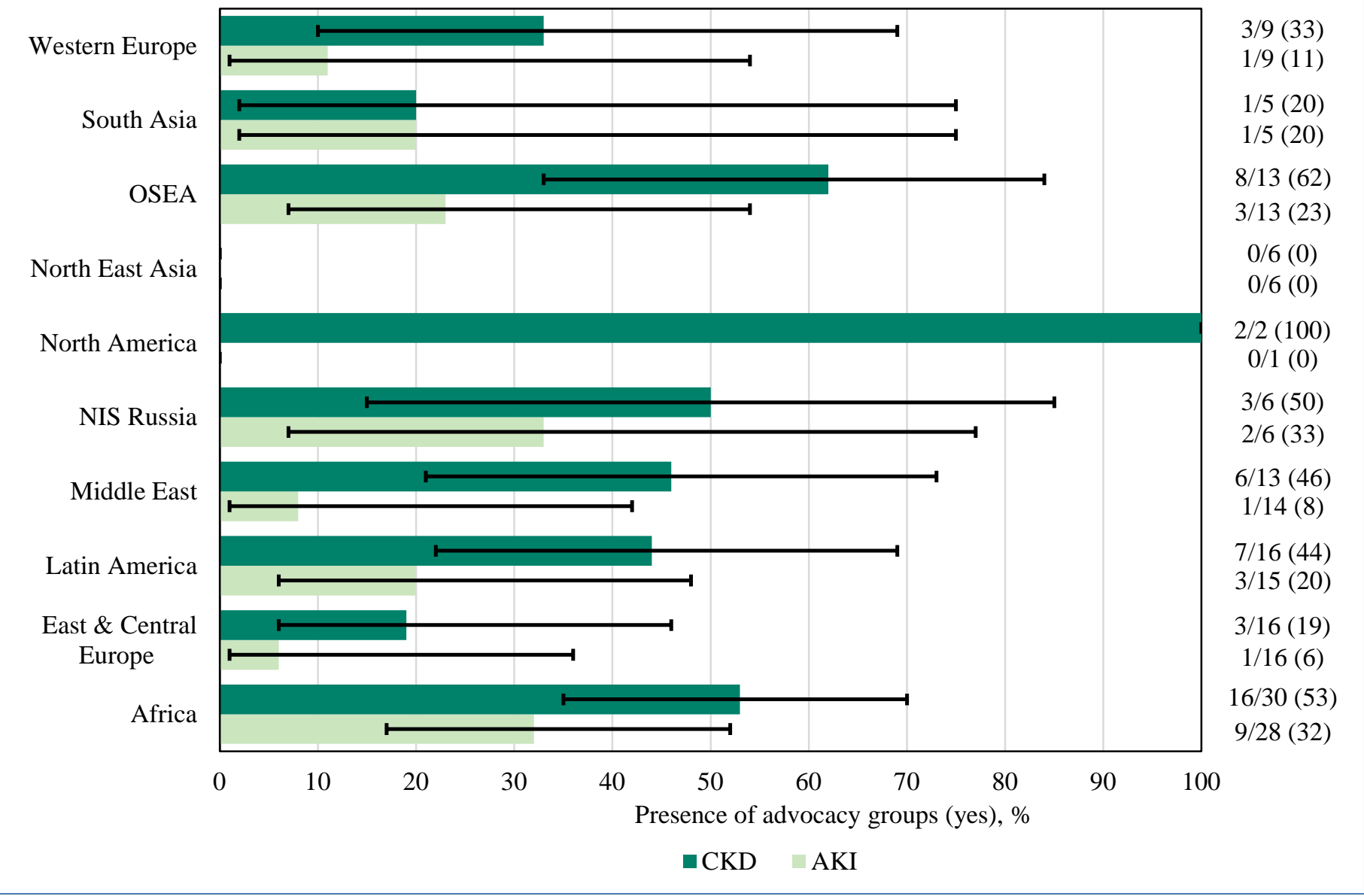

$\mathrm{n} / \mathrm{N}(\%): \mathrm{n}=$ Number of countries; $\mathrm{N}=$ Total countries in region

Abbreviations: AKI - acute kidney injury; CKD - chronic kidney disease; NIS - Newly Independent States; OSEA - Oceania and South East Asia 
eTable 1. Assessment of healthcare infrastructure available for providing kidney care (n, \%)

\begin{tabular}{|c|c|c|c|c|c|c|c|c|c|c|c|c|}
\hline & \multicolumn{6}{|c|}{ Infrastructure for AKI } & \multicolumn{6}{|c|}{ Infrastructure for CKD } \\
\hline & $\begin{array}{l}\text { No. of } \\
\text { responding } \\
\text { countries }\end{array}$ & $\begin{array}{l}\text { Extremely } \\
\text { poor }\end{array}$ & $\begin{array}{c}\text { Poor / } \\
\text { below } \\
\text { average }\end{array}$ & $\begin{array}{c}\text { Fair / } \\
\text { average }\end{array}$ & $\begin{array}{l}\text { Good / } \\
\text { above } \\
\text { average }\end{array}$ & Excellent & $\begin{array}{l}\text { No. of } \\
\text { responding } \\
\text { countries }\end{array}$ & $\begin{array}{l}\text { Extremely } \\
\text { poor }\end{array}$ & $\begin{array}{c}\text { Poor / } \\
\text { below } \\
\text { average }\end{array}$ & $\begin{array}{c}\text { Fair / } \\
\text { average }\end{array}$ & $\begin{array}{l}\text { Good / } \\
\text { above } \\
\text { average }\end{array}$ & Excellent \\
\hline Overall & 122 & $8(7)$ & $17(14)$ & $38(31)$ & $48(39)$ & $11(9)$ & 122 & $4(3)$ & $18(15)$ & $45(37)$ & $46(38)$ & $9(7)$ \\
\hline \multicolumn{13}{|l|}{ ISN regions: } \\
\hline - Africa & 34 & $6(18)$ & 11(32) & $9(26)$ & $8(24)$ & $0(0)$ & 34 & $4(12)$ & 11(32) & 13(38) & $6(18)$ & $0(0)$ \\
\hline - Middle East & 13 & $1(8)$ & $1(8)$ & $4(31)$ & $7(53)$ & $0(0)$ & 13 & $0(0)$ & $1(8)$ & $6(46)$ & $6(46)$ & $0(0)$ \\
\hline - North \& East Asia & 6 & $0(0)$ & $0(0)$ & $2(33)$ & $3(50)$ & $1(17)$ & 6 & $0(0)$ & $1(17)$ & $1(17)$ & $3(49)$ & $1(17)$ \\
\hline - South Asia & 5 & $0(0)$ & $0(0)$ & $3(60)$ & $2(40)$ & $0(0)$ & 5 & $0(0)$ & $1(20)$ & $2(40)$ & $2(40)$ & $0(0)$ \\
\hline - OSEA & 13 & $0(0)$ & $2(15)$ & $4(31)$ & $5(39)$ & $2(15)$ & 13 & $0(0)$ & $2(15)$ & $4(31)$ & $5(39)$ & $2(15)$ \\
\hline $\begin{array}{l}\text { - East \& Central } \\
\text { Europe }\end{array}$ & 17 & $0(0)$ & $0(0)$ & $6(35)$ & $9(53)$ & $2(12)$ & 17 & $0(0)$ & $1(6)$ & $7(41)$ & $7(41)$ & $2(12)$ \\
\hline - NIS \& Russia & 6 & $0(0)$ & $1(17)$ & $2(33)$ & $2(33)$ & $1(17)$ & 6 & $0(0)$ & $0(0)$ & $4(67)$ & $2(33)$ & $0(0)$ \\
\hline - Western Europe & 10 & $0(0)$ & $0(0)$ & $1(10)$ & $6(60)$ & $3(30)$ & 10 & $0(0)$ & $0(0)$ & $0(0)$ & $7(70)$ & $3(30)$ \\
\hline - North America & 2 & $0(0)$ & $0(0)$ & $0(0)$ & $0(0)$ & $2(100)$ & 2 & $0(0)$ & $0(0)$ & $1(50)$ & $0(0)$ & $1(50)$ \\
\hline \multicolumn{13}{|l|}{$\begin{array}{l}\text { World Bank } \\
\text { Groups: }\end{array}$} \\
\hline - Low income & 17 & $3(18)$ & $6(35)$ & $3(18)$ & $5(29)$ & $0(0)$ & 17 & $2(12)$ & $5(29)$ & $6(35)$ & $4(24)$ & $0(0)$ \\
\hline $\begin{array}{l}\text { - Lower-middle } \\
\text { income }\end{array}$ & 34 & $3(9)$ & $7(21)$ & $14(41)$ & $9(26)$ & $1(3)$ & 34 & $1(3)$ & $7(21)$ & $18(52)$ & $8(24)$ & $0(0)$ \\
\hline $\begin{array}{l}\text { - Upper-middle } \\
\text { income }\end{array}$ & 32 & $2(6)$ & $4(13)$ & $13(40)$ & $12(38)$ & $1(3)$ & 32 & $1(3)$ & $6(19)$ & $15(47)$ & $9(28)$ & $1(3)$ \\
\hline - High income & 39 & $0(0)$ & $0(0)$ & $8(21)$ & $22(56)$ & $9(23)$ & 39 & $0(0)$ & $0(0)$ & $6(15)$ & $25(64)$ & $8(21)$ \\
\hline
\end{tabular}

Ratings were based on a Likert scale: 1 (extremely poor), 2 (poor/below average), 3 (Fair/average), 4 (good/above average), and 5 (excellent).

Abbreviations: AKI=acute kidney injury; $C K D=$ chronic kidney disease; NIS - Newly Independent States; OSEA - Oceania and South East Asia

The proportion was calculated as the number of countries that choose the answer divided by the total number of responding countries. 
eTable 2. In your opinion, is there a shortage of any of the following providers in your country? (by region), $n$ (\%)

\begin{tabular}{|c|c|c|c|c|c|c|c|c|c|c|}
\hline & Africa & $\begin{array}{c}\text { Middle } \\
\text { East }\end{array}$ & $\begin{array}{c}\text { Latin } \\
\text { America }\end{array}$ & $\begin{array}{c}\text { North } \\
\text { East Asia }\end{array}$ & South Asia & $\begin{array}{l}\text { Oceania } \\
\text { and South } \\
\text { East Asia }\end{array}$ & $\begin{array}{l}\text { East \& } \\
\text { Central } \\
\text { Europe }\end{array}$ & $\begin{array}{l}\text { NIS \& } \\
\text { Russia }\end{array}$ & $\begin{array}{l}\text { Western } \\
\text { Europe }\end{array}$ & $\begin{array}{c}\text { North } \\
\text { America }\end{array}$ \\
\hline Total number of responding countries & 33 & 13 & 16 & 6 & 5 & 13 & 17 & 6 & 10 & 2 \\
\hline \multicolumn{11}{|c|}{ Countries with "yes" response by provider, n (\%) } \\
\hline Counselors and psychologists & $27(82)$ & $8(62)$ & $7(44)$ & $4(67)$ & $4(80)$ & $11(85)$ & $11(65)$ & $5(83)$ & $4(40)$ & $0(0)$ \\
\hline Dialysis nurses & $25(76)$ & $10(77)$ & $13(81)$ & $3(50)$ & $4(80)$ & $11(85)$ & $10(59)$ & $1(17)$ & $5(50)$ & $1(50)$ \\
\hline Dialysis technicians & $25(76)$ & $6(46)$ & $10(63)$ & $4(67)$ & $4(80)$ & $11(85)$ & $6(35)$ & $2(33)$ & $3(30)$ & $1(50)$ \\
\hline Dietitians & $30(91)$ & $10(77)$ & $9(56)$ & $5(83)$ & $4(80)$ & $12(92)$ & $13(76)$ & $6(100)$ & $5(50)$ & $0(0)$ \\
\hline GP and primary care physicians & $13(39)$ & $3(23)$ & $6(38)$ & $3(50)$ & $2(40)$ & $5(38)$ & $4(24)$ & $1(17)$ & $3(30)$ & $1(50)$ \\
\hline Laboratory technicians & $14(42)$ & $3(23)$ & $6(38)$ & $1(17)$ & $4(80)$ & $8(62)$ & $2(12)$ & $2(33)$ & $2(20)$ & $0(0)$ \\
\hline Nephrologists & $28(85)$ & $11(85)$ & $14(88)$ & $4(67)$ & $4(80)$ & $11(85)$ & $10(59)$ & $4(67)$ & $2(20)$ & $1(50)$ \\
\hline Nurse practitioners & $19(58)$ & $8(62)$ & $12(75)$ & $5(83)$ & $3(60)$ & $12(92)$ & $8(47)$ & $3(50)$ & $2(20)$ & $1(50)$ \\
\hline Pharmacists & $12(36)$ & $6(46)$ & $4(25)$ & $1(17)$ & $4(80)$ & $5(38)$ & $1(6)$ & $0(0)$ & $2(20)$ & $1(50)$ \\
\hline Social workers & $17(52)$ & $9(69)$ & $7(44)$ & $6(100)$ & $4(80)$ & $11(85)$ & $12(71)$ & $4(67)$ & $5(50)$ & $0(0)$ \\
\hline Transplant coordinators & $28(85)$ & $10(77)$ & $11(69)$ & $4(67)$ & $5(100)$ & $12(92)$ & $8(47)$ & $4(67)$ & $2(20)$ & $0(0)$ \\
\hline Vascular access coordinators & $29(88)$ & $9(69)$ & $15(94)$ & $6(100)$ & $4(80)$ & $12(92)$ & $14(82)$ & $4(67)$ & $5(50)$ & $0(0)$ \\
\hline
\end{tabular}

$\mathrm{n}=$ Number of countries

Abbreviations: GP=general practitioners; NIS= Newly Independent States 
eTable 3. Does your country have a national strategy for improving the care of CKD patients? (n, \%)

\begin{tabular}{|c|c|c|c|c|}
\hline$x^{2}$ & $\begin{array}{l}\text { No. of responding } \\
\text { countries }\end{array}$ & $\begin{array}{l}\text { Yes, a national CKD specific strategy } \\
\text { exists }\end{array}$ & $\begin{array}{c}\text { Yes, but the CKD strategy is incorporated into a NCD strategy that includes } \\
\text { other diseases }\end{array}$ & No \\
\hline Overall & 109 & $19(17)$ & $29(27)$ & $\begin{array}{c}61 \\
(56)\end{array}$ \\
\hline \multicolumn{5}{|l|}{ ISN regions: } \\
\hline - Middle East & 13 & $3(23)$ & $2(15)$ & $8(62)$ \\
\hline - Latin America & 16 & $5(31)$ & $5(31)$ & $6(38)$ \\
\hline - North \& East Asia & 6 & $1(17)$ & $3(50)$ & $2(33)$ \\
\hline - South Asia & 3 & $1(33)$ & $0(0)$ & $2(67)$ \\
\hline - OSEA & 12 & $4(33)$ & $3(25)$ & $5(42)$ \\
\hline $\begin{array}{l}\text { - East \& Central } \\
\text { Europe }\end{array}$ & 16 & $2(13)$ & $4(25)$ & $\begin{array}{c}10 \\
(62)\end{array}$ \\
\hline - NIS \& Russia & 6 & $0(0)$ & $2(33)$ & $4(67)$ \\
\hline - Western Europe & 9 & $2(22)$ & $2(22)$ & $5(56)$ \\
\hline - North America & 2 & $0(0)$ & $1(50)$ & $1(50)$ \\
\hline - Low income & 16 & $0(0)$ & $6(38)$ & $\begin{array}{c}10 \\
(62)\end{array}$ \\
\hline $\begin{array}{l}\text { - Lower-middle } \\
\text { income }\end{array}$ & 26 & $6(23)$ & $3(12)$ & $\begin{array}{l}17 \\
(65)\end{array}$ \\
\hline $\begin{array}{l}\text { - Upper-middle } \\
\text { income }\end{array}$ & 29 & $5(17)$ & $10(34)$ & $\begin{array}{c}14 \\
(49)\end{array}$ \\
\hline - High income & 38 & $8(21)$ & $10(26)$ & $\begin{array}{c}20 \\
(53)\end{array}$ \\
\hline
\end{tabular}

Abbreviations: CKD - chronic kidney disease; NCD - Non-communicable diseases; NIS - Newly Independent States; OSEA - Oceania and South East Asia.

The proportion was calculated as the number of countries that choose the answer divided by the total number of responding countries. 
eTable 4. Does your country have a national strategy for improving the identification of AKI? Response, (n, \%)

\begin{tabular}{|c|c|c|c|c|c|c|c|}
\hline 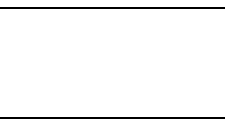 & $\begin{array}{l}\text { No. of } \\
\text { responding } \\
\text { countries }\end{array}$ & $\begin{array}{l}\text { National position } \\
\text { paper on AKI }\end{array}$ & $\begin{array}{l}\text { Tools available for } \\
\text { identification of AKI }\end{array}$ & $\begin{array}{l}\text { Incentives for } \\
\text { quality care }\end{array}$ & $\begin{array}{c}\text { Important regional/state level } \\
\text { strategy or strategies }\end{array}$ & $\begin{array}{l}\text { Increasing access to } \\
\text { acute dialysis facilities }\end{array}$ & $\begin{array}{l}\text { No strategies } \\
\text { exist for AKI }\end{array}$ \\
\hline Overall & 116 & $19(16)$ & $37(32)$ & $14(12)$ & $12(10)$ & $36(31)$ & $59(51)$ \\
\hline \multicolumn{8}{|l|}{ ISN regions: } \\
\hline - Africa & 30 & $3(10)$ & $8(27)$ & $1(3)$ & $2(7)$ & $7(23)$ & $18(60)$ \\
\hline - Middle East & 13 & $2(15)$ & $4(31)$ & $2(15)$ & $0(0)$ & $6(46)$ & $6(46)$ \\
\hline $\begin{array}{l}\text { - Latin } \\
\text { America }\end{array}$ & 16 & $4(25)$ & $3(19)$ & $0(0)$ & $1(6)$ & $4(25)$ & $10(63)$ \\
\hline $\begin{array}{l}\text { - North \& East } \\
\text { Asia }\end{array}$ & 6 & $3(50)$ & $2(33)$ & $2(33)$ & $0(0)$ & $1(17)$ & $2(33)$ \\
\hline - South Asia & 5 & $0(0)$ & $3(60)$ & $2(40)$ & $2(40)$ & $2(40)$ & $1(20)$ \\
\hline - OSEA & 13 & $2(15)$ & $6(46)$ & $1(8)$ & $3(23)$ & $8(62)$ & $4(31)$ \\
\hline $\begin{array}{l}\text { - East \& } \\
\text { Central } \\
\text { Europe }\end{array}$ & 16 & $1(6)$ & $5(31)$ & $4(25)$ & $2(13)$ & $5(31)$ & $9(56)$ \\
\hline $\begin{array}{l}\text { - NIS \& } \\
\text { Russia }\end{array}$ & 6 & $1(17)$ & $2(33)$ & $1(17)$ & $0(0)$ & $2(33)$ & $4(67)$ \\
\hline $\begin{array}{l}\text { - Western } \\
\text { Europe }\end{array}$ & 9 & $3(33)$ & $3(33)$ & $1(11)$ & $1(11)$ & $1(11)$ & $5(56)$ \\
\hline \multicolumn{8}{|c|}{ World Bank Groups: } \\
\hline - Low income & 17 & $0(0)$ & $5(29)$ & $1(6)$ & $2(12)$ & $2(12)$ & $11(65)$ \\
\hline $\begin{array}{l}\text { - Lower- } \\
\text { middle } \\
\text { income }\end{array}$ & 31 & $3(10)$ & $8(26)$ & $4(13)$ & $2(6)$ & $10(32)$ & $16(52)$ \\
\hline $\begin{array}{l}\text { - Upper- } \\
\text { middle } \\
\text { income }\end{array}$ & 30 & $7(23)$ & $11(37)$ & $3(10)$ & $4(13)$ & $15(50)$ & $15(50)$ \\
\hline - High income & 38 & $9(24)$ & $13(34)$ & $6(16)$ & $4(11)$ & $9(24)$ & $17(45)$ \\
\hline
\end{tabular}

Abbreviations: AKI - acute kidney injury; NIS - Newly Independent States; OSEA - Oceania and South East Asia

The proportion was calculated as the number of countries that choose the answer divided by the total number of responding countries. 
eTable 5. Access to clinical practice guidelines for kidney care (n, \%)

\begin{tabular}{|c|c|c|c|c|c|c|c|c|}
\hline & \multicolumn{4}{|c|}{ CKD management and referral guidelines } & \multicolumn{4}{|c|}{ AKI management and referral guidelines } \\
\hline & $\begin{array}{c}\text { No. of } \\
\text { responding } \\
\text { countries }\end{array}$ & $\begin{array}{c}\text { national } \\
\text { guidelines }\end{array}$ & $\begin{array}{l}\text { major regional } \\
\text { guidelines }\end{array}$ & $\begin{array}{c}\text { international } \\
\text { guidelines }\end{array}$ & $\begin{array}{l}\text { No. of responding } \\
\text { countries }\end{array}$ & $\begin{array}{c}\text { national } \\
\text { guidelines }\end{array}$ & $\begin{array}{l}\text { major regional } \\
\text { guidelines }\end{array}$ & $\begin{array}{c}\text { international } \\
\text { guidelines }\end{array}$ \\
\hline Overall & 116 & $31(27)$ & $1(1)$ & $60(52)$ & 116 & $8(7)$ & $1(1)$ & $52(45)$ \\
\hline \multicolumn{9}{|l|}{ ISN regions: } \\
\hline - Africa & 30 & $4(13)$ & $0(0)$ & $13(43)$ & 30 & $2(7)$ & $0(0)$ & $8(27)$ \\
\hline - Middle East & 13 & $1(8)$ & $1(8)$ & $8(62)$ & 13 & $0(0)$ & $0(0)$ & $5(38)$ \\
\hline - Latin America & 16 & $9(56)$ & $0(0)$ & $7(44)$ & 16 & $1(6)$ & $0(0)$ & $7(44)$ \\
\hline - South Asia & 5 & $0(0)$ & $0(0)$ & $3(60)$ & 5 & $0(0)$ & $0(0)$ & $1(20)$ \\
\hline - OSEA & 13 & $6(46)$ & $0(0)$ & $2(15)$ & 13 & $2(15)$ & $1(8)$ & $3(23)$ \\
\hline - East \& Central Europe & 16 & $2(13)$ & $0(0)$ & $13(81)$ & 16 & $0(0)$ & $0(0)$ & $15(94)$ \\
\hline - NIS \& Russia & 6 & $1(17)$ & $0(0)$ & $5(83)$ & 6 & $2(33)$ & $0(0)$ & $3(50)$ \\
\hline - Western Europe & 9 & $4(44)$ & $0(0)$ & $5(56)$ & 9 & $1(11)$ & $0(0)$ & $6(67)$ \\
\hline - North America & 2 & $1(50)$ & $0(0)$ & $1(50)$ & 2 & $0(0)$ & $0(0)$ & $2(100)$ \\
\hline - Low income & 17 & $1(6)$ & $0(0)$ & $6(35)$ & 17 & $0(0)$ & $0(0)$ & $3(18)$ \\
\hline - Lower-middle income & 31 & $7(23)$ & $0(0)$ & $16(52)$ & 31 & $5(16)$ & $0(0)$ & $11(35)$ \\
\hline - Upper-middle income & 30 & $9(30)$ & $0(0)$ & $16(53)$ & 30 & $1(3)$ & $1(3)$ & $14(47)$ \\
\hline - High income & 38 & $14(37)$ & $1(3)$ & $22(58)$ & 38 & $2(5)$ & $0(0)$ & $24(63)$ \\
\hline
\end{tabular}

The proportion was calculated as the number of countries that choose the answer divided by the total number of responding countries. 
eTable 6. Capacity and availability of regulatory framework for clinical research (n, \%)

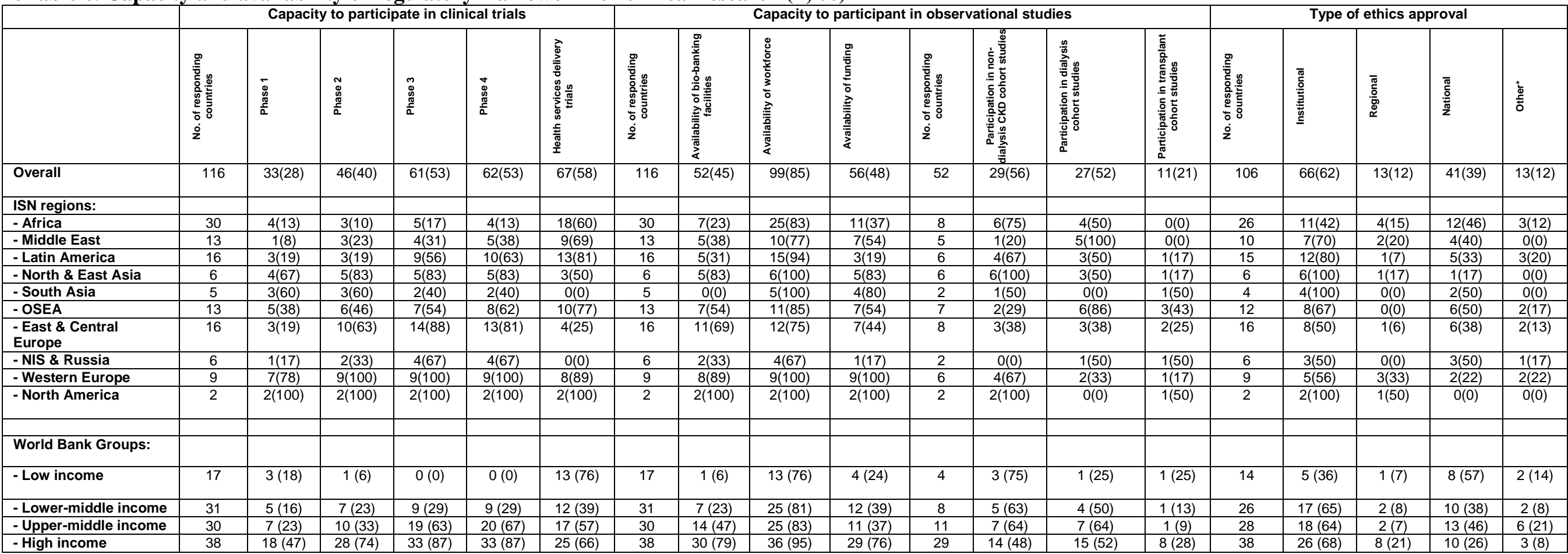

*Other forms of regulatory approval framework not in conformity with the stated ones.

Abbreviations: ISN - International Society of Nephrology; NIS - Newly Independent States; OSEA= Oceania and South East Asia

The proportion was calculated as the number of countries that choose the answer divided by the total number of responding countries.

(c) 2017 American Medical Association. All rights reserved. 


\section{Global Kidney Health Atlas (GKHA) Questionnaire}

Assessing Country and Regional Profile for Readiness, Capacity and Response to CKD and AKI

The International Society of Nephrology (ISN) plans to work collaboratively with existing organizations and initiatives at international and nationaal levels - to promote early detection and effective treatment of kidney diseases in order to improve patient health and quality of life. Through understanding and potentially helping to shape relevant health policies, practices and infrastructure, ISN aims to facilitate the implementation of equitable and ethical care for kidney patients in all regions and countries of the world.

ISN intends to conduct a research exercise on the current status of care for kidney patients across all countries of the world. This project will determine the global status of CKD and AKI care structures and organization towards achieving universal health care (UHC), and devise policy implications for including CKD and AKI in the global health agenda.

This questionnaire is designed to address the 6 core areas which inform aspects of universal health coverage: health finance, health workforce, essential medications and health products access, health information systems and statistics, national health policy, and service delivery and safety as well as the response of nephrology community and capacity for research and development. Using this framework, we will be able to develop an appropriate global perspective on the state of kidney health and disease.

If you have any questions about completing the questionnaire please contact: Sandrine Damster (email: SDamster@theisn.org).

Thank you for your involvement and readiness to participate.

Dr. Adeera Levin, MD, FRCPC, FACP

President, International Society of Nephrology 


\section{Global Kidney Health Atlas (GKHA) Questionnaire}

Questionnaire modules:

Standardized questions to allow comparisons of country capacities and readiness based on WHO six domains of UHC, and responses (based on awareness, identified barriers and capacity for research and development in nephrology community)

Assessing capacity and readiness on nations for kidney care based UHC domains

1. HF - Health Finance: Funding mechanism and availability

2. SDS - Service delivery and safety:

a. Structure and organization of care delivery for CKD

b. Structure and organization of care delivery for AKI

3. HW - Health workforce: Essential workforce for CKD and AKI care

4. EMHPA - Essential medications and Health products access: Availability, coverage and access

5. HISS - Health information systems and statistics: Databases, registries and surveillance systems

6. NHP - National health policy:

a. CKD policy, strategies and frameworks in the context of existing NCD programs

b. AKI policy, strategies and frameworks

Assessing response of nephrology community (awareness, identified barriers and capacity for research and development)
a. Awareness and education on CKD
b. Awareness and education on AKI
c. Identified barriers to CKD care
d. Identified barriers to AKI care
e. Capacity for research and development 


\section{Global Kidney Health Atlas (GKHA) Questionnaire}

Assessing Country and Regional Profile for Readiness, Capacity and Response to CKD and AKI

\section{CONTACT}

* Who is the focal person completing this survey?

First Name

Last Name

Current position

* Status? (please tick all that apply)

Nephrologist

Non-nephrologist (physician)

Other (please specify)
Non-nephrologist (non-physician)

Administrator/policy maker

* In which country do you reside?

* ISN region?

* Email contact person

Telephone (optional) contact person:

Fax (optional) contact person: 


\section{Global Kidney Health Atlas (GKHA) Questionnaire}

\section{A. Health Finance, Service delivery and Safety}

\section{A.1. Description of the healthcare system}

* A.1.1. In general, what best describes your healthcare system?

Publicly funded by government and free at the point of deliver $\sqrt{\square}$ Solely private and out-of-pocket

Publicly funded by government but with some fees at the point

Multiple systems -programs provided by government, nonof delivery governmental organizations (NGOs), and communities

A mix of publicly funded (whether or not publicly funded component is free at point of delivery) and private systems (please explain)

If a mix of publicly funded and private systems (please explain) or "Other" (please specify)

A.1.2. If your healthcare system is publicly funded, (in whole or in part) is this coverage universal (ie: are all residents of your country eligible to participate?)?

Yes, all residents are included in the coverage

Not applicable: there is no publicly funded health care in my country

No, not all residents are included (please specify details)

A.1.3. If your healthcare system is publicly funded (in whole or in part), which aspects of care are not included in the coverage? (please tick all that apply)

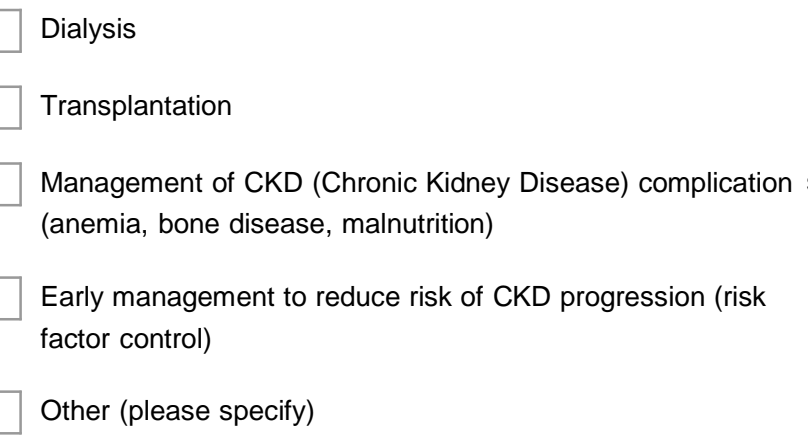


* A.1.4. What best describes your healthcare system's coverage for care of patients with kidney disease (excluding medications)?

Publicly funded for all patients with AKI

Publicly funded for all patients living on kidney transplant only

Publicly funded for all patients with CKD

Solely private and out-of-pocket for all AKI patients

Publicly funded for all patients on Renal Replacement Therapy Solely private and out-of-pocket for all CKD patients (RRT) only

Publicly funded for all patients on dialysis only

Other (please specify)

* A.1.5. We are interested in understanding within-country variation in kidneycare delivery as well as between-country variation. In your opinion, is there important variation in the way that kidney care is organized or delivered between different regions/states within your country?

Yes (if possible please

provide brief details)

No (please explain why) 


\section{Global Kidney Health Atlas (GKHA) Questionnaire}

\section{A.2 Service delivery and safety: Structure and organization of care delivery for CKD}

and $A K I$

* A.2.1. What system best describes the oversight/direction of kidney disease care in your country?

Managed/overseen by a national body

Managed/overseen by provincial/regional/state level

authorities only

Managed by individual Hospitals/Trusts/Organizations

Other (please specify)
Managed by non-governmental organizations (NGOs)

No organized system

* A.2.2. How would you rate the health infrastructure in your country, in terms of adequacy for providing CKD care on a scale of $1-5$ ( $1=$ extremely poor, $5=$ excellent)?

* A.2.3. Apart from health infrastructure, how would you rate the availability of other types of funding in your country, in terms of adequacy for providing CKD care?

* A.2.4. How would you rate the health infrastructure in your country, in terms of adequacy for providing AKI care on a scale of $1-5$ ( $1=$ extremely poor, $5=$ excellent)?

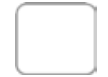

* A.2.5. Apart from health infrastructure, how would you rate the availability of other types of funding in your country, in terms of adequacy for providing AKI care? 


\section{Global Kidney Health Atlas (GKHA) Questionnaire}

\section{Data sources for Section A}

We would like you to consult as many colleagues or sources of data as needed to provide the answers that best describe nephrology care in your country.

* What is/are the sources for the data you provided above for Section A?

\section{provided for Section A?}




\section{Global Kidney Health Atlas (GKHA) Questionnaire}

\section{B. Health workforce for nephrology care}

\section{B1. Existing manpower capacity}

* B.1.1. Who bears primary responsibility for the delivery of CKD care in your country (please tick all that apply)?

Nephrologists

Primary care physicians

Nurse practitioners or specialized nurses

Other specialists? (please specify)
Multidisciplinary teams

Health officers/extension workers

* B.1.2. Who bears primary responsibility for the delivery of AKI care in your country (please tick all that apply)?

Nephrologists

Intensive care specialists

Primary care physicians

Other specialists? (please specify)
Nurse practitioners or specialized nurses

Health officers/extension workers

Technicians

* B.1.3. How many nephrologists are there in your country, and how many nephrology trainees?

Nephrologists

Nephrology trainees

* B.1.4. In your opinion, is there a shortage of any of the following providers in your country (please tick all that apply)?

Nephrologists

Dietitians

Social workers

Pharmacists
Vascular Access Coordinators

Nurse Practitioners

Counselors/Psychologists

Transplant Coordinators
Dialysis nurses

Dialysis technicians

General practitioners/primary care physicians

No shortage of any of the staff mentioned above 
Global Kidney Health Atlas (GKHA) Questionnaire

\section{B2. Training capacity}

* B.2.1. Is there a nephrology training program in your country?

Yes

No

* B.2.2. How long is the training in nephrology (years)?

* B.2.3. How is the training in nephrology structured?

Following general internal medicine

A mix of $1 \& 2$ depending on region and/or training centre

Solo training after basic qualification as medical doctor

Other (please specify) 


\section{Global Kidney Health Atlas (GKHA) Questionnaire}

\section{Data sources for Section B}

We would like you consult as many colleagues or sources of data as needed to provide the answers that best describe nephrology care in your country.

* What is/are the sources for the data you provided above for Section B?

* On a scale of $1-5$ ( 1 = very uncertain, $5=$ very certain) how certain are you of the answers you have provided for Section B? 
Global Kidney Health Atlas (GKHA) Questionnaire

C. Essential medications and health products access

\section{C1. Identification and Management of CKD}

* C.1.1. Indicate the availability of the following services for CKD monitoring and management at PRIMARY care level in your country; where: If generally available $=>50 \%$ of healthcare facilities; if generally not available $=<50 \%$ of healthcare facilities

Blood pressure

measurement

Height and weight

measures to calculate

body mass index

Serum glucose

measurement

$\mathrm{HbA} 1 \mathrm{C}$ test

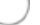

Serum cholesterol

measurement

Serum creatinine

measurement without

automated eGFR

reporting

Serum creatinine measurement with automated eGFR reporting

Urinalysis using test strips for albumin/protein (qualitative assays)

Urinalysis using test strips for

albumin/protein

(quantitative assays)

Urine albumin:

creatinine ratio (ACR)

or protein: creatinine

(PCR) measurements 
* C.1.2. Indicate the availability of the following services for CKD monitoring and management at SECONDARY OR TERTIARY care level in your country; where: Generally available $=>50 \%$ of healthcare facilities; if generally not available $=<50 \%$ of healthcare facilities

Available

Not Available

\section{Blood pressure}

measurement

Height and weight

measures to calculate
0
body mass index

Serum glucose

measurement

$\mathrm{HbA1C}$ test

Serum cholesterol

measurement

Serum creatinine

measurement without

automated eGFR

reporting

\section{Serum creatinine \\ measurement with \\ automated eGFR \\ reporting}

Renal biopsy

Urinalysis using test

strips for

albumin/protein

(qualitative assays)

Urinalysis using test

strips for

albumin/protein

(quantitative assays)

Urine albumin:

creatinine ratio (ACR)

or protein: creatinine

(PCR) measurements 


\section{Global Kidney Health Atlas (GKHA) Questionnaire}

\section{C2. Capacity for chronic RRT service provision}

* C.2.1 Is chronic hemodialysis available in your country?

Yes

No

C.2.1.1 If yes, how is chronic hemodialysis funded in your country?

Publicly funded by government and free at the point of delivery

Publicly funded by government but with some fees at the point of delivery

A mix of publicly funded (whether or not publicly funded component is free at point of delivery) and private systems (please explain)

Solely private and out-of-pocket

Multiple funding sources - government, non-governmental organizations (NGOs), and communities

If a mix of publicly funded and private systems (please explain) or "Other" (please specify)

* C.2.2 Is chronic peritoneal dialysis available in your country?

Publicly funded by government and free at the point of delivery

Publicly funded by government but with some fees at the point of delivery

A mix of publicly funded (whether or not publicly funded component is free at point of delivery) and private systems (please explain)
Solely private and out-of-pocket

Multiple funding sources - government, non-governmental organizations (NGOs), and communities

If a mix of publicly funded and private systems (please explain) or "Other" (please specify)

* C.2.3 Is kidney transplantation available in your country? 


\section{C.2.3.1 If yes, how is kidney transplantation funded in your country?}

Publicly funded by government and free at the point of delivery

Publicly funded by government but with some fees at the point of delivery

A mix of publicly funded (whether or not publicly funded component is free at point of delivery) and private systems (please explain)
Solely private and out-of-pocket

Multiple funding sources - government, non-governmental organizations (NGOs), and communities

If a mix of publicly funded and private systems (please explain) or "Other" (please specify) 


\section{Global Kidney Health Atlas (GKHA) Questionnaire}

\section{C3. Capacity for acute}

* C.3.1 Is acute hemodialysis available in your country?

\section{C.3.1.1 If yes, how is acute hemodialysis funded in your country?}

Publicly funded by government and free at the point of delivery

Publicly funded by government but with some fees at the point of delivery

A mix of publicly funded and private systems (please explain)

If a mix of publicly funded and private systems (please explain) or "Other" (please specify)

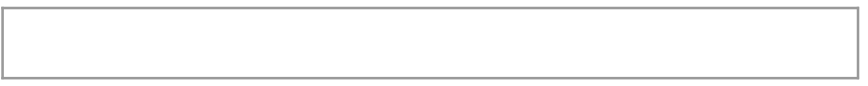

* C.3.2 Is acute peritoneal dialysis available in your country?

Solely private and out-of-pocket

Multiple funding sources - government, non-governmental organizations (NGOs), and communities

\section{C.3.2.1 If yes, how is acute peritoneal dialysis funded in your country?}

Publicly funded by government and free at the point of delivery

Publicly funded by government but with some fees at the point of delivery

A mix of publicly funded (whether or not publicly funded component is free at point of delivery) and private systems (please explain)
Solely private and out-of-pocket

Multiple funding sources - government, non-governmental organizations (NGOs), and communities

If a mix of publicly funded and private systems (please explain) or "Other" (please specify) 


\section{Global Kidney Health Atlas (GKHA) Questionnaire}

\section{C4. Access to Medications and reimbursement plans}

* C.4.1 For all CKD patients: How are medications funded?

Publicly funded by government and free at the point of delivery

Publicly funded by government but with some fees at the point of delivery

A mix of publicly funded (whether or not publicly funded component is free at point of delivery) and private systems (please explain)
Solely private and out-of-pocket

Multiple funding sources - government, non-governmental organizations (NGOs), and communities

If a mix of publicly funded and private systems (please explain) or "Other" (please specify)

* C.4.2 For all dialysis patients: How are medications funded?

Publicly funded by government and free at the point of delivery

Publicly funded by government but with some fees at the point of delivery

A mix of publicly funded and private systems (please explain)

If a mix of publicly funded and private systems (please explain) or "Other" (please specify)

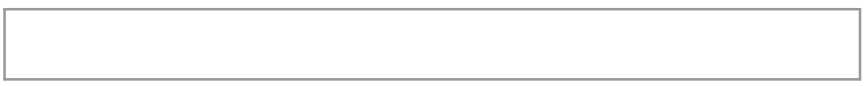

* C.4.3 For all transplant patients: How are medications funded?

Publicly funded by government and free at the point of delivery

Publicly funded by government but with some fees at the point of delivery

A mix of publicly funded and private systems (please explain)
Solely private and out-of-pocket

Multiple funding sources - government, non-governmental organizations (NGOs), and communities

If a mix of publicly funded and private systems (please explain) or "Other" (please specify) 


\section{Global Kidney Health Atlas (GKHA) Questionnaire}

\section{Data sources for Section C}

We would like you to consult as many colleagues or sources of data as needed to provide the answers that best describe nephrology care in your country.

* What is/are the sources for the data you provided above for Section C?

* On a scale of $1-5$ ( 1 = very uncertain, 5 = very certain) how certain are you of the answers you have provided for Section C? 


\section{Global Kidney Health Atlas (GKHA) Questionnaire}

\section{Health information systems \& statistics}

\section{D1. Availability of registry}

* D.1.1. Is there an 'official' registry in your country for?

$$
\text { Yes available No }
$$

CKD

Dialysis

Transplantation

AKI

D.1.1.1. If yes [CKD], how is the registry run?

Voluntary

Mandatory

I don't know/Information not available

D.1.1.2. If there is a CKD registry for patients who do not require RRT, what does this registry cover (please tick all that apply)?

The whole spectrum of CKD (Stages 1-5)

Advanced CKD only (Stages 4/5)

The whole country

Specific regions only (please name)

D.1.1.3. If yes [Dialysis], how is the registry run?

Voluntary

Mandatory

I don't know/Information not available

D.1.1.4. If yes [Transplantation], how is the registry run?

Voluntary

Mandatory

I don't know/Information not available 
D.1.1.5. If yes $[\mathrm{AKI}]$, how is the registry run?

Voluntary

Mandatory

I don't know/Information not available 
Global Kidney Health Atlas (GKHA) Questionnaire

D2. Burden of CKD (CKD incidence and prevalence)

* D.2.1. Are there data on the prevalence of CKD in your country?

Yes

No

D.2.1.1. If yes there are data on the prevalence of CKD in my country, please provide figures if known. Please enter NA for "not available" figures

All CKD (non-dialysis)

Stage 1

Stage 2

Stage 3

Stage 4

Stage 5 (Not on RRT)

On HD

On PD

With a kidney transplant

* D.2.2. Are there data on the incidence of CKD in your country?

Yes

No 
D.2.2.1. If yes there are data on the incidence of $C K D$ in my country, please provide figures if known. Please enter NA for "not available" figures

All CKD (non-dialysis)

Stage 1

Stage 2

Stage 3

Stage 4

Stage 5 (Not on RRT)

On HD

On PD

With a kidney transplant
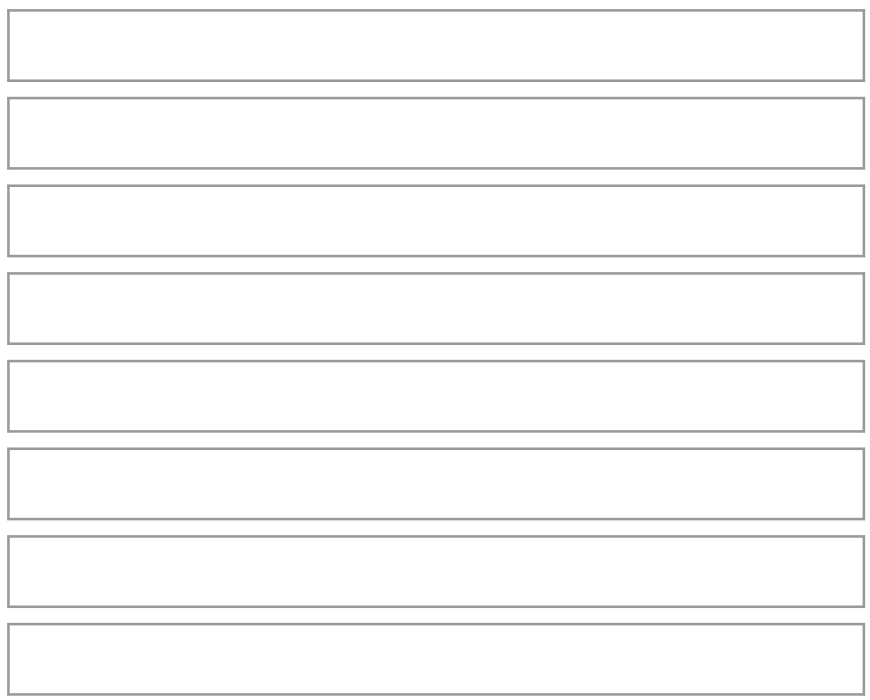


\section{Global Kidney Health Atlas (GKHA) Questionnaire}

\section{D3. Identification of CKD}

* D.3.1. For which of the following high-risk groups do practitioners in your country routinely offer testing for CKD?

Those with hypertension

Those with diabetes

Those with cardiovascular disease (Ischaemic heart disease, stroke, PVD, heart failure)

Those with autoimmune/multisystem diseases (SLE, Rheumatoid arthritis)

The elderly
Those with urological disorders (structural, stone diseases)

Chronic users of nephrotoxic medications

Members of high-risk ethnic groups (Aboriginal, Africans, Indo-asians)

Those with a family history of CKD

* D.3.2. In your country, are there ethnic groups considered to be at increased risk for CKD?

No

Yes (please specify)

* D.3.3. In your country, is there an active CKD detection program based on national policy and/or guidelines?

Yes

No

C.3.3.1. If yes, how is this program implemented (please tick all that apply)?

Reactive approach - cases managed as identified through practice
Active screening of population at-risk through specific screening processes

\section{Active screening of population at-risk through routine health} encounters

Other (please specify) 


\section{Global Kidney Health Atlas (GKHA) Questionnaire}

\section{D4. Burden of AKI (incidence and prevalence)}

* D.4.1. Does your country have the ability to determine the prevalence of AKI not requiring dialysis?

Yes

Don't know/info not available

No

* D.4.2. Does your country have the ability to determine the incidence of AKI not requiring dialysis?

Yes

Don't know/info not available

No

* D.4.3. Does your country have the ability to determine the prevalence of AKI requiring dialysis?

Yes

Don't know/info not available

No

* D.4.4. Does your country have the ability to determine the incidence of AKI not requiring dialysis?

Yes

Don't know/info not available

No 


\section{Global Kidney Health Atlas (GKHA) Questionnaire}

\section{D5. Identification of AKI}

* D.5.1. In your country, are there specific groups considered to be at increased risk for AKI?

$$
\text { No }
$$

Yes (please specify)

* D.5.2. In your country, is there an active AKI detection program based on national policy and/or guidelines?

D.5.2.1. If yes, how is this program implemented (please tick all that apply)?

Reactive approach- cases managed as identified through practice

Active screening of population at-risk through routine health encounters

Other (please specify)
Active screening of population at-risk through specific screening processes 


\section{Global Kidney Health Atlas (GKHA) Questionnaire}

\section{Data sources for Section D}

We would like you to consult as many colleagues or sources of data as needed to provide the answers that best describe nephrology care in your country.

* What is/are the sources for the data you provided above for Section D?

* On a scale of $1-5$ ( 1 = very uncertain, $5=$ very certain) how certain are you of the answers you have provided for Section D? 
Global Kidney Health Atlas (GKHA) Questionnaire

\section{E. National Health Policy}

\section{E1. CKD advocacy}

* E.1.1. In your opinion, is CKD recognized as a health priority by the government in your country? Yes (please provide details)

No (please explain why)

* E.1.2. Is there an advocacy group at the higher levels of government (ie: a Parliamentary committee) or an NGO to raise the profile of CKD and its prevention?
Yes (please provide details)
No (please explain why) 
Global Kidney Health Atlas (GKHA) Questionnaire

\section{E2. AKI advocacy}

* E.2.1. Is there an advocacy group at the higher levels of government (ie: a Parliamentary committee) or an NGO to raise the profile of $\mathrm{AKI}$ and its prevention?

Yes (please provide

details)

No (please explain why) 


\section{Global Kidney Health Atlas (GKHA) Questionnaire}

\section{E3. CKD \& Noncommunicable chronic (NCD) disease policy and strategy}

* E.3.1. Does your country have a national noncommunicable chronic disease strategy?

Yes (please provide

details)

Yes, under development

(please provide details)

No (not detail needed)

* E.3.2. Does your country have a national strategy for improving the care of CKD patients?

Non-dialysis dependent CKD Kidney transplantation Chronic dialysis

Yes, a national CKD-

specific strategy exists

for the following

populations (please tick

all that apply):

Yes, but the CKD

strategy is incorporated into a NCD strategy that includes other diseases.

The CKD strategy

applies to the following

populations (please tick

all that apply):

No

* E.3.3. If your country does not have a national strategy for improving the care of CKD patients, are there other initiatives that identify CKD as a health care priority in your country (please tick all that apply)?

National position paper on CKD care

Provider incentives for identifying CKD
Incentives for providing quality care to CKD patients Important regional/state level strategy or strategies (please provide details)

If Important regional/state level strategy or strategies or Other (please specify) 


\section{Global Kidney Health Atlas (GKHA) Questionnaire}

\section{E4. CKD specific policies, guidelines and/or service frameworks}

* E.4.1. Are there available CKD management \& referral guidelines in your country?

Yes, national guidelines

Yes, major regional guidelines
Yes, uses or adopt the existing international guidelines (eg KDIGO)

No

E.4.1.1. If yes, what do these management \& referral guidelines cover (please tick all that apply)?

Identification of CKD Progression

Timing and Urgency for Nephrology Referral

Multidisciplinary Care Approach
Risk factor management

Management of Complications (Cardiovascular Disease, Hematologic and Bone disorders, Malnutrition)

E.4.1.2. If ticked "yes" above: On a scale of 1 to 5 , please rate the awareness of the CKD guideline among non-nephrologists in your country ( $1=$ very low, $5=$ very high)

E.4.1.3. If ticked "yes" above: On a scale of 1 to 5 , please rate the adoption (application in clinical practice) of the CKD guideline among non-nephrologists in your country ( $1=$ very low, $5=$ very high)

E.4.1.4. If ticked "yes" above: On a scale of 1 to 5 , please rate the awareness of the CKD guideline among nephrologists in your country ( $1=$ very low, $5=$ very high)

E.4.1.5. If ticked "yes" above: On a scale of 1 to 5 , please rate the adoption (application in clinical practice) of the CKD guideline among nephrologists in your country (1=very low, $5=$ =very high) 


\section{Global Kidney Health Atlas (GKHA) Questionnaire}

\section{E5. AKI specific policy and strategy}

* E.5.1. Does your country have a national strategy for improving the identification of AKI, are there other initiatives that identify $\mathrm{AKI}$ as an important health care priority in your country (please tick all that apply)?

National position paper on AKI identification and care Important regional/state level strategy or strategies (please provide details)

Tools available for identification of AKI

Increasing access to acute dialysis facilities

Incentives for providing quality care to AKI patients

No strategies exist for AKI

If Important regional/state level strategy or strategies or Other (please specify)

* Additional details on important regional/state level strategy or strategies important regional/state level strategy or strategies (5 lines): 


\section{Global Kidney Health Atlas (GKHA) Questionnaire}

\section{E6. AKI specific policies, guidelines and/or service frameworks}

* E.6.1. Are there AKI management \& referral guidelines in your country?

Yes, national guidelines

Yes, major regional guidelines
Yes, uses or adopt the existing international guidelines (eg KDIGO)

No

E.6.1.1. If yes, what do these management \& referral guidelines cover (please tick all that apply)?

Identification of $\mathrm{AKI}$ in outpatient settings

Identification of $\mathrm{AKI}$ in in-patient settings

Timing and Urgency for Nephrology Referral
Access to dialysis treatment(s)

Protocols for mitigating risk of AKI in specific situations?

E.6.1.2. If ticked "yes" above: On a scale of 1 to 5 , please rate the awareness of the AKI management guideline among non-nephrologists in your country (1=very low, $5=$ very high)

E.6.1.3. If ticked "yes" above: On a scale of 1 to 5, please rate the ADOPTION (application in clinical practice) of the AKI management guideline among non-nephrologists in your country (1=very low, $5=$ very high)

E.6.1.4. If ticked "yes" above: On a scale of 1 to 5 , please rate the awareness of the AKI management guideline among nephrologists in your country ( $1=$ very low, $5=$ very high)

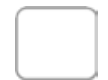

E.6.1.5. If ticked "yes" above: On a scale of 1 to 5, please rate the ADOPTION (application in clinical practice) of the AKI management guideline among nephrologists in your country (1=very low, $5=$ very high) 


\section{Global Kidney Health Atlas (GKHA) Questionnaire}

\section{Data sources for Section E}

We would like you to consult as many colleagues or sources of data as needed to provide the answers that best describe nephrology care in your country.

* What is/are the sources for the data you provided above for Section E?

* On a scale of $1-5$ ( 1 = very uncertain, 5 = very certain $)$ how certain are you of the answers you have provided for Section E? 
Global Kidney Health Atlas (GKHA) Questionnaire

Assessing response of nephrology community: awareness, identified barriers and capacity for research

- Awareness and education about CKD

- Awareness and education about AKI

'Identified barriers to kidney disease care

${ }^{\circ}$ Capacity for research and development 
Global Kidney Health Atlas (GKHA) Questionnaire

\section{Awareness and education about CKD}

* 1.1. On a scale of 1-5 (1=poor, $5=$ excellent). Please rate the typical level of CKD awareness among non-nephrologist specialists.

* 1.2. On a scale of 1-5 (1=poor, $5=$ excellent). Please rate the typical level of CKD awareness among primary care physicians (GPs) 
Global Kidney Health Atlas (GKHA) Questionnaire

\section{Awareness and education about AKI}

* 2.1. On a scale of 1-5 ( $1=$ poor, $5=$ excellent). Please rate the typical level of $A K I$ awareness among nonnephrologist specialists.

* 2.2. On a scale of $1-5$ ( $1=$ poor, $5=$ excellent). Please rate the typical level of $A K I$ awareness among primary care physicians (GPs) 


\section{Global Kidney Health Atlas (GKHA) Questionnaire}

\section{Barriers to optimal kidney disease care}

* 3.1. Barriers to optimal kidney disease care: Are there specific barriers to optimal kidney disease care in your country (please tick all that apply)?

Geography (distance from care or prolonged travel time)

Physician (availability, access, knowledge, attitude)

Patient (knowledge, attitude)
Number of nephrologists per capita

Healthcare system (availability, access, capability)

Other

* 3.2 Barriers to optimal RRT provision: Are there specific barriers to optimal RRT care in your country (please tick all that apply)?

Geography (distance from care or prolonged travel time)

Physician (availability, access, knowledge, attitude)

Patient (knowledge, attitude)
Number of nephrologists per capita

Healthcare system (availability, access, capability) 


\section{Global Kidney Health Atlas (GKHA) Questionnaire}

\section{Capacity for research and development}

* 4.1. Is there a national agency responsible for funding clinical trials in your country?

Yes

No

* 4.2. Does your country participate in clinical trials in kidney disease? (Tick all that apply)

Phase 1

Phase 4

Phase 2

Health service delivery trials

Phase 3

* 4.3. Does your country have formal training for physicians in clinical trial conduct?

Yes

Don't know/info not available

No

4.3.1. If yes, is it mandatory?

Yes

Don't know/info not available

No

* 4.4. Does your country have formal training for non-physicians/ research assistants and associates in clinical trial conduct?

Yes

Don't know/info not available

No

4.4.1. If yes, is it mandatory?

Yes

Don't know/info not available

No

* 4.5. Does your country have biobanking facilities?

Yes

Don't know/info not available

No

* 4.6. Does your country have the capacity (trained workforce) to conduct observational cohort studies?

Yes

Don't know/info not available

No 
* 4.7. Does your country usually have resources (funding) to conduct observational cohort studies?

Don't know/info not available

Ye

s

No

* 4.8. Is your country involved in any observational cohort studies in CKD?

Don't know/info not available

Ye

$s$

No

4.8.1. If yes, where?

In non dialysis CKD populations

In transplant populations

In dialysis populations

* 4.9. Is Ethical approval in your country mandatory for observational cohort studies in CKD?

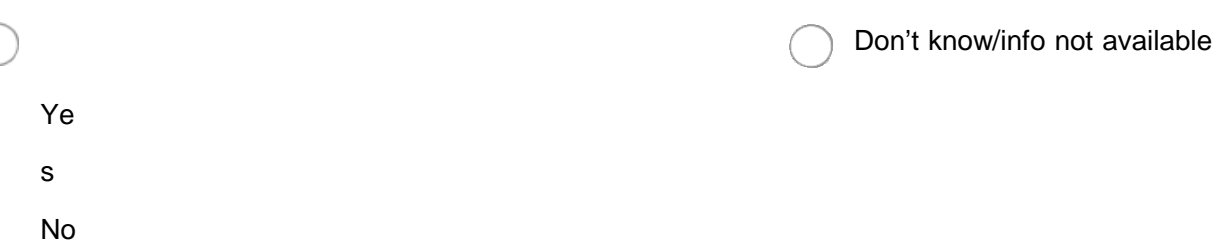

* 4.9.1. If yes, is the Ethical approval

National

Institutional

Regional

* 4.10. Which regulatory agencies oversee clinical trials in your country? Please list if known

* 4.11. Are there challenges in getting timely regulatory approvals in your country?

Often

Sometimes
Occasionally

No 
4.11.1. If yes, please list any common issues you are aware of

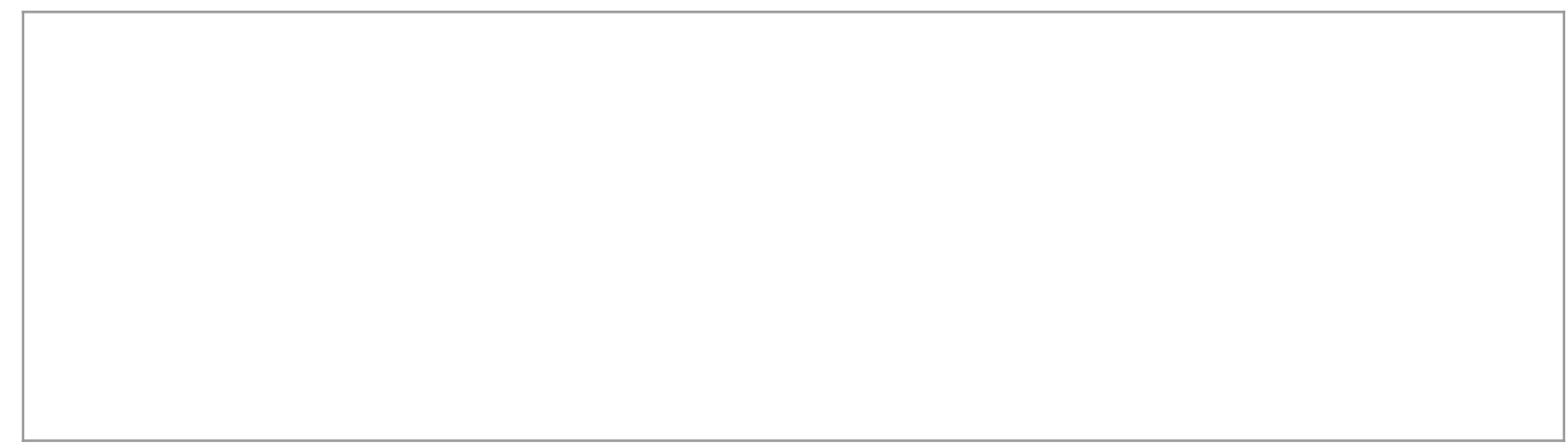

* 4.12. Are there academic centres that co-ordinate and monitor sites involved in renal clinical trials in your country?

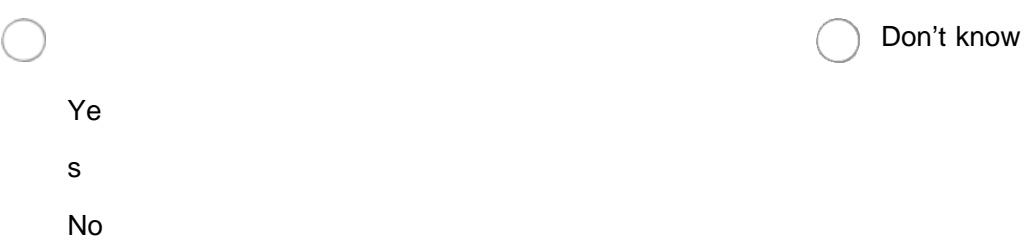

4.12.1. If so, please list any you are aware of, and if possible provide website links and/or contact details

* 4.13. In what proportion of sites in your country is there capacity for storing clinical trial medications?

All

Most

Some
Few

None

Unknown 
Definition of Terms

Action plan: A scheme of course of action, which may correspond to a policy or strategy, with defined activities indicating who does what (type of activities and people responsible for implementation), when (time frame), how and with what resources to accomplish an objective AKI or CKD care.

Appropriate referral and management: Availability of an organized system and/or structures to ensure that people with CKD who may benefit from specialist care are referred for specialist assessment appropriately.

Capacity: The ability to perform appropriate tasks effectively, efficiently and sustainably.

Guidelines: A recommended evidence-based course of action for prevention and/or management of AKI or CKD.

Identification and early detection: Availability of an organized system and/or structures for identification of people with risk factors for CKD (hypertension, diabetes, cardiovascular diseases [ischemic heart disease, heart failure, peripheral vascular disease and stroke], urological problems [structural renal tract disease, kidney stones, prostatic disorders], multisystem diseases (systemic lupus erythematosus, rheumatoid arthritis, infective endocarditis,etc) family history of kidney disease.

Identification: Measures preformed in at-risk population in order to identify individuals who have risk factor or early stages of disease, but do not yet have symptoms.

Monitoring of complications, risk factor control and disease progression Availability of an organized system and/or structures to ensure that people with established CKD are:

NGO: Nongovernmental organization

Noncommunicable diseases (NCDs): Cardiovascular diseases (like heart attacks and stroke), cancers, chronic respiratory diseases (such as chronic obstructed pulmonary disease and asthma) and diabetes.

Policy: A specific official decision or set of decisions designed to carry out a course of action endorsed by a government body, including a set of goals, priorities and main directions for attaining these goals. The policy document may include a strategy to give effect to the policy.

Programs: A planned set of activities or procedures directed at a specific purpose.

Registry: A systematic collection of data about CKD or AKI.

RRT availability: Availability of an organized system and/or structures deliver dialysis and/or kidney transplant when and where needed: 
Standard care plan: Availability of an organized system and/or structures to ensure that people with CKD have a current agreed care plan appropriate to the stage and rate of progression of CKD. This means those with early stages are being monitored appropriately at the primary care level and those in need of specialist care have access to it.

Strategy: a long term plan designed to achieve a particular goal for AKI or CKD care.

Under development: Something which is still being developed or finalized and is not yet being implemented in the country. 
Global Kidney Health Atlas (GKHA) Questionnaire

THANK YOU

Thank you very much for taking the time to respond to this survey!

Your active participation in helping ISN develop an appropriate global perspective on the state of kidney health and disease is greatly appreciated.

The Global Kidney Disease Atlas (GKHA) Questionnaire team 


\section{eAppendix 2. Access to RRT, medication funding and workforce capacity}

Green and red boxes indicate that the survey participants answered Yes and No, respectively. Grey boxes indicate no data were provided.

Universal coverage for RRT refers to publicly funded by the government and free at the point of delivery.

Availability of PD (peritoneal dialysis) and Tx (transplantation) refers to the availability of chronic peritoneal dialysis and transplantation.

Adequacy of workforce component: is No if the respondent reported a national shortage of health care providers of the specified type, and Yes otherwise.

Funding for CKD medications component refers to medication funding for non-dialysis dependent chronic kidney disease.

Abbreviations: $\mathrm{CKD}=$ chronic kidney disease, $\mathrm{RRT}=$ renal replacement therapy, NIS \& Russia $=$ Newly Independent States and

Russia.

Pub Free = publicly funded by government and free at the point of delivery, Pub $\$=$ publicly funded by government but with some fees at the point of delivery, Mix PP = a mix of publicly funded (whether or not publicly funded component is free at point of delivery) and private systems, Priv OOP = solely private and out-of-pocket, Priv $\mathrm{HI}=$ solely private through health insurance providers, Multi Sys $=$ multiple systems - programs provided by government, nongovernmental organizations, and communities.

\begin{tabular}{|l|l|l|l|l|l|}
\hline & & & & & \\
\hline Pub Free & Pub \$ & Mix PP & Priv OOP & Priv HI & Multi Sys \\
\hline
\end{tabular}

\begin{tabular}{|c|c|c|c|c|c|c|c|c|c|c|c|c|c|c|c|c|c|c|}
\hline \multirow[b]{2}{*}{ 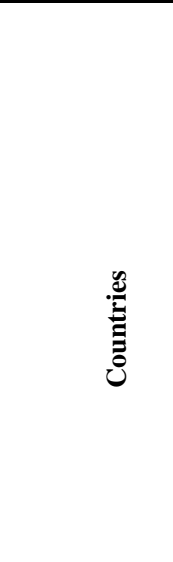 } & \multicolumn{5}{|c|}{ Universal coverage for RRT } & \multicolumn{2}{|c|}{\begin{tabular}{|c|} 
Availability \\
of PD and \\
Tx
\end{tabular}} & \multicolumn{10}{|c|}{ Adequacy of workforce component } & \multirow{2}{*}{ 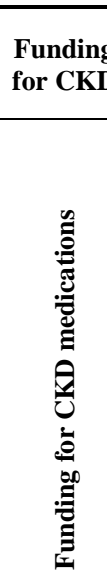 } \\
\hline & 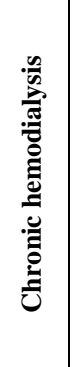 & 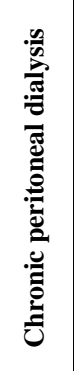 & 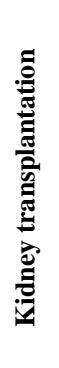 & 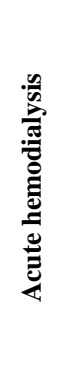 & 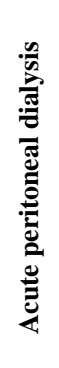 & 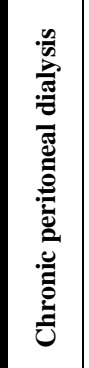 & 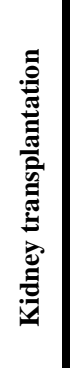 & 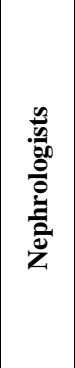 & 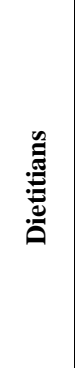 & 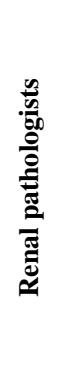 & 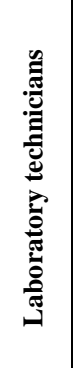 & 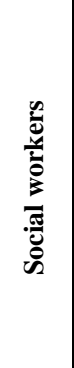 & 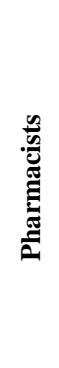 & 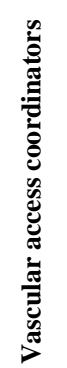 & 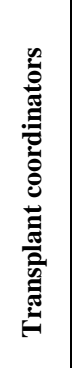 & 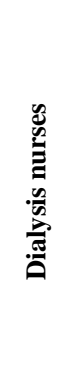 & 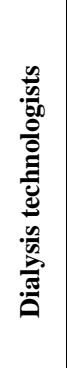 & \\
\hline \multicolumn{19}{|l|}{ Africa } \\
\hline \multicolumn{19}{|l|}{ Algeria } \\
\hline \multicolumn{19}{|l|}{ Benin } \\
\hline \multicolumn{19}{|l|}{ Botswana } \\
\hline \multicolumn{19}{|l|}{ Burkina Faso } \\
\hline \multicolumn{19}{|l|}{ Burundi } \\
\hline \multicolumn{19}{|l|}{ Cameroon } \\
\hline \multicolumn{19}{|l|}{ Cape Verde } \\
\hline \multicolumn{19}{|l|}{ Chad } \\
\hline \multicolumn{19}{|c|}{ Congo, Republic } \\
\hline \multicolumn{19}{|c|}{ Cote d'Ivoire } \\
\hline \multicolumn{19}{|l|}{ Djibouti } \\
\hline \multicolumn{19}{|l|}{ Egypt } \\
\hline \multicolumn{19}{|l|}{ Ethiopia } \\
\hline \multicolumn{19}{|l|}{ Gambia } \\
\hline \multicolumn{19}{|l|}{ Ghana } \\
\hline \multicolumn{19}{|l|}{ Guinea } \\
\hline \multicolumn{19}{|l|}{ Kenya } \\
\hline \multicolumn{19}{|l|}{ Libya } \\
\hline \multicolumn{19}{|l|}{ Malawi } \\
\hline \multicolumn{19}{|l|}{ Mali } \\
\hline \multicolumn{19}{|l|}{ Morocco } \\
\hline Mozambique & & & & & & & & & & & & & & & & & & \\
\hline Namibia & & & & & & & & & & & & & & & & & & \\
\hline
\end{tabular}




\begin{tabular}{|c|c|c|c|c|c|c|c|c|c|c|c|c|c|c|c|c|c|c|}
\hline \multirow[b]{2}{*}{ 递 } & \multicolumn{5}{|c|}{ Universal coverage for RRT } & \multicolumn{2}{|c|}{\begin{tabular}{|c|}
$\begin{array}{c}\text { Availability } \\
\text { of PD and } \\
\text { Tx }\end{array}$ \\
\end{tabular}} & \multicolumn{10}{|c|}{ Adequacy of workforce component } & \multirow{2}{*}{ 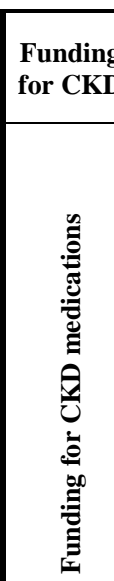 } \\
\hline & 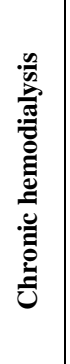 & 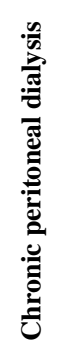 & 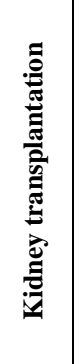 & 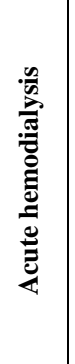 & 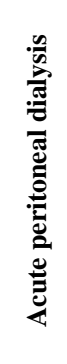 & 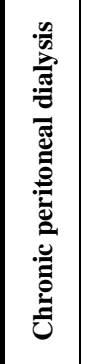 & 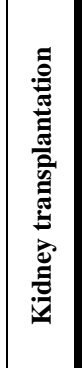 & 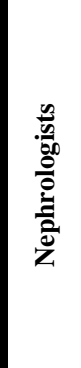 & 节 & 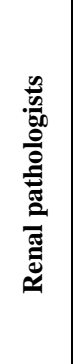 & 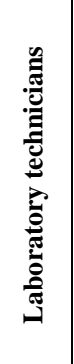 & 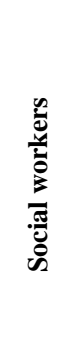 & 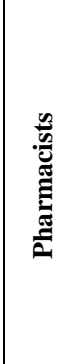 & 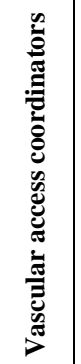 & 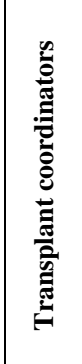 & 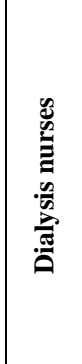 & 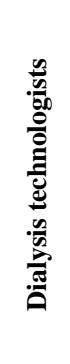 & \\
\hline \multicolumn{19}{|l|}{ Niger } \\
\hline \multicolumn{19}{|l|}{ Nigeria } \\
\hline \multicolumn{19}{|l|}{ Senegal } \\
\hline \multicolumn{19}{|c|}{ South Africa } \\
\hline \multicolumn{19}{|c|}{ Sudan } \\
\hline \multicolumn{19}{|l|}{ Swaziland } \\
\hline \multicolumn{19}{|l|}{ Tanzania } \\
\hline \multicolumn{19}{|l|}{ Togo } \\
\hline \multicolumn{19}{|l|}{ Tunisia } \\
\hline \multicolumn{19}{|l|}{ Uganda } \\
\hline \multicolumn{19}{|l|}{ Zambia } \\
\hline \multicolumn{19}{|l|}{ Zimbabwe } \\
\hline \multicolumn{19}{|c|}{ Eastern \& Central } \\
\hline \multicolumn{19}{|c|}{ Albania } \\
\hline \multicolumn{19}{|c|}{ Bosnia and Herzegovina } \\
\hline Croatia & & & & & & & & & & & & & & & & & & \\
\hline Czech Rep & & & & & & & & & & & & & & & & & & \\
\hline Estonia & & & & & & & & & & & & & & & & & & \\
\hline Hungary & & & & & & & & & & & & & & & & & & \\
\hline Latvia & & & & & & & & & & & & & & & & & & \\
\hline Lithuania & & & & & & & & & & & & & & & & & & \\
\hline Macedonia & & & & & & & & & & & & & & & & & & \\
\hline Moldova & & & & & & & & & & & & & & & & & & \\
\hline Monteneg & & & & & & & & & & & & & & & & & & \\
\hline Poland & & & & & & & & & & & & & & & & & & \\
\hline Romania & & & & & & & & & & & & & & & & & & \\
\hline Serbia & & & & & & & & & & & & & & & & & & \\
\hline Slovakia & & & & & & & & & & & & & & & & & & \\
\hline Slovenia & & & & & & & & & & & & & & & & & & \\
\hline Turkey & & & & & & & & & & & & & & & & & & \\
\hline Latin Ame & & & & & & & & & & & & & & & & & & \\
\hline Anguilla & & & & & & & & & & & & & & & & & & \\
\hline Argentina & & & & & & & & & & & & & & & & & & \\
\hline Bolivia & & & & & & & & & & & & & & & & & & \\
\hline Brazil & & & & & & & & & & & & & & & & & & \\
\hline Chile & & & & & & & & & & & & & & & & & & \\
\hline Colombia & & & & & & & & & & & & & & & & & & \\
\hline Costa Rica & & & & & & & & & & & & & & & & & & \\
\hline
\end{tabular}




\begin{tabular}{|c|c|c|c|c|c|c|c|c|c|c|c|c|c|c|c|c|c|c|}
\hline \multirow[b]{2}{*}{$\frac{\stackrel{\mathscr{n}}{E}}{\tilde{E}}$} & \multicolumn{5}{|c|}{ Universal coverage for RRT } & \multicolumn{2}{|c|}{$\begin{array}{c}\text { Availability } \\
\text { of PD and } \\
\text { Tx }\end{array}$} & \multicolumn{10}{|c|}{ Adequacy of workforce component } & \multirow{2}{*}{ 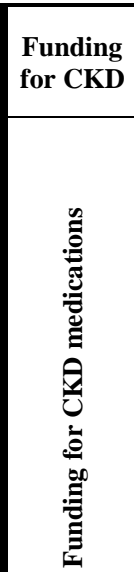 } \\
\hline & 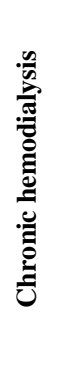 & 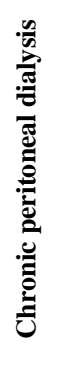 & 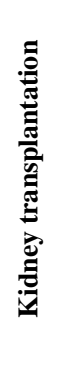 & 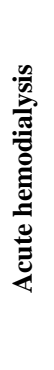 & 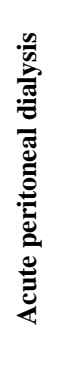 & 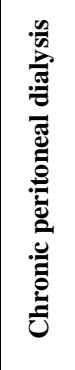 & 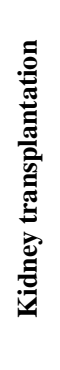 & $\begin{array}{l}\frac{n}{0.0} \\
\frac{0}{00} \\
\frac{0}{0} \\
\frac{0}{0}\end{array}$ & & 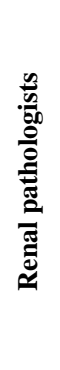 & 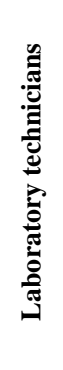 & 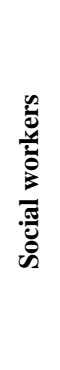 & 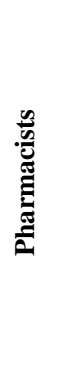 & 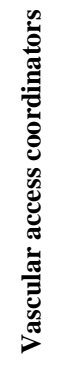 & 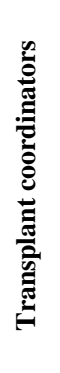 & 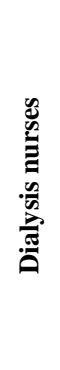 & 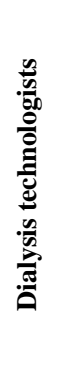 & \\
\hline \multicolumn{19}{|c|}{ Dominican Republic } \\
\hline \multicolumn{19}{|l|}{ El Salvador } \\
\hline \multicolumn{19}{|l|}{ Guatemala } \\
\hline \multicolumn{19}{|l|}{ Mexico } \\
\hline \multicolumn{19}{|l|}{ Nicaragua } \\
\hline \multicolumn{19}{|l|}{ Panama } \\
\hline \multicolumn{19}{|l|}{ Paraguay } \\
\hline \multicolumn{19}{|l|}{ Peru } \\
\hline \multicolumn{19}{|l|}{ Uruguay } \\
\hline \multicolumn{19}{|l|}{ Venezuela } \\
\hline \multicolumn{19}{|l|}{ Middle East } \\
\hline \multicolumn{19}{|l|}{ Bahrain } \\
\hline \multicolumn{19}{|l|}{ Iran } \\
\hline \multicolumn{19}{|l|}{ Iraq } \\
\hline \multicolumn{19}{|l|}{ Jordan } \\
\hline Kuwait & & & & & & & & & & & & & & & & & & \\
\hline Lebanon & & & & & & & & & & & & & & & & & & \\
\hline Oman & & & & & & & & & & & & & & & & & & \\
\hline Qatar & & & & & & & & & & & & & & & & & & \\
\hline Saudi Arabia & & & & & & & & & & & & & & & & & & \\
\hline Syria & & & & & & & & & & & & & & & & & & \\
\hline United Arab & & & & & & & & & & & & & & & & & & \\
\hline West Bank 8 & & & & & & & & & & & & & & & & & & \\
\hline Yemen & & & & & & & & & & & & & & & & & & \\
\hline NIS \& Russia & & & & & & & & & & & & & & & & & & \\
\hline Armenia & & & & & & & & & & & & & & & & & & \\
\hline Belarus & & & & & & & & & & & & & & & & & & \\
\hline Georgia & & & & & & & & & & & & & & & & & & \\
\hline Kazakhstan & & & & & & & & & & & & & & & & & & \\
\hline Russia & & & & & & & & & & & & & & & & & & \\
\hline Ukraine & & & & & & & & & & & & & & & & & & \\
\hline North Amer & & & & & & & & & & & & & & & & & & \\
\hline Canada & & & & & & & & & & & & & & & & & & \\
\hline United State & & & & & & & & & & & & & & & & & & \\
\hline North and $\mathrm{E}$ & & & & & & & & & & & & & & & & & & \\
\hline China & & & & & & & & & & & & & & & & & & \\
\hline Hong Kong & & & & & & & & & & & & & & & & & & \\
\hline Japan & & & & & & & & & & & & & & & & & & \\
\hline
\end{tabular}




\begin{tabular}{|c|c|c|c|c|c|c|c|c|c|c|c|c|c|c|c|c|c|c|}
\hline \multirow[b]{2}{*}{ 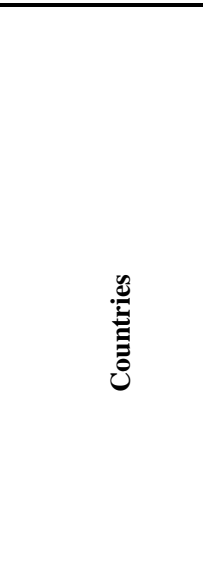 } & \multicolumn{5}{|c|}{ Universal coverage for RRT } & \multicolumn{2}{|c|}{$\begin{array}{c}\text { Availability } \\
\text { of PD and } \\
\text { Tx }\end{array}$} & \multicolumn{10}{|c|}{ Adequacy of workforce component } & \multirow{2}{*}{ 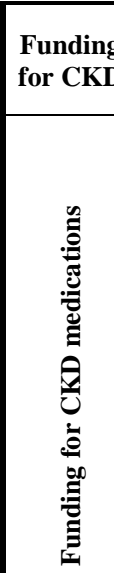 } \\
\hline & 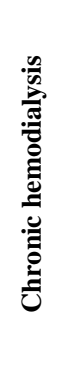 & 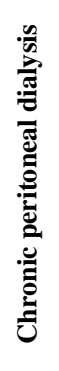 & 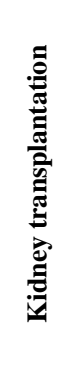 & 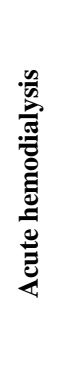 & 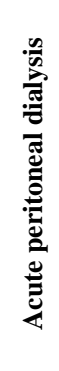 & 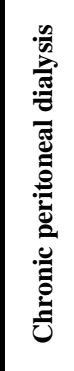 & 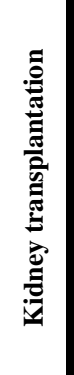 & 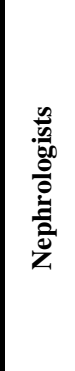 & 岕 & 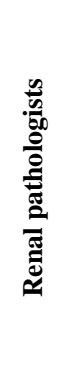 & 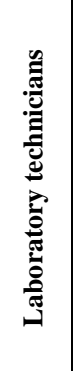 & 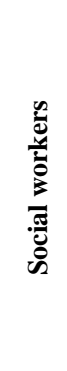 & 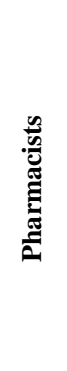 & 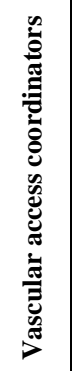 & 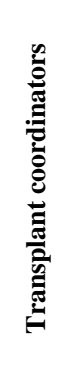 & 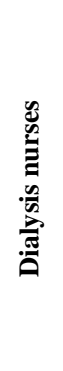 & 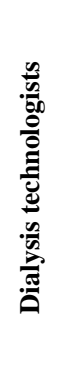 & \\
\hline \multicolumn{19}{|l|}{ Korea, South } \\
\hline \multicolumn{19}{|l|}{ Mongolia } \\
\hline \multicolumn{19}{|l|}{ Taiwan } \\
\hline \multicolumn{19}{|c|}{ Oceania \& South East } \\
\hline \multicolumn{19}{|c|}{ Australia } \\
\hline \multicolumn{19}{|l|}{ Burma } \\
\hline \multicolumn{19}{|l|}{ Cambodia } \\
\hline \multicolumn{19}{|l|}{ Fiji } \\
\hline \multicolumn{19}{|l|}{ Indonesia } \\
\hline \multicolumn{19}{|l|}{ Laos } \\
\hline \multicolumn{19}{|l|}{ Malaysia } \\
\hline \multicolumn{19}{|l|}{ New Zealand } \\
\hline \multicolumn{19}{|l|}{ Philippines } \\
\hline \multicolumn{19}{|l|}{ Samoa } \\
\hline \multicolumn{19}{|l|}{ Singapore } \\
\hline \multicolumn{19}{|l|}{ Thailand } \\
\hline Vietnam & & & & & & & & & & & & & & & & & & \\
\hline South Asia & & & & & & & & & & & & & & & & & & \\
\hline Bangladesh & & & & & & & & & & & & & & & & & & \\
\hline India & & & & & & & & & & & & & & & & & & \\
\hline Nepal & & & & & & & & & & & & & & & & & & \\
\hline Pakistan & & & & & & & & & & & & & & & & & & \\
\hline Sri Lanka & & & & & & & & & & & & & & & & & & \\
\hline Western Europe & & & & & & & & & & & & & & & & & & \\
\hline Andorra & & & & & & & & & & & & & & & & & & \\
\hline Belgium & & & & & & & & & & & & & & & & & & \\
\hline Denmark & & & & & & & & & & & & & & & & & & \\
\hline France & & & & & & & & & & & & & & & & & & \\
\hline Germany & & & & & & & & & & & & & & & & & & \\
\hline Greece & & & & & & & & & & & & & & & & & & \\
\hline Israel & & & & & & & & & & & & & & & & & & \\
\hline Netherlands & & & & & & & & & & & & & & & & & & \\
\hline Norway & & & & & & & & & & & & & & & & & & \\
\hline Spain & & & & & & & & & & & & & & & & & & \\
\hline United Kingdom & & & & & & & & & & & & & & & & & & \\
\hline
\end{tabular}


eAppendix 3. Services for CKD care, information systems, advocacy structures, and capacity for clinical trials Green and red boxes indicate that the survey participants answered Yes and No, respectively. Grey boxes indicate no data were provided.

*Advocacy group refers to the presence of a mechanism at the higher levels of government or a non-governmental organization to raise the profile of the condition and its prevention.

Abbreviations: $\mathrm{AKI}=$ acute kidney injury, $\mathrm{CKD}=$ chronic kidney disease, $\mathrm{eGFR}=$ estimated glomerular filtration rate, $\mathrm{UACR}=$ urine albumin to creatinine ratio, UPCR = urine protein to creatinine ratio, NIS \& Russia= Newly Independent States and Russia.

\begin{tabular}{|c|c|c|c|c|c|c|c|c|c|c|c|c|c|c|c|c|c|c|c|c|c|c|}
\hline \multirow[b]{2}{*}{ 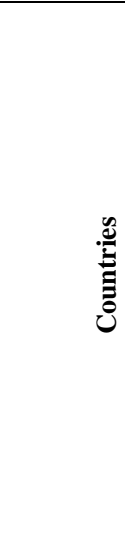 } & \multicolumn{5}{|c|}{$\begin{array}{c}\text { Availability of services for } \\
\text { CKD monitoring and } \\
\text { management at primary } \\
\text { care level }\end{array}$} & \multicolumn{6}{|c|}{$\begin{array}{l}\text { Availability of services for CKD } \\
\text { monitoring and management at } \\
\text { secondary or tertiary care level }\end{array}$} & \multicolumn{4}{|c|}{$\begin{array}{l}\text { Availability and } \\
\text { type of registry }\end{array}$} & \multicolumn{2}{|c|}{$\begin{array}{l}\text { Advocacy } \\
\text { group }\end{array}$} & \multicolumn{5}{|c|}{$\begin{array}{l}\text { Capacity to participate in } \\
\text { clinical trials }\end{array}$} \\
\hline & 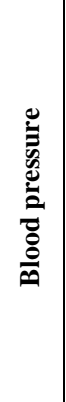 & 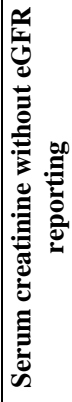 & 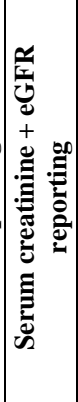 & 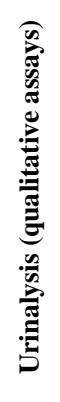 & 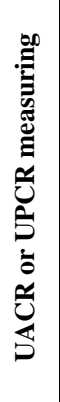 & 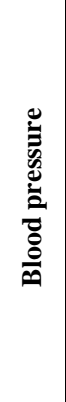 & 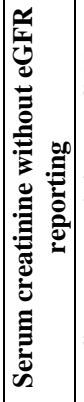 & 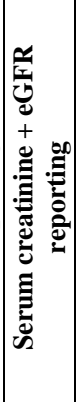 & 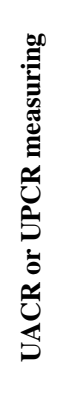 & 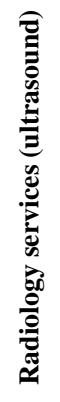 & 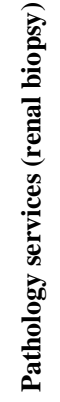 & 光 & 商 & 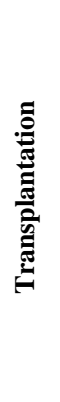 & $\overline{4}$ & 总 & 幽 & 式 & 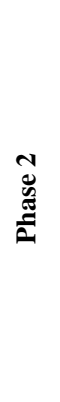 & 范 & 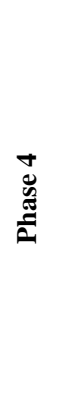 & 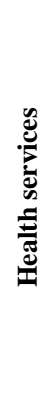 \\
\hline \multicolumn{23}{|l|}{ Africa } \\
\hline \multicolumn{23}{|l|}{ Algeria } \\
\hline \multicolumn{23}{|l|}{ Benin } \\
\hline \multicolumn{23}{|l|}{ Botswana } \\
\hline \multicolumn{23}{|c|}{ Burkina Faso } \\
\hline \multicolumn{23}{|l|}{ Burundi } \\
\hline \multicolumn{23}{|c|}{ Cameroon } \\
\hline \multicolumn{23}{|c|}{ Cape Verde } \\
\hline \multicolumn{23}{|l|}{ Chad } \\
\hline \multicolumn{23}{|c|}{ Congo, Republic } \\
\hline \multicolumn{23}{|c|}{ Cote d'Ivoire } \\
\hline \multicolumn{23}{|l|}{ Djibouti } \\
\hline \multicolumn{23}{|l|}{ Egypt } \\
\hline Ethiopia & & & & & & & & & & & & & & & & & & & & & & \\
\hline Gambia & & & & & & & & & & & & & & & & & & & & & & \\
\hline Ghana & & & & & & & & & & & & & & & & & & & & & & \\
\hline Guinea & & & & & & & & & & & & & & & & & & & & & & \\
\hline Kenya & & & & & & & & & & & & & & & & & & & & & & \\
\hline Libya & & & & & & & & & & & & & & & & & & & & & & \\
\hline Malawi & & & & & & & & & & & & & & & & & & & & & & \\
\hline Mali & & & & & & & & & & & & & & & & & & & & & & \\
\hline Morocco & & & & & & & & & & & & & & & & & & & & & & \\
\hline Mozambic & & & & & & & & & & & & & & & & & & & & & & \\
\hline Namibia & & & & & & & & & & & & & & & & & & & & & & \\
\hline Niger & & & & & & & & & & & & & & & & & & & & & & \\
\hline Nigeria & & & & & & & & & & & & & & & & & & & & & & \\
\hline Senegal & & & & & & & & & & & & & & & & & & & & & & \\
\hline South Afri & & & & & & & & & & & & & & & & & & & & & & \\
\hline Sudan & & & & & & & & & & & & & & & & & & & & & & \\
\hline Swaziland & & & & & & & & & & & & & & & & & & & & & & \\
\hline Tanzania & & & & & & & & & & & & & & & & & & & & & & \\
\hline Togo & & & & & & & & & & & & & & & & & & & & & & \\
\hline Tunisia & & & & & & & & & & & & & & & & & & & & & & \\
\hline Uganda & & & & & & & & & & & & & & & & & & & & & & \\
\hline Zambia & & & & & & & & & & & & & & & & & & & & & & \\
\hline
\end{tabular}




\begin{tabular}{|c|c|c|c|c|c|c|c|c|c|c|c|c|c|c|c|c|c|c|c|c|c|c|}
\hline \multirow[b]{2}{*}{ 己气 } & \multicolumn{5}{|c|}{$\begin{array}{c}\text { Availability of services for } \\
\text { CKD monitoring and } \\
\text { management at primary } \\
\text { care level } \\
\end{array}$} & \multicolumn{6}{|c|}{$\begin{array}{l}\text { Availability of services for CKD } \\
\text { monitoring and management at } \\
\text { secondary or tertiary care level }\end{array}$} & \multicolumn{4}{|c|}{$\begin{array}{l}\text { Availability and } \\
\text { type of registry }\end{array}$} & \multicolumn{2}{|c|}{$\begin{array}{l}\text { Advocacy } \\
\text { group }\end{array}$} & \multicolumn{5}{|c|}{$\begin{array}{c}\text { Capacity to participate in } \\
\text { clinical trials }\end{array}$} \\
\hline & 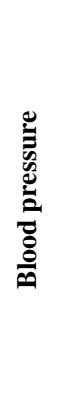 & 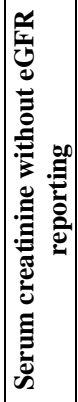 & 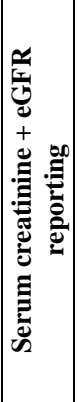 & 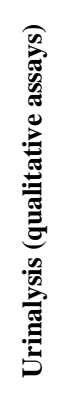 & 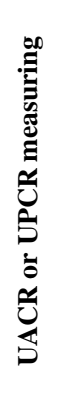 & 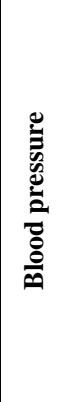 & 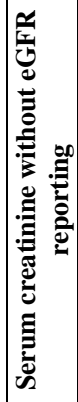 & 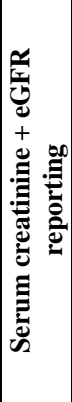 & 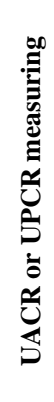 & 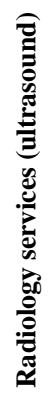 & 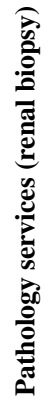 & ชి & 商 & 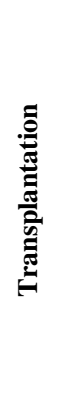 & 逍 & 胥 & 乎 & 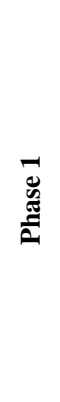 & 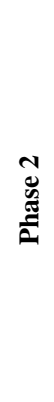 & 总 & 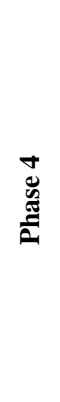 & 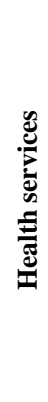 \\
\hline \multicolumn{23}{|l|}{ Zimbabwe } \\
\hline \multicolumn{23}{|c|}{ Eastern \& Central } \\
\hline \multicolumn{23}{|l|}{ Albania } \\
\hline \multicolumn{23}{|l|}{ Bosnia and } \\
\hline \multicolumn{23}{|l|}{ Croatia } \\
\hline \multicolumn{23}{|c|}{ Czech Republic } \\
\hline \multicolumn{23}{|l|}{ Estonia } \\
\hline \multicolumn{23}{|l|}{ Hungary } \\
\hline \multicolumn{23}{|l|}{ Latvia } \\
\hline \multicolumn{23}{|l|}{ Lithuania } \\
\hline Macedonia & & & & & & & & & & & & & & & & & & & & & & \\
\hline Moldova & & & & & & & & & & & & & & & & & & & & & & \\
\hline Montenegrc & & & & & & & & & & & & & & & & & & & & & & \\
\hline Poland & & & & & & & & & & & & & & & & & & & & & & \\
\hline Romania & & & & & & & & & & & & & & & & & & & & & & \\
\hline Serbia & & & & & & & & & & & & & & & & & & & & & & \\
\hline Slovakia & & & & & & & & & & & & & & & & & & & & & & \\
\hline Slovenia & & & & & & & & & & & & & & & & & & & & & & \\
\hline Turkey & & & & & & & & & & & & & & & & & & & & & & \\
\hline Latin Ameri & & & & & & & & & & & & & & & & & & & & & & \\
\hline Anguilla & & & & & & & & & & & & & & & & & & & & & & \\
\hline Argentina & & & & & & & & & & & & & & & & & & & & & & \\
\hline Bolivia & & & & & & & & & & & & & & & & & & & & & & \\
\hline Brazil & & & & & & & & & & & & & & & & & & & & & & \\
\hline Chile & & & & & & & & & & & & & & & & & & & & & & \\
\hline Colombia & & & & & & & & & & & & & & & & & & & & & & \\
\hline Costa Rica & & & & & & & & & & & & & & & & & & & & & & \\
\hline Dominican & & & & & & & & & & & & & & & & & & & & & & \\
\hline El Salvador & & & & & & & & & & & & & & & & & & & & & & \\
\hline Guatemala & & & & & & & & & & & & & & & & & & & & & & \\
\hline Mexico & & & & & & & & & & & & & & & & & & & & & & \\
\hline Nicaragua & & & & & & & & & & & & & & & & & & & & & & \\
\hline Panama & & & & & & & & & & & & & & & & & & & & & & \\
\hline Paraguay & & & & & & & & & & & & & & & & & & & & & & \\
\hline Peru & & & & & & & & & & & & & & & & & & & & & & \\
\hline Uruguay & & & & & & & & & & & & & & & & & & & & & & \\
\hline Venezuela & & & & & & & & & & & & & & & & & & & & & & \\
\hline Middle East & & & & & & & & & & & & & & & & & & & & & & \\
\hline Bahrain & & & & & & & & & & & & & & & & & & & & & & \\
\hline Iran & & & & & & & & & & & & & & & & & & & & & & \\
\hline Iraq & & & & & & & & & & & & & & & & & & & & & & \\
\hline
\end{tabular}




\begin{tabular}{|c|c|c|c|c|c|c|c|c|c|c|c|c|c|c|c|c|c|c|c|c|c|c|}
\hline \multirow[b]{2}{*}{ 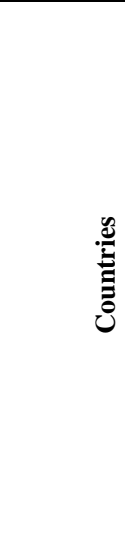 } & \multicolumn{5}{|c|}{$\begin{array}{c}\text { Availability of services for } \\
\text { CKD monitoring and } \\
\text { management at primary } \\
\text { care level }\end{array}$} & \multicolumn{6}{|c|}{$\begin{array}{l}\text { Availability of services for CKD } \\
\text { monitoring and management at } \\
\text { secondary or tertiary care level }\end{array}$} & \multicolumn{4}{|c|}{$\begin{array}{l}\text { Availability and } \\
\text { type of registry }\end{array}$} & \multicolumn{2}{|c|}{$\begin{array}{l}\text { Advocacy } \\
\text { group }\end{array}$} & \multicolumn{5}{|c|}{$\begin{array}{l}\text { Capacity to participate in } \\
\text { clinical trials }\end{array}$} \\
\hline & 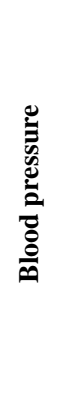 & 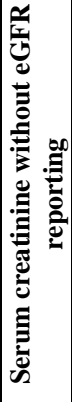 & 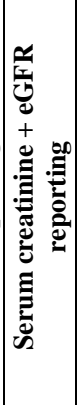 & 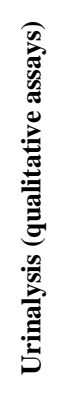 & 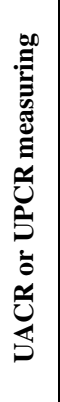 & 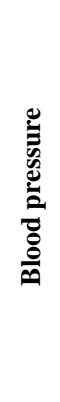 & 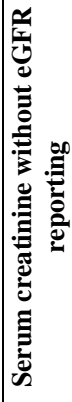 & 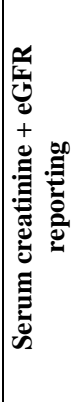 & 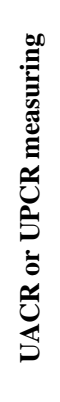 & 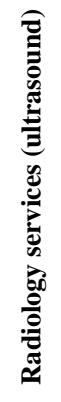 & 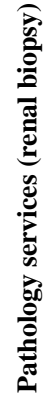 & 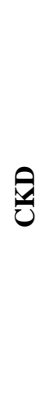 & $\frac{n}{\frac{n}{n}}$ & 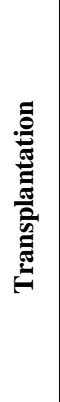 & 蛋 & 胥 & $\frac{1}{4}$ & $\begin{array}{l}\vec{\Xi} \\
\bar{\Xi} \\
\vec{E}\end{array}$ & $\underset{\mathscr{U}}{\tilde{\Xi}}$ & 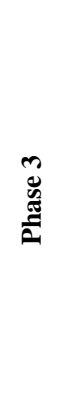 & 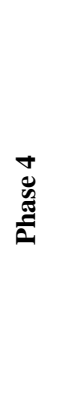 & 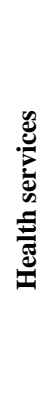 \\
\hline \multicolumn{23}{|l|}{ Jordan } \\
\hline \multicolumn{23}{|l|}{ Kuwait } \\
\hline \multicolumn{23}{|l|}{ Lebanon } \\
\hline \multicolumn{23}{|l|}{ Oman } \\
\hline \multicolumn{23}{|l|}{ Qatar } \\
\hline \multicolumn{23}{|c|}{ Saudi Arabia } \\
\hline \multicolumn{23}{|l|}{ Syria } \\
\hline \multicolumn{23}{|c|}{ United Arab } \\
\hline \multicolumn{23}{|c|}{ West Bank \& Gaza } \\
\hline \multicolumn{23}{|c|}{ Yemen } \\
\hline NIS \& Russ & & & & & & & & & & & & & & & & & & & & & & \\
\hline Armenia & & & & & & & & & & & & & & & & & & & & & & \\
\hline Belarus & & & & & & & & & & & & & & & & & & & & & & \\
\hline Georgia & & & & & & & & & & & & & & & & & & & & & & \\
\hline Kazakhstan & & & & & & & & & & & & & & & & & & & & & & \\
\hline Russia & & & & & & & & & & & & & & & & & & & & & & \\
\hline Ukraine & & & & & & & & & & & & & & & & & & & & & & \\
\hline North Ame & & & & & & & & & & & & & & & & & & & & & & \\
\hline Canada & & & & & & & & & & & & & & & & & & & & & & \\
\hline United Stat & & & & & & & & & & & & & & & & & & & & & & \\
\hline North and & & & & & & & & & & & & & & & & & & & & & & \\
\hline China & & & & & & & & & & & & & & & & & & & & & & \\
\hline Hong Kong & & & & & & & & & & & & & & & & & & & & & & \\
\hline Japan & & & & & & & & & & & & & & & & & & & & & & \\
\hline Korea, Sou & & & & & & & & & & & & & & & & & & & & & & \\
\hline Mongolia & & & & & & & & & & & & & & & & & & & & & & \\
\hline Taiwan & & & & & & & & & & & & & & & & & & & & & & \\
\hline Oceania \& & & & & & & & & & & & & & & & & & & & & & & \\
\hline Australia & & & & & & & & & & & & & & & & & & & & & & \\
\hline Burma & & & & & & & & & & & & & & & & & & & & & & \\
\hline Cambodia & & & & & & & & & & & & & & & & & & & & & & \\
\hline Fiji & & & & & & & & & & & & & & & & & & & & & & \\
\hline Indonesia & & & & & & & & & & & & & & & & & & & & & & \\
\hline Laos & & & & & & & & & & & & & & & & & & & & & & \\
\hline Malaysia & & & & & & & & & & & & & & & & & & & & & & \\
\hline New Zealar & & & & & & & & & & & & & & & & & & & & & & \\
\hline Philippines & & & & & & & & & & & & & & & & & & & & & & \\
\hline Samoa & & & & & & & & & & & & & & & & & & & & & & \\
\hline Singapore & & & & & & & & & & & & & & & & & & & & & & \\
\hline Thailand & & & & & & & & & & & & & & & & & & & & & & \\
\hline Vietnam & & & & & & & & & & & & & & & & & & & & & & \\
\hline
\end{tabular}




\begin{tabular}{|c|c|c|c|c|c|c|c|c|c|c|c|c|c|c|c|c|c|c|c|c|c|c|}
\hline \multirow[b]{2}{*}{ 这 } & \multicolumn{5}{|c|}{$\begin{array}{c}\text { Availability of services for } \\
\text { CKD monitoring and } \\
\text { management at primary } \\
\text { care level } \\
\end{array}$} & \multicolumn{6}{|c|}{$\begin{array}{l}\text { Availability of services for CKD } \\
\text { monitoring and management at } \\
\text { secondary or tertiary care level }\end{array}$} & \multicolumn{4}{|c|}{$\begin{array}{l}\text { Availability and } \\
\text { type of registry }\end{array}$} & \multicolumn{2}{|c|}{$\begin{array}{l}\text { Advocacy } \\
\text { group }\end{array}$} & \multicolumn{5}{|c|}{$\begin{array}{l}\text { Capacity to participate in } \\
\text { clinical trials }\end{array}$} \\
\hline & 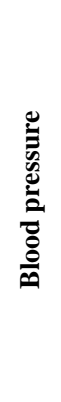 & 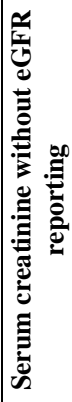 & 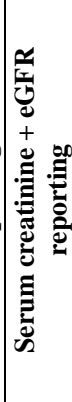 & 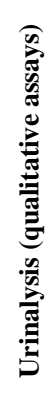 & 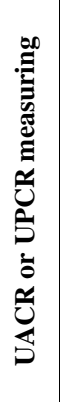 & 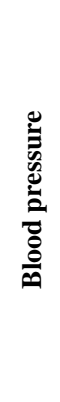 & 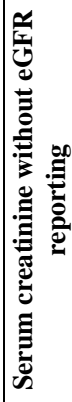 & 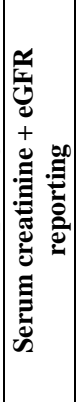 & 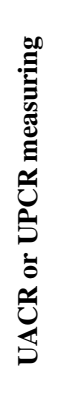 & 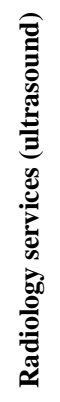 & 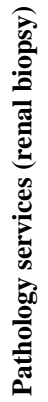 & $\underline{0}$ & $\frac{n}{\frac{n}{n}}$ & 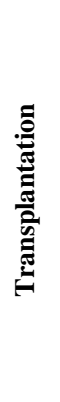 & $\overline{2}$ & 穵 & $\sqrt{2}$ & $\begin{array}{l}\overline{0} \\
\bar{E} \\
\bar{E}\end{array}$ & 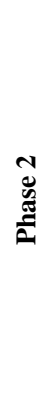 & 苞 & 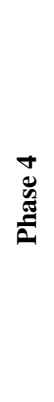 & 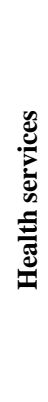 \\
\hline \multicolumn{23}{|l|}{ South Asia } \\
\hline \multicolumn{23}{|l|}{ Bangladesh } \\
\hline \multicolumn{23}{|l|}{ India } \\
\hline \multicolumn{23}{|l|}{ Nepal } \\
\hline \multicolumn{23}{|l|}{ Pakistan } \\
\hline \multicolumn{23}{|l|}{ Sri Lanka } \\
\hline \multicolumn{23}{|l|}{ Western Europe } \\
\hline \multicolumn{23}{|l|}{ Andorra } \\
\hline \multicolumn{23}{|l|}{ Belgium } \\
\hline \multicolumn{23}{|l|}{ Denmark } \\
\hline \multicolumn{23}{|l|}{ France } \\
\hline \multicolumn{23}{|l|}{ Germany } \\
\hline \multicolumn{23}{|l|}{ Greece } \\
\hline \multicolumn{23}{|l|}{ Israel } \\
\hline \multicolumn{23}{|l|}{ Netherlands } \\
\hline \multicolumn{23}{|l|}{ Norway } \\
\hline \multicolumn{23}{|l|}{ Spain } \\
\hline United Kingdom & & & & & & & & & & & & & & & & & & & & & & \\
\hline
\end{tabular}

